\title{
Enhancing binding affinity of an intrinsically disordered protein by $\alpha$-methylation of key amino acid residues
}

\author{
Valentin Bauer $^{1 \dagger}$, Boris Schmidtgall ${ }^{1 \dagger}$, Gergő Gógl ${ }^{2 \#}$, Jozica Dolenc ${ }^{3}$, Judit Osz ${ }^{2}$, Yves \\ Nominé$^{2 \#, ~ C a m i l l e ~ K o s t m a n n ~}{ }^{2 \#, ~ A l e x a n d r a ~ C o u s i d o-S i a h ~}{ }^{2 \#}$, André Mitschler ${ }^{2 \#, ~ N a t a c h a ~}$ \\ Rochel $^{2}$, Gilles Travé2\#, Bruno Kieffer ${ }^{2}$ and Vladimir Torbeev ${ }^{1 *}$ \\ ${ }^{1}$ Institut de Science et d'Ingénierie Supramoléculaires (ISIS), International Center for Frontier \\ Research in Chemistry (icFRC), University of Strasbourg, CNRS (UMR 7006), Strasbourg, \\ France. *Correspondence should be addressed to V. T. (torbeev@unistra.fr). \\ ${ }^{2}$ Institut de Génétique et de Biologie Moléculaire et Cellulaire (IGBMC), INSERM (U964), \\ University of Strasbourg, CNRS (UMR 7104), Illkirch, France \\ ${ }^{3}$ Chemistry | Biology | Pharmacy Information Center, ETH Zurich, Zurich, Switzerland \\ $\dagger$ - these authors equally contributed to this work \\ \# - Équipe Labellisée Ligue 2015
}

\begin{abstract}
Intrinsically disordered proteins (IDPs), which undergo folding upon binding to their targets, are critical players in protein interaction networks. Here we demonstrate that incorporation of non-canonical $\alpha$-methylated amino acids into the unstructured activation domain of the transcriptional coactivator ACTR can stabilize helical conformations and strengthen binding interactions with the nuclear coactivator binding domain (NCBD) of CREB-binding protein (CBP). A combinatorial $\alpha$-methylation scan of the ACTR sequence converged on two substitutions at positions 1055 and 1076 that increase affinity for both NCBD and the fulllength $270 \mathrm{kDa} \mathrm{CBP}$ by one order of magnitude. The first X-ray structure of the modified ACTR domain bound to NCBD revealed that the key $\alpha$-methylated amino acids were localized within $\alpha$-helices. Biophysical studies showed that the observed changes in binding energy are the result of long-range interactions and redistribution of enthalpy and entropy. This proof-ofconcept study establishes a potential strategy for selective inhibition of protein-protein interactions involving IDPs in cells.
\end{abstract}




\section{INTRODUCTION}

Intrinsically disordered proteins (IDPs) and protein domains complement the functions of well-folded proteins ${ }^{1-3}$. They are particularly abundant in eukaryotes, where they contribute to the higher complexity of biological organization and regulatory processes ${ }^{4}$. Intrinsic disorder confers distinctive molecular recognition and structural properties compared to well-folded proteins $^{5}$. These include high affinity even if the complexes remain unstructured ${ }^{6}$, multivalent interactions that may lead to phase separation ${ }^{7,8}$, and promiscuity in forming complexes with structurally unrelated targets 9 .

The gene transcription machinery of eukaryotes is particularly rich in IDPs ${ }^{10,11}$ where intrinsic disorder plays a key role, providing high structural and compositional diversity in protein complexes that regulate gene expression ${ }^{12-14}$. More than a half of eukaryotic transcription factors are predicted to contain highly disordered regions, especially within their activation domains ${ }^{15}$. Thus, being able to target IDPs could represent an attractive strategy to interfere with biological processes at the level of gene transcription ${ }^{16}$. However, a lack of wellstructured binding pockets makes it challenging to identify molecules, either by design or highthroughput screening, that bind IDPs specifically and with high affinity ${ }^{17}$.

In general, folding of IDPs upon complex formation leads to a large loss of conformational entropy ${ }^{18}$. Introduction of conformational constraints that minimize such losses is one approach to enhance overall affinity. For example, side-chains in peptide fragments of the IDP that correspond to the most important site at the protein-protein interaction (PPI) interface can be covalently tethered. The successful development of stapled peptides as inhibitors of PPIs is illustrative of this strategy ${ }^{19}$. Nevertheless, such methods are best suited to protein complexes where binding energy is localized over a few proximal residues and not dispersed over several distant regions of the protein surface.

As an alternative, we are exploring backbone conformational constraints as a means to enhance binding affinity of protein-protein interactions involving IDPs (Fig. 1). We chose a complex formed by domains from two transcriptional coactivators, CBP (CREB-binding protein) ${ }^{20}$ and ACTR (activator for thyroid hormone and retinoid receptors; also called SRC3 - steroid receptor coactivator 3 from p160 family), ${ }^{21}$ to implement this strategy. Both CBP (and its paralog p300) and ACTR function as cellular integrators of various signalling pathways that transduce these signals into fine-tuned transcriptional outputs ${ }^{20-22}$. In its isolated state, the nuclear coactivator binding domain (NCBD) of CBP has the properties of a molten globule with residual helical structure, ${ }^{23}$ whereas the activation domain 1 (AD1) of ACTR (Fig. 1b) is highly disordered ${ }^{24}$. Together, they undergo coupled binding and folding to form a complex that is predominantly $\alpha$-helical ${ }^{25}$.

One efficient way to stabilize helical conformations involves introduction of non-canonical $\alpha$-methylated amino acids (Fig. 1c) ${ }^{26}$. The additional methyl group increases steric bulk insignificantly, while side-chains important for protein-protein interactions are left unmodified. Here, to illustrate the potential of this approach, we assembled a combinatorial library of $\alpha$ methylated AD1-ACTR variants and performed biophysical studies to characterize their binding to NCBD. The NCBD and AD1-ACTR domains are both $\sim 50$ residues long and can be synthesized chemically ${ }^{27}$. Hence, single or multiple $\alpha$-methylated amino acids can be introduced at any site in their sequences. This effort led to the discovery of a set of variants with enhanced affinity for the isolated NCBD as well as for the full length, $270 \mathrm{kDa}$ CBP. The 
key advantage of the approach developed herein is that modified ( $\alpha$-methylated) protein domains form nearly native protein-protein interaction interfaces, which will retain unique specificity for their target. Moreover, $\alpha$-methylated peptides are protease-resistant, ${ }^{28}$ a strong advantage for in vivo applications.

\section{RESULTS}

Combinatorial library of $\alpha$-methylated variants of AD1-ACTR. Prior to our study, no crystal structure of the AD1-ACTR/NCBD complex was available. However, the structure of an AD1-ACTR/NCBD complex in solution had been determined by NMR and showed that the two proteins each contribute three $\alpha$-helices to a tight hydrophobic interface. ${ }^{25}$ The seventeen sites in the [1040-1086] fragment of AD1-ACTR that we chose for $\alpha$-methylation are depicted in Fig. 1c, and the corresponding sequences are listed in Supplementary Table 1. The substituted residues are located in $\alpha$-helical segments, in loop regions, at the buried AD1ACTR/NCBD protein interface, and on the solvent-accessible surface of the protein complex. Single and multiple substitutions were made, with up to six $\alpha$-methylated amino acids introduced simultaneously. In total, we prepared 17 single, 22 double, 2 triple, 4 tetra, 1 penta and 1 hexa $\alpha$-methylated analogues. In addition, we have synthesized two variants containing canonical amino acids with different helical propensities [S1043M;D1050E;T1054Q] and [A1047G] previously reported to have distinct binding properties to $\mathrm{NCBD}^{24}$. To assemble the 50 variants of AD1-ACTR (Supplementary Tables 1 and 2), we used combinatorial native chemical ligation of $\mathrm{N}$-terminal and $\mathrm{C}$-terminal peptide precursor segments as described previously ${ }^{27}$. In a few cases, the entire polypeptide chain was assembled by microwave-assisted solid-phase peptide synthesis (see Supplementary Materials and Methods).

$\alpha$-Methylation modifies the affinity of AD1-ACTR binding to NCBD. Isothermal titration calorimetry was used to characterize the formation of complexes between $\alpha$ methylated variants of AD1-ACTR and NCBD (the [2066-2112]-fragment of CBP) to obtain Gibbs free energy $(\Delta \mathrm{G})$ as well as the enthalpy $(\Delta \mathrm{H})$ and entropy $(-\mathrm{T} \Delta \mathrm{S})$ of binding. The results of measurements at $\mathrm{T}=304 \mathrm{~K}$ are summarized in Fig. 2 and Supplementary Table 3 and indicate that the effect of $\alpha$-methylation on complex formation is position-dependent (binding diagrams are depicted in Supplementary Fig. 1).

Despite the helix-inducing tendencies of $\alpha$-methylated amino acids, $\alpha$-methylation caused a decrease in complex stability in most cases. The greatest destabilization $(\Delta \Delta \mathrm{G} \sim 1.5-2.0$ $\mathrm{kcal} / \mathrm{mol}$ ) occurred for variants when Leu1071 was replaced by its $\alpha$-methylated analogue. Other substitutions that resulted in significant destabilization were meLeu 1056, meLeu1064, meLeu1049 and meAsp1050. The decrease in stability may be due to unfavorable steric interactions or incorrect folding. $\alpha$-Methylation increases local steric interactions between backbone and side chain and can also alter side-chain rotamer conformations ${ }^{29}$. Furthermore, the energy difference between right- and left-handed helical conformations for $\alpha, \alpha$ disubstituted residues is lower than for canonical $\alpha$-amino acids ${ }^{29}$. For example, the most destabilizing meLeu1071 is located next to achiral Gly1072, which may allow meLeu1071 to induce a non-native left-handed helical conformation and thus lead to incorrect folding.

However, we identified a few sites where $\alpha$-methylation enhanced binding. Complexes with the highest stability were obtained when meLeu1055 was introduced $(\Delta \Delta \mathrm{G}=-0.61$ 
$\mathrm{kcal} / \mathrm{mol}$ ), whereas the $1047 \mathrm{meAla}$-containing variant exhibited slightly increased binding affinity for $\mathrm{NCBD}(\Delta \Delta \mathrm{G}=-0.21 \mathrm{kcal} / \mathrm{mol})$. Given its exceptionally favorable effect on overall

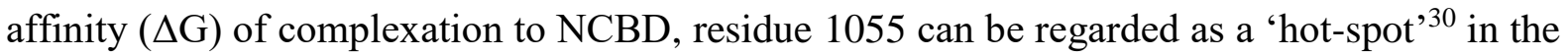
$\alpha$-methylation scan experiment.

The binding of wild-type AD1-ACTR to NCBD is enthalpy-driven. Formation of favorable inter-residue contacts in the resulting complex presumably compensates for the loss of entropy due to coupled folding. ${ }^{31}$ Incorporation of $\alpha$-methylated amino acids resulted in changes in the enthalpic $(\Delta \mathrm{H})$ and entropic $(-\mathrm{T} \Delta \mathrm{S})$ contributions to binding depending on the position and number of substituted residues (Fig. 2b). Thus, the AD1-ACTR analogue with 1055meLeu at the 'hot spot' site in the N-terminal helix exhibits an anomalously favorable $\Delta \mathrm{H}$, offset by a more unfavorable $-\mathrm{T} \Delta \mathrm{S}$ than seen for the wild type protein domain. Similarly, higher enthalpyentropy compensation was observed for variants with substitutions in the C-terminal helix (e.g., 1076meLeu, 1077meVal, 1080meAla, 1083meAla). In contrast, compensation with the opposite sign (enthalpy became less favorable while entropy more favorable) was observed for the highly destabilized complexes containing 1071meLeu or 1056meLeu.

Increasing the number of $\alpha$-methylated residues further reinforced the observed enthalpyentropy compensation. The elevated $\Delta \mathrm{H}$ and $-\mathrm{T} \Delta \mathrm{S}$ contributions are consistent with the formation of more stable electrostatic or hydrogen bonding interactions, leading to gains in $\Delta \mathrm{H}$ that are counter-balanced by losses in conformational degrees of freedom $(-\mathrm{T} \Delta \mathrm{S})$ resulting from reduced accessible values of the Ramachandran $(\varphi, \psi)$-dihedral angles. The most elevated values of $-\mathrm{T} \Delta \Delta \mathrm{S}(7.3-8.6 \mathrm{kcal} / \mathrm{mol})$ relative to wild type are seen for the tetra-, penta- and hexa-substituted variants, which would correspond to folding of approximately 5 to 6 additional residues assuming the theoretically estimated value for entropy changes upon folding of $1.4 \mathrm{kcal} / \mathrm{mol}$ per residue $\mathrm{e}^{33}$.

The large set of variants in the library containing two $\alpha$-methylations enabled assessment of coupling energies (cross-talk) between the modified sites in the sequence. Standard "doublemutant cycle" analyses were performed according to the relationship $\Delta \Delta \Delta \mathrm{G}=\Delta \Delta \mathrm{G}_{\mathrm{variant}-\mathrm{X}}+$ $\Delta \Delta \mathrm{G}_{\text {variant-Y }}-\Delta \Delta \mathrm{G}_{\text {double-XY, }}$, where $\Delta \Delta \mathrm{G}_{\text {variant }}$ is the variation in Gibbs free energy for a singly modified ACTR variant and $\Delta \Delta \mathrm{G}_{\text {double-XY }}$ is the variation in Gibbs free energy for the doubly $\alpha$-methylated protein ${ }^{34}$. The Gibbs free energy for most of the analogues (nearly $70 \%$ ) containing two modifications displays positive cooperativity $(\Delta \Delta \Delta \mathrm{G}>0$ in the $0.25-1.0$ $\mathrm{kcal} / \mathrm{mol}$ range); for several variants it is nearly 0; and only one, [1047Aib;1072Aib], shows significant negative cooperativity $(\Delta \Delta \Delta \mathrm{G}=-0.82 \mathrm{kcal} / \mathrm{mol})$ (Supplementary Fig. 2). These findings indicate that multiple $\alpha$-methylations are generally more favorable for protein complex stability than the theoretical combination of the corresponding single modifications even if they are destabilizing when introduced individually. These results support the notion that the protein interfaces of IDP complexes, and the AD1-ACTR/NCBD complex in particular, are nonoptimal or "frustrated" 35 .

An AD1-ACTR variant with two $\alpha$-methylations ([1055meLeu; 1076meLeu]) was found to be the best NCBD binder in the entire library (variant 34 in Supplementary Table 1). According to ITC, it exhibits approximately 5-fold stronger affinity $\left(\mathrm{K}_{\mathrm{D}}=0.042 \mu \mathrm{M}\right)$ at $304 \mathrm{~K}$ than WT AD1 $\left(\mathrm{K}_{\mathrm{D}}=0.206 \mu \mathrm{M}\right)$. The $1076 \mathrm{meLeu}$ substitution alone had nearly no effect on the binding of AD1-ACTR to NCBD but when combined with $1055 \mathrm{meLeu}$ it contributed to enhanced affinity. Note that insertion of a larger number of $\alpha$-methylated residues does not 
necessarily improve binding. Indeed, several variants containing four, five and six $\alpha-$ methylated amino acids bound NCBD with lower affinity than [1055meLeu;1076meLeu]AD1ACTR. The more favorable enthalpic contributions provided by these substitutions were 'overridden' in most cases by losses in entropy.

Shorter peptide fragments corresponding to the most structured N-terminal portion of AD1ACTR, including a peptide containing meLeu at the 1055 'hot spot', did not show appreciable binding to NCBD. For efficient binding, the full-length AD1-ACTR sequence is apparently essential.

$\alpha$-Methylation induces helical structure in the disordered ACTR activation domain. Circular dichroism of the isolated AD1-ACTR domain indicates a highly disordered protein that is mostly random coil with only a small percentage of $\alpha$-helical structure. Upon $\alpha$ methylation, helical content increased for all members of the library judging from the ratio of ellipticities for $\alpha$-helix versus random coil, $\theta_{222} / \theta_{199}$ (Supplementary Figs. 3, 4a and Table 5). Moreover, $\alpha$-methylation of the 'hot spot' residue 1055 had a greater effect on $\alpha$-helical content than modification of any other residue. Thus, the $\theta_{222} / \theta_{199}$ value for [1055meLeu]AD1-ACTR is significantly higher than for wild type ( 0.44 versus 0.23$)$ and progressively increases when other $\alpha$-methylated residues are added. For comparison, a previously reported triple mutant [S1043M;D1050E;T1054Q] that was engineered to have high $\alpha$-helicity by incorporating residues with high helical propensities ${ }^{24}$ has a lower $\alpha$-helical content $\left(\theta_{222} / \theta_{199}=0.33\right.$, measured in our lab) than [1055meLeu]AD1-ACTR, showing that $\alpha$-methylated amino acids are superior to standard amino acids at inducing helical structure. This is also reflected in the triple mutant's lower affinity for NCBD ( $\mathrm{K}_{\mathrm{D}}$ for [S1043M;D1050E;T1054Q] variant is 0.188 $\mu \mathrm{M}$ versus $0.204 \mu \mathrm{M}$ for $\mathrm{WT}$ and $0.042 \mu \mathrm{M}$ for [1055meLeu;1076meLeu]AD1-ACTR as measured by ITC at $304 \mathrm{~K}$ ).

NMR analysis provided residue-specific insights into the structural changes induced by $\alpha$ methylation of residues 1055 and 1076. ${ }^{1} \mathrm{H}-{ }^{13} \mathrm{C}$ HSQC spectra were recorded for the wild type domain and two variants, [1055meLeu]AD1-ACTR and [1055meLeu,1076meLeu]AD1ACTR (Supplementary Fig. 6). Assignment of $\mathrm{H} \alpha, \mathrm{C} \alpha$ and $\mathrm{C} \beta$ resonances was achieved using a combination of ${ }^{1} \mathrm{H}$-TOCSY, ${ }^{1} \mathrm{H}$-NOESY, ${ }^{1} \mathrm{H}-{ }^{13} \mathrm{C}$ HSQC and $\mathrm{HMBC}$ experiments (Supplementary Figs. 7-8 and Tables 7-10). The backbone chemical shifts in the two variants were compared with random coil values ${ }^{36}$. In both cases, positive deviations in ${ }^{13} \mathrm{C} \alpha$ chemical shifts indicate the presence of helical conformation in the vicinity of meLeu1055 and meLeu1076 (Fig. 3a). Moreover, local enhancement of helicity at position 1055 propagates towards the N-terminus, resulting in stabilization of the helical structure via long-range effects.

Although longitudinal relaxation rates $\left(\mathrm{R}_{1}\right)$ were not affected by $\alpha$-methylation (Supplementary Fig. 9 and Table 10), elevated values for transverse relaxation rates $\left(\mathrm{R}_{2}\right)$ were observed, particularly for residues near 1055 meLeu (Fig. 3b, Supplementary Table 11). These results likely reflect the contribution of conformational exchange $\left(\mathrm{R}_{\mathrm{ex}}\right)$ between locally folded and unfolded states, usually a very fast dynamical process that is presumably slowed down to the chemical shift time scale ( $\mu \mathrm{s}-\mathrm{ms})$.

X-ray structure of the [1055meLeu;1076meLeu]AD1-ACTR complex with NCBD. In an attempt to obtain high-resolution structural information, we tethered NCBD to a crystallization-prone mutant of the maltose binding protein $(\mathrm{MBP})^{37}$. While the complex of 
wild-type AD1-ACTR with MBP-fused NCBD did not yield crystals, we succeeded in solving an X-ray structure of the analogous complex with the best binder, [1055meLeu;1076meLeu]AD1-ACTR (Fig. 4a, Supplementary Figs. 11-15 and Table 12). The $\mathrm{X}$-ray diffraction data were collected at $2.2 \AA$ resolution and the structure was solved by molecular replacement using a high resolution MBP crystal structure and the previously reported NMR structure of AD1-ACTR ${ }^{25}$.

A comparison of the crystallized complex with the two NMR structures of activation domain of ACTR and NCBD, as well as other structures of NCBD is provided in Supplementary Fig. 12. The overall arrangement of the three AD1-ACTR helices in the crystal structure is most similar to the NMR structure with PDB ID: 1KBH. However, the interaction interface with NCBD in the crystal is less tight than in the NMR structure, with the overall buried surface area (BSA) decreasing to $1066 \AA$ from $1655 \AA$ for $1 \mathrm{KBH}$ structure (Supplementary Fig. 14). The most prominent difference is seen in the C-terminal helix, which no longer forms a tight interface with NCBD in the X-ray structure. Analysis of crystal packing did not reveal any interactions with symmetry related molecules (Supplementary Fig. 15), suggesting that this is not a crystal packing artifact. In [meLeu1055;meLeu1076]AD1-ACTR, both meLeu residues adopt canonical $\alpha$-helical backbone conformations with $(\varphi, \psi)$-angles of $-58.2^{\circ},-65.3^{\circ}$ for meLeu 1055 and $-39.9^{\circ},-57.0^{\circ}$ for meLeu1076, respectively (Fig. 4 a). This result further supports our hypothesis that $\alpha$-methylation can be used to stabilize $\alpha$-helical structures in IDPs.

A comparison with another available NMR structure of the complex (PDB ID: 6ES7) ${ }^{39}$, shows much larger deviations including a completely different orientation of the C-terminal helix of AD1-ACTR. The same is true for the NMR structure of the complex of NCBD with a homologous activation domain from SRC-1 isoform of p160 (PDB ID: 2C52) ${ }^{40}$ in which only the NCBD chain and N-terminal helix of SRC-1 can be reasonably superimposed, whereas the remaining part of SRC-1 adopts a completely different conformation.

$\alpha$-Methylation attenuates the conformational dynamics of AD1-ACTR/NCBD complex. Explicit-solvent all-atom molecular dynamics (MD) simulations were performed for $200 \mathrm{~ns}$ for the wild-type AD1-ACTR/NCBD complex as well as for two complexes with the $\alpha$ methylated analogues [1055meLeu]AD1-ACTR and [1055meLeu,1076meLeu]AD1-ACTR. As can be seen from the reduced RMSF (root-mean-square fluctuations) of backbone atom positions in the complexes with the variants compared to wild type (Fig. 4b), $\alpha$-methylation at positions 1055 and 1076 causes a substantial decrease in the amplitudes of motion. Moreover, the overall shape of the $\alpha$-methylated complexes was more compact as judged by their radii of gyration (Supplementary Fig. 16b). In addition, the $(\varphi, \psi)$-backbone conformations were clearly constrained by $\alpha$-methylation for the $\alpha$-methylated amino acids as well as for nearby residues (Fig. 4c and Supplementary Fig. 16d).

The higher stability of the $\alpha$-methylated complexes can also be inferred from the overall higher occurrence of hydrogen bonds in the corresponding complexes than in the wild type complex (Supplementary Table 13). A salt bridge analysis showed different patterns of populated salt bridges (Supplementary Table 14). Given the non-optimal ("frustrated") interface between AD1-ACTR and $\mathrm{NCBD}^{35}$, deviations of the average structure of the $\alpha$ methylated complexes from the corresponding structure of the wild-type complex would be 
expected. Different chemical shifts in the ${ }^{1} \mathrm{H}-{ }^{13} \mathrm{C}$ HSQC spectra of the [1055meLeu;1076meLeu] variant complexed with NCBD and the corresponding wild-type complex support this possibility, especially for the methyl resonances of aliphatic side chains indicating non identical hydrophobic protein-protein interfaces (Supplementary Fig. 10).

[1055meLeu;1076meLeu]AD1-ACTR is a superior binder both to NCBD and to full length CBP. CBP (like its paralog p300) is a large $(270 \mathrm{kDa})$ multi-domain protein containing folded and unstructured domains, including $\mathrm{NCBD}^{20}$. To test molecular recognition of methylated AD1-ACTR variants by CBP in comparison to isolated NCBD and whether these modified sequences bind CBP more potently than wild-type we performed surface plasmon resonance (SPR) experiments (Fig. 5). The C-termini of wild-type AD1-ACTR and [1055meLeu;1076meLeu]AD1-ACTR were conjugated to biotin via a polyethyleneglycol spacer, and the proteins were immobilized on the chip via biotin - streptavidin approach. Singly $\alpha$-methylated variants [1055meLeu]AD1-ACTR, [1076meLeu]AD1-ACTR and a weak binder [1064meLeu;1071meLeu]AD1-ACTR were prepared in the same way to use as additional experimental points and a negative control, respectively.

The kinetics and thermodynamics of binding to NCBD were measured at five different temperatures (from 20 to $31{ }^{\circ} \mathrm{C}$ ). The [1055meLeu;1076meLeu]AD1-ACTR analogue proved to be the best binder at all temperatures, with a binding affinity $\left(\mathrm{K}_{\mathrm{D}}\right)$ strengthened by 11-14 fold in comparison to wild-type (the tightest binding at $\sim 15 \mathrm{nM}$ was observed at $20{ }^{\circ} \mathrm{C}$, see Supplementary Table 16). This effect originates in the dissociation kinetics that is affected most strongly ( $k_{\text {off }}$ was reduced by an order of magnitude), whereas the association kinetics were affected to a lesser extent and is only slightly increased for the dimethylated variant (Supplementary Table 15). Finally, the higher binding affinity of [1055meLeu;1076meLeu]AD1-ACTR was confirmed for full-length CBP (apparent $\mathrm{K}_{\mathrm{D}}$ improved from $\sim 1.2 \mu \mathrm{M}$ to $\sim 60 \mathrm{nM}$ at $10{ }^{\circ} \mathrm{C}$ ) (Supplementary Fig. 20), suggesting that conformational editing of an intrinsically disordered domain by $\alpha$-methylation can be used to derive a selective and high affinity binder with the ability to target a multi-domain binding partner.

\section{DISCUSSION}

Protein engineering has been successfully applied to elucidate the mechanistic details of folding and complex formation of many proteins ${ }^{41,42}$. In a typical study, amino acid residues are substituted with analogues that contain smaller side-chains, often alanine (Ala) in Alascanning mutagenesis ${ }^{30}$. The resulting alteration of interactions, when performed systematically with single-residue resolution, provides insight into the importance of each residue for the stability of the folded protein or protein complex. In addition, $\Phi$-values, defined as the ratio of the free energy destabilization of transition state versus ground state upon mutation, can be derived to evaluate the structural roles of specific residues in folding mechanisms ${ }^{43}$. Double mutant cycles can also be used to determine the effects of long range inter-residue cooperativity ${ }^{34}$. This set of tools has enabled comprehensive analysis of many protein systems. 
In this work, we have developed a different strategy to study folding and complex formation that is particularly useful for IDPs. Instead of altering interactions by replacing large residues by smaller ones, which generally causes destabilization, we reinforced inter-residue contacts by conformationally constraining backbone $\varphi / \psi$-dihedral angles in a residue-specific manner. $\alpha$-Helical conformations, which are very abundant in IDP complexes, can be enhanced locally by strategic incorporation of $\alpha$-methyl groups ${ }^{26,29}$. A significant advantage of this approach is the preservation of the native amino acid side chains that mediate inter-residue contacts.

Our results with the intrinsically disordered transcription coactivator ACTR domain validate the potential of this strategy. In addition to showing that $\alpha$-methylation can modulate the free energy landscape of coupled binding and folding, we discovered several $\alpha$-methylated variants of AD1-ACTR with enhanced affinity for NCBD, its natural binding partner. A priori prediction of positions for $\alpha$-methylation that increase $\alpha$-helical content and also improve binding affinity is not trivial, however. Stabilization does not simply correlate with amino acid secondary structure propensities, since replacing a helix-favoring Leu amino acid with its $\alpha$ methylated counterpart at two different sites in the sequence (i.e., 1055 and 1071 both in helical segments) gave totally opposite effects. Choosing appropriate methylation sites based on structural data is also challenging because IDP complexes often possess a certain degree of "fuzziness" 44 and can adapt to small perturbations, such as introduction of a few $\alpha$-methyl groups, with hard-to-predict structural and dynamic consequences. Our combinatorial library approach was therefore essential for effectively exploring position- and context-dependence as well as long-range interactions between distant residues. Overall, approximately $30 \%$ of the variants were found to bind the NCBD domain of CBP more tightly than wild-type AD1ACTR, whereas the remaining 70\% bound more weakly. Most likely, for most of the positions, including analogues with multiple substitutions, $\alpha$-methylation can lead to alternative conformations of side-chains and/or steric clashes.

For the best binding variant, [1055meLeu;1076meLeu]AD1-ACTR, we succeeded in obtaining the first crystal structure of this transcriptional activator in complex with its binding partner NCBD. The X-ray data complement and extend previous structural information gleaned by NMR spectroscopy ${ }^{25,39}$. A comparison of crystal structure and NMR structures generally supports the notion that the N-terminal helix of AD1-ACTR is critical for complex formation $^{45,46}$ as it superimposes rather well for all structures, whereas the rest of the sequence of AD1-ACTR is rather malleable. A given AD1-ACTR conformer "caught" in the crystal resulted in high accuracy structural information, which can be used for designing small molecules that can specifically bind and allosterically modulate the interaction between NCBD and wild-type AD1-ACTR. As our failure to crystallize the more dynamic wild-type complex attests, crystallizing complexes resulting from the mutual interactions of IDPs can be difficult, so targeted $\alpha$-methylation could conceivably become a valuable tool for structurally characterizing the complexes formed by many other IDPs. So-called "fuzzy" complexes that exhibit substantial binding affinities and specificities despite enhanced conformational dynamics would be particularly interesting in this regard ${ }^{44}$.

Among singly methylated AD1-ACTR variants, substitution of Leu with meLeu at position 1055 in AD1-ACTR provided the largest increase in binding affinity for NCBD. In this case, $\alpha$-methylation results in a "gain-of-function". In contrast, when this residue was replaced by Ala for $\Phi$-value analysis of the protein, a weaker binding constant was obtained, constituting a 
"loss-of-function" due to substitution of a bulky isopropyl moiety with a smaller methyl group ${ }^{45}$. Notably, this was the only site in the protein that gave an elevated $\Phi$-value (close to 0.8), indicating that residue 1055 adopts a near native conformation in the folding transition state $^{45}$.

Consistent with this interpretation, NMR measurements showed that $\alpha$-methylation of Leu1055 leads to partial folding of the N-terminal helix in free AD1-ACTR protein resulting in faster association and slower dissociation rates with NCBD (Fig. 5a). The acceleration of binding reflects a reduction of Gibbs free energy barrier for folding: for instance, the residue 1055, which is most important for folding, is already pre-folded in free [1055meLeu]AD1ACTR variant. Slower dissociation results from higher stability of complex and enhanced barrier for unfolding.

Thus, our results are consistent with previous data suggesting that coupled binding and folding of AD1-ACTR and NCBD occurs via an induced fit mechanism in which the two highly unstructured polypeptides undergo major conformational rearrangements to form the wellstructured final protein complex ${ }^{27}$. The observed increased on-rate $\left(k_{\mathrm{on}}\right)$, in particular upon $\alpha-$ methylation of AD1-ACTR residue 1055, reveals that elements of conformational selection are also likely operative. Thus, the overall mechanism of complex formation may be best explained by 'extended conformational selection' 47 or 'conformational funneling' ${ }^{48}$ models, which synergistically combine both induced fit and conformational selection mechanisms.

A particularly intriguing consequence of our work is the possibility of using $\alpha$-methylated IDPs to inhibit native PPIs. Both CBP and ACTR have been implicated in various diseases (neurological, metabolic disorders and cancers), and regulating their function has been proposed as a possible means of therapeutic intervention. ${ }^{49,50}$ Indeed, potent small molecule inhibitors have been developed for the well-structured histone acetyltransferase (HAT) domain in $\mathrm{CBP} / \mathrm{p} 300^{51}$. However, intrinsically disordered domains in large, complex proteins such as CBP and ACTR are often considered to be 'undruggable' by small molecules ${ }^{52}$. Formation of complexes between IDPs is governed by different physicochemical principles than well-folded proteins $^{5,18}$. Delocalization of binding energy over a large surface area may be the most important difference, making it difficult for small molecules to compete with the native protein binding partners. Our results establish the feasibility of an alternative approach that is based on conformational editing of the IDP domain itself, utilizing backbone conformational constraints to enhance the native structural features and facilitate binding to the protein target. Remarkably, $\mathrm{CBP}$, which contains nine interaction domains in addition to $\mathrm{NCBD}^{21}$, senses the presence of two extra $\alpha$-methyl groups in the [1055meLeu;1076meLeu]AD1-ACTR variant and binds it more tightly than wild type AD1-ACTR. We anticipate that such modified peptides may serve as useful lead compounds for development of potent inhibitors that can be used in cell culture to probe the diverse roles of $\mathrm{CBP} / \mathrm{p} 300$ and ACTR in signaling and regulation pathways in gene transcription. Furthermore, the feasibility of biosynthetic incorporation of $\alpha$-methylated amino acids into proteins via stop codon suppression using aminoacylated tRNA was demonstrated previously. ${ }^{53}$ Therefore, the conformational editing of interaction domains of IDPs can in principle be performed via an expanded genetic code ${ }^{54}$. 
Acknowledgements. X-ray data collection was performed on the PXIII beamline at the Swiss Light Source synchrotron, P. Scherrer Institute, Villigen, Switzerland. We thank V. Olieric and C.-Y. Huang for their help on the beamline. We also thank IGBMC staff members P. PoussinCourmontagne, A. McEwen and C. Birck from structural and biophysics platforms and to Prof. S. Riniker from the ETH Zurich for providing CPU time. This work has been funded by the European Research Council (ERC-2016-StG, grant number 715062-HiChemSynPro), the CNRS, the INSERM, the Université de Strasbourg (IDEX program R701/W15RPE19), the Région Alsace and the Hôpital Civil de Strasbourg. The authors acknowledge the support and the use of resources of the French Infrastructure for Integrated Structural Biology FRISBI ANR-10-INBS-05 and of Instruct-ERIC. 


\section{References:}

1. van der Lee R. et al. Classification of intrinsically disordered regions and proteins. Chem. Rev. 114, 6589-6631 (2014).

2. Oldfield, C. J., Dunker, A. K. Intrinsically disordered proteins and intrinsically disordered protein regions. Annu. Rev. Biochem. 83, 553-584 (2014).

3. Wright, P. E., Dyson, H. J. Intrinsically disordered proteins in cellular signaling and regulation. Nat. Rev. Mol. Cell. Biol. 16, 18-29 (2015).

4. Pancsa, R., Tompa, P. Structural disorder in eukatyotes. PLoS ONE 7, e34687 (2012).

5. Uversky, V. N. Unusual biophysics of intrinsically disordered proteins. Biochim. Biophys. Acta 1834, 932-951 (2013).

6. Borgia, A., Borgia, M. B., Bugge, K., Kissling, V. M., Heidarsson, P. O., Fernandes, C. B., Sottini, A., Soranno, A., Buholzer, K. J., Nettels, D., Kragelund, B. B., Best, R. B., Schuler, B. Extreme disorder in an ultrahigh-affinity protein complex. Nature 555, 61-66 (2018).

7. Brangwynne, C. P., Tompa, P., Pappu, R. V. Polymer physics of intracellular phase transitions. Nat. Phys. 11, 899-904 (2015).

8. Banani, S. F., Lee, H. O., Hyman, A. A., Rosen, M. K. Biomolecular condensates: organizers of cellular biochemistry. Nat. Rev. 18, 285-298 (2017).

9. Dunker, A. K., Cortese, M. S., Romero, P., Iakoucheva, L. M., Uversky, V. N. Flexible nets. The roles of intrinsic disorder in protein interaction networks. FEBS J. 272, 5129-5148 (2005).

10. Fuxreiter, M., Tompa, P., Simon, I., Uversky, V. N., Hansen, J. C., Asturias, F. J. Malleable machines take shape in eukaryotic transcriptional regulation. Nat. Chem. Biol. 4, 728-737 (2008).

11. Shammas, S. L. Mechanistic roles of protein disorder within transcription. Curr. Opin. Struct. Biol. 42, 155-161 (2017).

12. Martinez, E. Multi-protein complexes in eukaryotic gene transcription. Plant Molecular Biology 50, 925-947 (2002).

13. Nakagawa, T., Yoneda, M., Higashi, M., Ohkuma, Y., Ito, T. Enhancer function regulated by combinations of transcription factors and cofactors. Genes Cells 23, 808-821 (2018).

14. Perissi, V., Rosenfeld, M. G. Controlling nuclear receptors: the circular logic of cofactor cycles. Nat. Rev. 6, 542-554 (2005).

15. Liu, J., Perumal, N. B., Oldfield, C. J., Su, E. W., Uversky, V. N., Dunker, A. K. Intrinsic disorder in transcription factors. Biochemistry 45, 6873-6888 (2006).

16. Dunker, A. K., Uversky, V. N. Drugs for 'protein clouds': targeting intrinsically disordered transcription factors. Curr. Opin. Pharmacol. 10, 782-788 (2010).

17. Scott, D. E., Bayly, A. R., Abell, C., Skidmore, J. Small molecules, big targets: drug discovery faces the protein-protein interaction challenge. Nat. Rev. 15, 533-550 (2016).

18. Flock, T., Weatheritt, R. J., Latysheva, N. S., Babu, M. M. Controlling entropy to tune the functions of intrinsically disordered regions. Curr. Opin. Struct. Biol. 26, 62-72 (2014).

19. Walensky, L. D., Bird, G. H. Hydrocarbon-stapled peptides: principles, practice, and progress. J. Med. Chem. 57, 6275-6288 (2014).

20. Vo, N., Goodman, R. H. CREB-binding protein and p300 in transcriptional regulation. $J$. Biol. Chem. 276, 13505-13508 (2001). 
21. Dyson, H. J., Wright, P. E. Role of intrinsic protein disorder in the function and interactions of the transcriptional coactivators CREB-binding protein (CBP) and p300. J. Biol. Chem. 291, 6714-6722 (2016).

22. Xu, J., Wu, R.-C., O’Malley, B. W. Normal and cancer-related functions of the p160 steroid receptor co-activator (SRC) family. Nat. Rev. 9, 615-630 (2009).

23. Kjaergaard, M., Teilum, K., Poulsen, F. M. Conformational selection in the molten globule state of the nuclear coactivator binding domain of CBP. Proc. Natl. Acad. Sci. USA 107, 12535-12540 (2010).

24. Iesmantavicius, V., Dogan, J., Jemth, P., Teilum, K., Kjaergaard, M. Helical propensity in an intrinsically disordered protein accelerates ligand binding. Angew. Chem. Int. Ed. 53, 1548-1551 (2014).

25. Demarest, S. J., Martinez-Yamout, M., Chung, J., Chen, H., Xu, W., Dyson, H. J., Evans, R. M., Wright, P. E. Mutual synergistic folding in recruitment of $\mathrm{CBP} / \mathrm{p} 300$ by $\mathrm{p} 160$ nuclear receptor coactivators. Nature 415, 549-553 (2002).

26. Kaul, R., Balaram, P. Stereochemical control of peptide folding. Bioorg. Med. Chem. 7, 105-117 (1999).

27. Schmidtgall, B., Chaloin, O., Bauer, V., Sumyk, M., Birck, C., Torbeev, V. Dissecting mechanism of coupled folding and binding of an intrinsically disordered protein by chemical synthesis of conformationally constrained analogues. Chem. Commun. 53, 73697372 (2017).

28. Werner, H. M., Cabalteja, C. C., Horne, W. S. Peptide backbone composition and protease susceptibility: impact of modification type, position, and tandem substitution. Chembiochem 17, 712-718 (2016).

29. Crisma, M., Toniolo, C. Helical screw-sense preferences of peptides based on chiral, C $\alpha-$ tetrasubstituted $\alpha$-amino acids. Biopolymers 104, 46-64 (2014).

30. Clackson, T., Wells, J. A. A hot spot of binding energy in a hormone-receptor interface. Science 267, 383-386 (1995).

31. Dobson, C. M., Šali, A., Karplus, M. Protein folding: a perspective from theory and experiment. Angew. Chem. Int. Ed. 37, 868-893 (1998).

32. Clodera, J. D., Mobley, D. L. Entropy-enthalpy compensation: role and ramifications in biomolecular ligand recognition and design. Annu. Rev. Biophys. 42, 121-142 (2013).

33. Baxa, M. C., Haddadian, E. J., Jumper, J. M., Freed, K. F., Sosnick, T. R. Loss of conformational entropy in protein folding calculated using realistic ensembles and its implications for NMR-based calculations. Proc. Natl. Acad. Sci. USA 111, 15396-15401 (2014).

34. Horovitz, A., Fersht, A. R. Co-operative interactions during protein folding. J. Mol. Biol. 224, 733-740 (1992).

35. Jemth, P., Mu, X., Engström, Å., Dogan, J. A frustrated binding interface for intrinsically disordered proteins. J. Biol. Chem. 289, 5528-5533 (2014).

36. Tamiola, K., Acar, B., Mulder, F. A. Sequence-specific random coil chemical shifts of intrinsically disordered proteins. J. Am. Chem. Soc. 132, 18000-18003 (2010).

37. Zanier, K., Charbonnier, S., Sidi, A. O., McEwen, A. G., Ferrario, M. G., PoussinCourmontagne, P., Cura, V., Brimer, N., Babah, K. O., Ansari, T., Muller, I., Stote, R. H., Cavarelli, J., Vande Pol, S., Travé, G. Structural basis for hijacking of cellular LxxLL motifs by papillomavirus E6 oncoproteins. Science 339, 694-698 (2013). 
38. Dunbrack, Jr., R. L., Cohen, F. E. Bayesian statistical analysis of protein side-chain rotamer preferences. Prot. Sci. 6, 1661-1681 (1997).

39. Jemth, P., Karlsson, E., Vögeli, B., Guzovsky, B., Andersson, E., Hultqvist, G., Dogan, J., Güntert, P., Riek, R., Chi, C. N. Structure and dynamics conspire in the evolution of affinity between intrinsically disordered proteins. Sci. Adv. 4, eaau4130 (2018).

40. Waters, L., Yue, B., Veverka, V., Renshaw, P., Bramham, J., Matsuda, S., Frenkiel, T., Kelly, G., Muskett, F., Carr, M., Heery, D. M. Structural diversity in p160/CREB-binding protein coactivator complexes. J. Biol. Chem. 281, 14787-14795 (2006).

41. Fersht, A. R., Daggett, V. Protein folding and unfolding at atomic resolution. Cell 108, 120 (2002).

42. DeLano, W. L. Unraveling hot spots in binding interfaces: progress and challenges. Curr. Opin. Struct. Biol. 12, 14-20 (2002).

43. Matouschek, A., Kellis, J. T., Serrano, L., Fersht, A. R. Mapping the transition state and pathway of protein folding by protein engineering. Nature 340, 122-126 (1989).

44. Fuxreiter, M., Tompa, P. Fuzzy complexes: a more stochastic view of protein function. Adv. Exp. Med. Biol. 725, 1-14 (2012).

45. Dogan, J., Mu, X., Engström, Å., Jemth, P. The transition state structure for coupled binding and folding of disordered protein domains. Sci Rep. 3, 2076 (2013).

46. Karlsson, E., Andersson, E., Dogan, J., Gianni, S., Jemth, P., Camilloni, C. A structurally heterogeneous transition state underlies coupled binding and folding of disordered proteins. J. Biol. Chem. 294, 1230-1239 (2019).

47. Ganguly, D., Zhang, W., Chen, J. Synergistic folding of two intrinsically disordered proteins : searching for conformational selection. Mol. BioSyst. 8, 198-209 (2012).

48. Schneider, R., Maurin, D., Communie, G., Kragelj, J., Hansen, D. F., Ruigrok, R. W. H., Jensen, M. R., Blackledge, M. Visualizing the molecular recognition trajectory of an intrinsically disordered protein using multinuclear relaxation dispersion NMR. J. Am. Chem. Soc. 137, 1220-1229 (2015).

49. Lonard, D. M., O'Malley, B. W. Molecular pathways: targeting steroid receptor coactivators in cancer. Clin. Cancer Res. 22, 5403-5407 (2016).

50. Breen, M. E., Mapp, A. K. Modulating the masters: chemical tools to dissect CBP and p300 function. Curr. Opin. Chem. Biol. 45, 195-203 (2018).

51. Lasko, L. M. et al. Discovery of a selective catalytic p300/CBP inhibitor that targets lineage-specific tumours. Nature 550, 128-132 (2017).

52. Dang, C. V., Reddy, E. P., Shokat, K. M., Soucek, L. Drugging the 'undruggable' cancer targets. Nat. Rev. Cancer 17, 502-508 (2017).

53. Mendel, D., Ellman, J., Schultz, P. G. Protein biosynthesis with conformationally restricted amino acids. J. Am. Chem. Soc. 115, 4359-4360 (1993).

54. Chin, J. W. Expanding and reprogramming the genetic code. Nature 550, 53-60 (2017). 
a

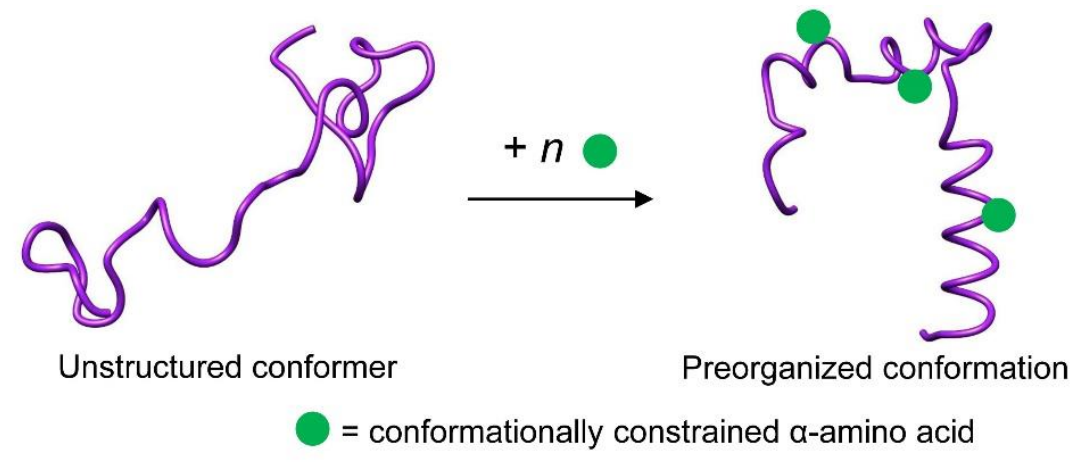

b
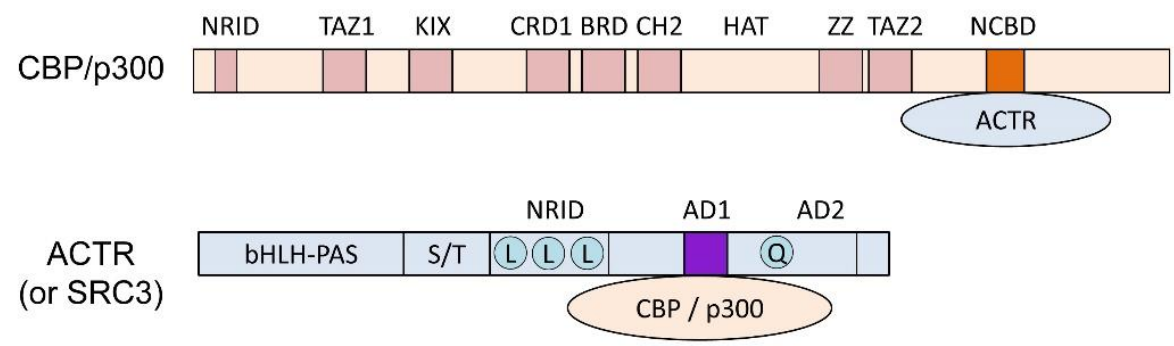

C [1040-1086] ACTR:

EGQSDERALLDQLHTLLSNTDATGLEEIDRALGIPELVNQGQALEPK

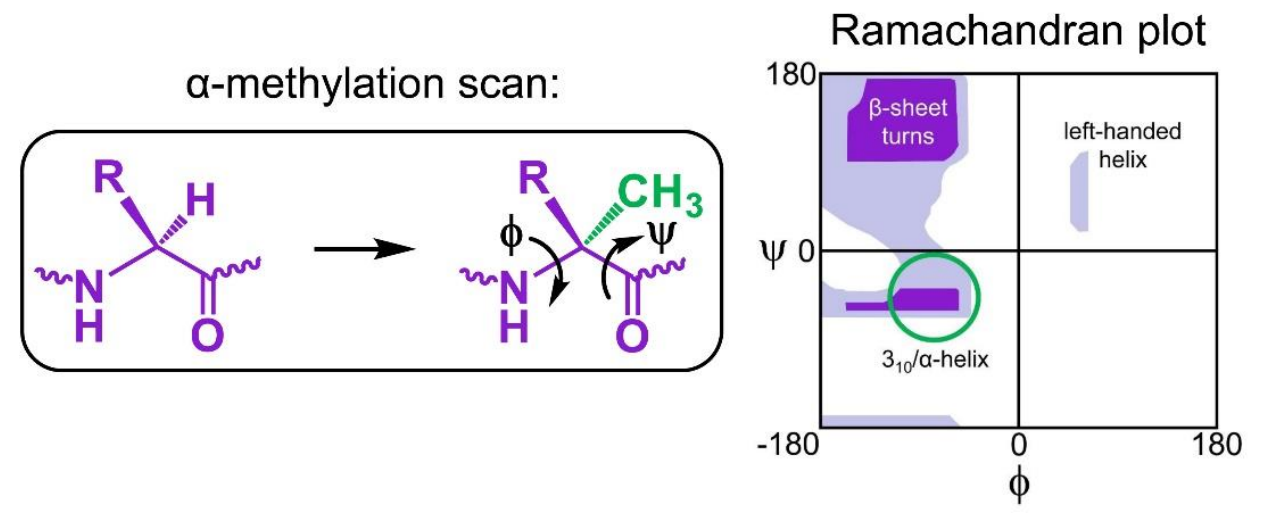

Fig. 1. Backbone $\alpha$-methylation to stabilize helical conformations in intrinsically disordered proteins. (a) Disordered conformations adopt secondary structures upon incorporation of conformationally constrained amino acids. (b) Domain organization of CBP/p300 and ACTR (or SRC3), which interact with each other via NCBD (in orange) and AD1 (in violet) domains. For clarification of domain abbreviations, see refs ${ }^{21,22}$. (c) Sequence of [1040-1086]fragment of ACTR that binds to NCBD of CBP/p300 with residues that were replaced by $\alpha$ methylated congeners in green. Additional methyl groups attached at $\alpha$-carbon constrain backbone $(\varphi, \psi)$-dihedral angles to values that correspond to $3_{10} / \alpha$-helix (green circle) in lower, left quadrangle of the Ramachandran plot. 
a

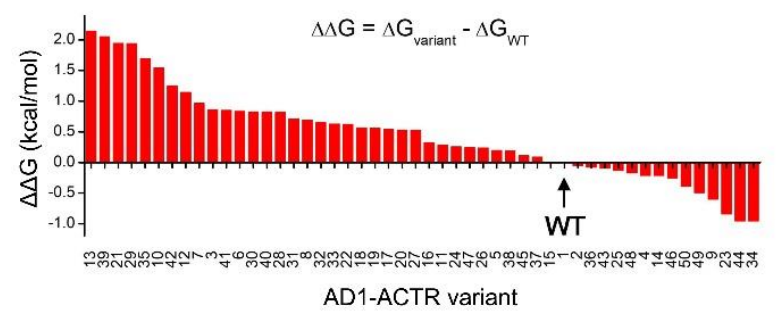

List of variants:

$\begin{array}{llll}1 & \text { wild type (WT) AD1-ACTR } & 10 & {[1056 \mathrm{~mL}]} \\ 2 & {[1047 \mathrm{~mA}]} & 11 & {[1061 \mathrm{~mA}]} \\ 3 & {[S 1043 \mathrm{M} ; D 1050 E ; T 1054 \mathrm{Q}]} & 12 & {[1064 \mathrm{~mL}]} \\ 4 & {[A 1047 \mathrm{G}]} & 13 & {[1071 \mathrm{~mL}]} \\ 5 & {[1048 \mathrm{~mL}]} & 14 & {[1072 \mathrm{~mA}]} \\ 6 & {[1049 \mathrm{~mL}]} & 15 & {[1076 \mathrm{~mL}]} \\ 7 & {[1050 \mathrm{mD}]} & 16 & {[1077 \mathrm{mV}]} \\ 8 & {[1052 \mathrm{~mL}]} & 17 & {[1080 \mathrm{~mA}]} \\ 9 & {[1055 \mathrm{~mL}]} & 18 & {[1082 \mathrm{~mA}]}\end{array}$

\section{i}

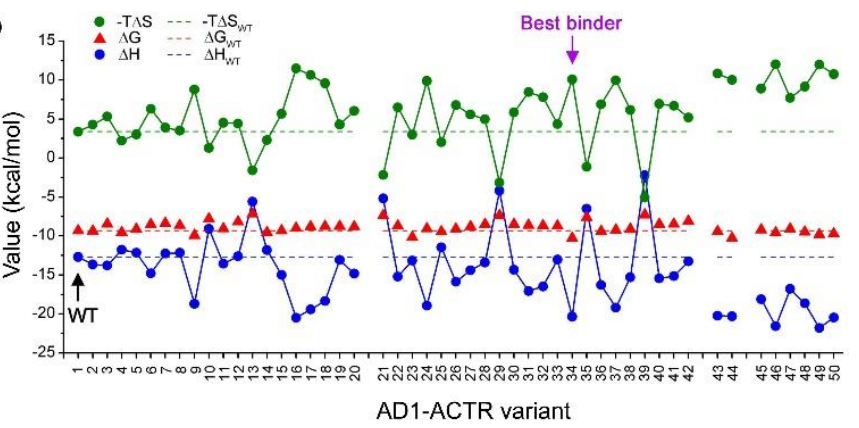

AD1-ACTR variant

Fig. 2. Thermodynamic dissection of the effect of $\alpha$-methylation on binding of AD1-ACTR and NCBD by ITC measurements. (a) Chemically synthesized variants of AD1-ACTR are arranged along $x$-axis according to their binding affinities to NCBD (from low to high). The corresponding sites of $\alpha$-methylation and numbering of AD1-ACTR variants are listed below. In $y$ axis Gibbs free energy of binding for wild type is subtracted from the corresponding values for each variant $(\Delta \Delta G)$. All studied complexes were additionally characterized by circular dichroism spectroscopy (Supplementary Fig. 3, Fig. 4b and Supplementary Table 6). The stabilities of the selected complexes determined by thermal denaturation (Supplementary Fig. 5 and Supplementary Table 4) are in agreement with the ITC data. (b) Gibbs free energy $(\Delta G)$, enthalpy $(\Delta \mathrm{H})$ and entropy $(-\mathrm{T} \Delta \mathrm{S})$ of complex formation (at $\mathrm{T}=304 \mathrm{~K}$ ) between $\alpha$-methylated variants of AD1-ACTR and NCBD. The respective values of $\Delta \mathrm{H}$ and $\Delta S$ can be fitted with a linear regression $(\Delta \mathrm{H}=\alpha+\beta \times \Delta S)$, where the slope $\beta$ or "compensation temperature" 32 is $340 \pm 7 \mathrm{~K}$. Different magnitudes of enthalpy-entropy changes reflect the modification of free energy surface of coupled binding and folding upon $\alpha$-methylation ${ }^{31}$. 

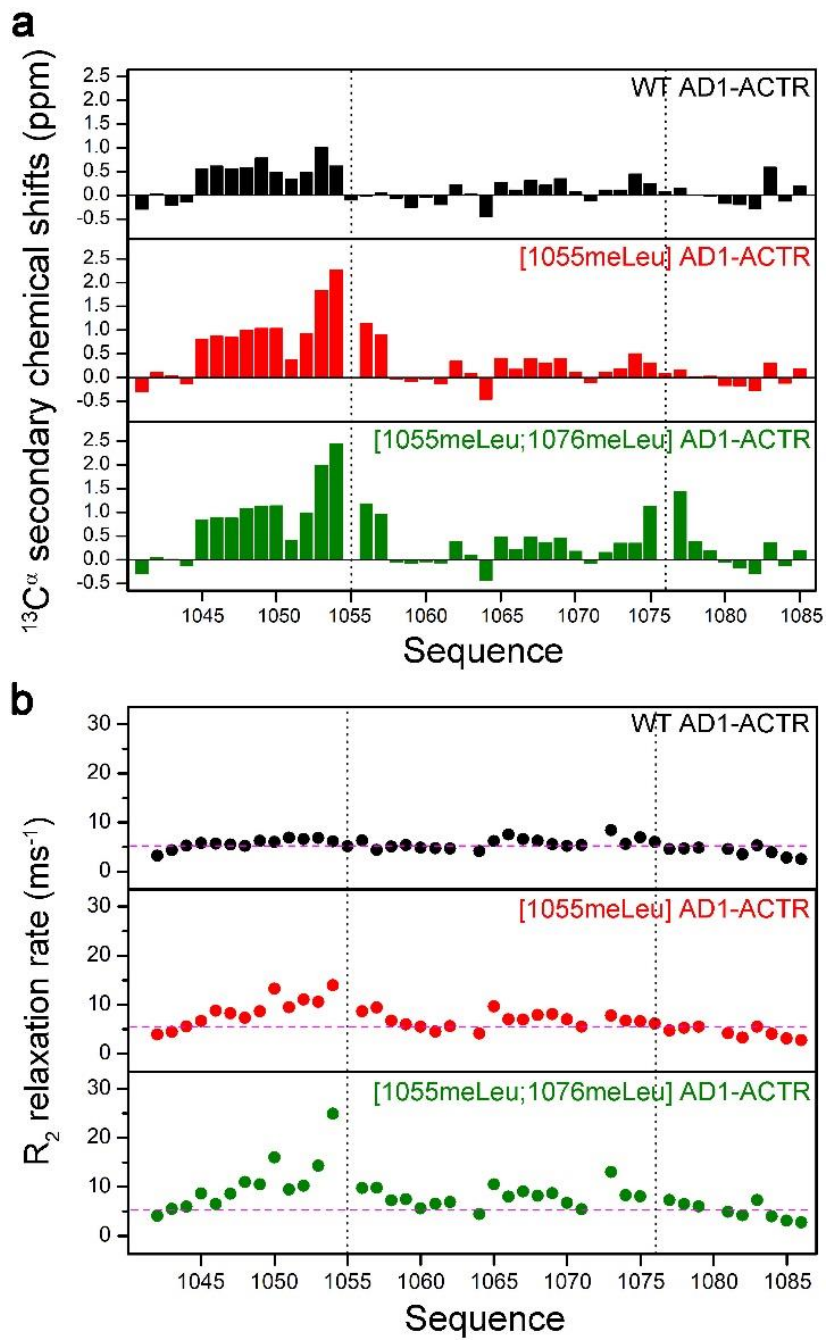

Fig. 3. $\alpha$-Methylation enhances helical structures in free ACTR activation domain. (a) ${ }^{13} \mathrm{C}^{\alpha}$ secondary chemical shift analysis indicates higher helical content in the proximity to the sites of incorporated a-methylated amino acids 1055 and 1076 (indicated by black dashed line). Furthermore, substitution at 1055 position results in higher population of helical structure at Nterminus (segment 1045-1054). (b) $\mathrm{C}^{\alpha}$ transverse relaxation rates $\left(\mathrm{R}_{2}\right)$ display increased values upon a-methylation, especially in double methylated [1055meLeu;1076meLeu]AD1-ACTR variant, suggesting the presence of conformational exchange between disordered and structured states. The $R_{2}$ measurement uncertainties correspond to $\sim 10 \%$ of the $R_{2}$ values and are within the dimension of the circles in the plot. The average $R_{2}$ value calculated for all residues in WT AD1-ACTR is included as pink dashed line in all three panels to highlight the overall $R_{2}$ increase observed upon $\alpha$-methylation. 
a

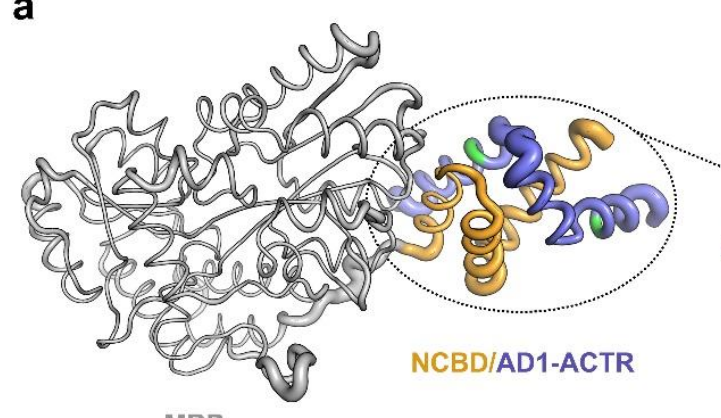

MBP

b

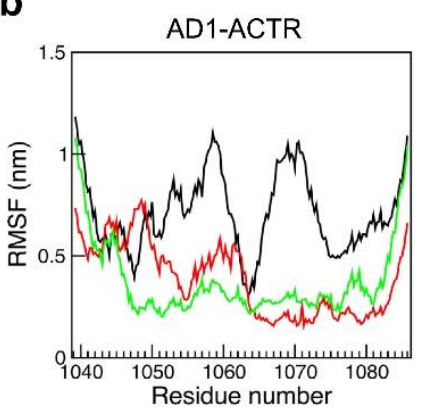

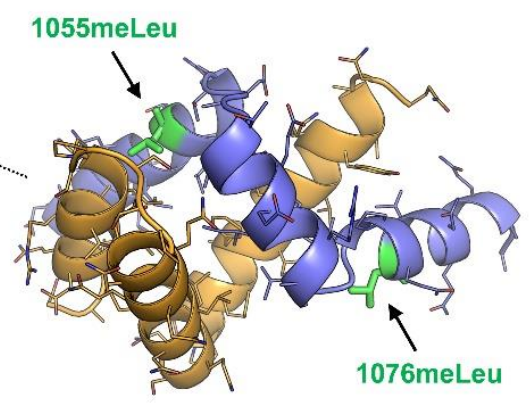

1076meLeu

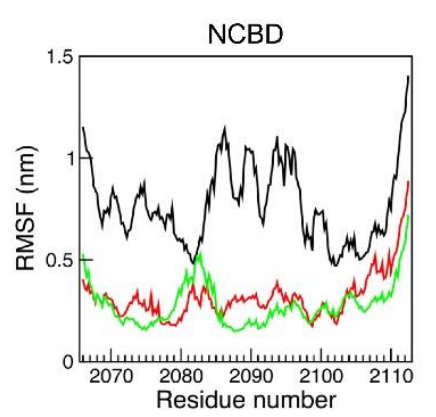

C 1055Leu

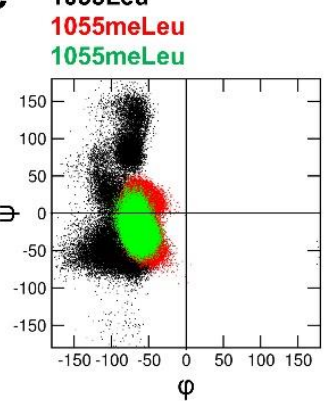

1055meLeu: $\varphi-58.2^{\circ} \psi-65.3^{\circ}$

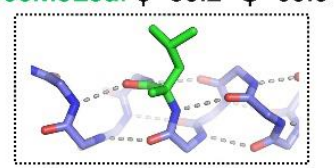

1076meLeu: $\varphi-39.9^{\circ} \Psi-57.0^{\circ}$
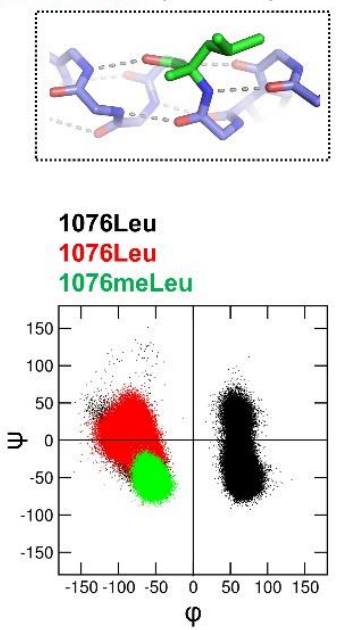

Fig. 4. Properties of the complex with the highest binding affinity. (a) An X-ray structure of NCBD bound to [1055meLeu;1076meLeu]AD1-ACTR (PDB ID: 6SQC). To facilitate the crystallization, NCBD was fused to maltose-binding protein (MBP) depicted in gray in the leftmost panel. The NCBD (in gold) and [1055meLeu;1076meLeu]AD1-ACTR (in purple-blue) have significantly higher thermal B-factors (thicker tube) than MBP reflecting the "fuzziness" of the complex. Enlarged structure of the complex in the middle illustrates the arrangement of six $\alpha$ helices and the positions of $\alpha$-methylated Leu residues (1055meLeu and 1076meLeu). Both residues adopt $\alpha$-helical conformations (corresponding helices are on the right). The side chain of 1055 meLeu adopts [trans $\left(t, \mathrm{X}_{1}=-167.4^{\circ}\right)$, trans $\left(t, \mathrm{X}_{2}=153^{\circ}\right)$ ] rotamer conformation, while 1076 meLeu has its side chain in [gauche- $\left(g-X_{1}=-59.3^{\circ}\right)$, trans $\left(t, X_{2}=137^{\circ}\right)$ ] conformation ${ }^{38}$. Dihedral angles $\mathrm{C} \gamma-\mathrm{C} \beta 1-\mathrm{C} \alpha-\mathrm{C} \beta 2$ (methyl) are $-35.4^{\circ}$ and 62.3ำ for meLeu1055 and meLeu1076, respectively, allowing a-methyl groups to avoid steric clashes with isopropyl side chains (stereochemical Newman projections are provided in Supplementary Fig. 13). (b) Root-mean square fluctuations (RMSF) in MD simulations (GROMOS, $200 \mathrm{~ns}$ ) of three complexes (wild type in black, [1055meLeu]AD1-ACTR/NCBD in red and [1055meLeu;1076meLeu]AD1-ACTR/NCBD in green) showing that $\alpha$-methylation rigidifies motions in both AD1-ACTR and NCBD (see Supplementary Figs. 16 and 17 for an additional analysis). (c) The corresponding Ramachandran plots depict well-defined helical distributions of $(\varphi, \Psi)$-dihedral angles for a-methylated residues 1055 meLeu and 1076meLeu in contrast to less defined conformations for non-methylated Leu residues in the corresponding complexes. 

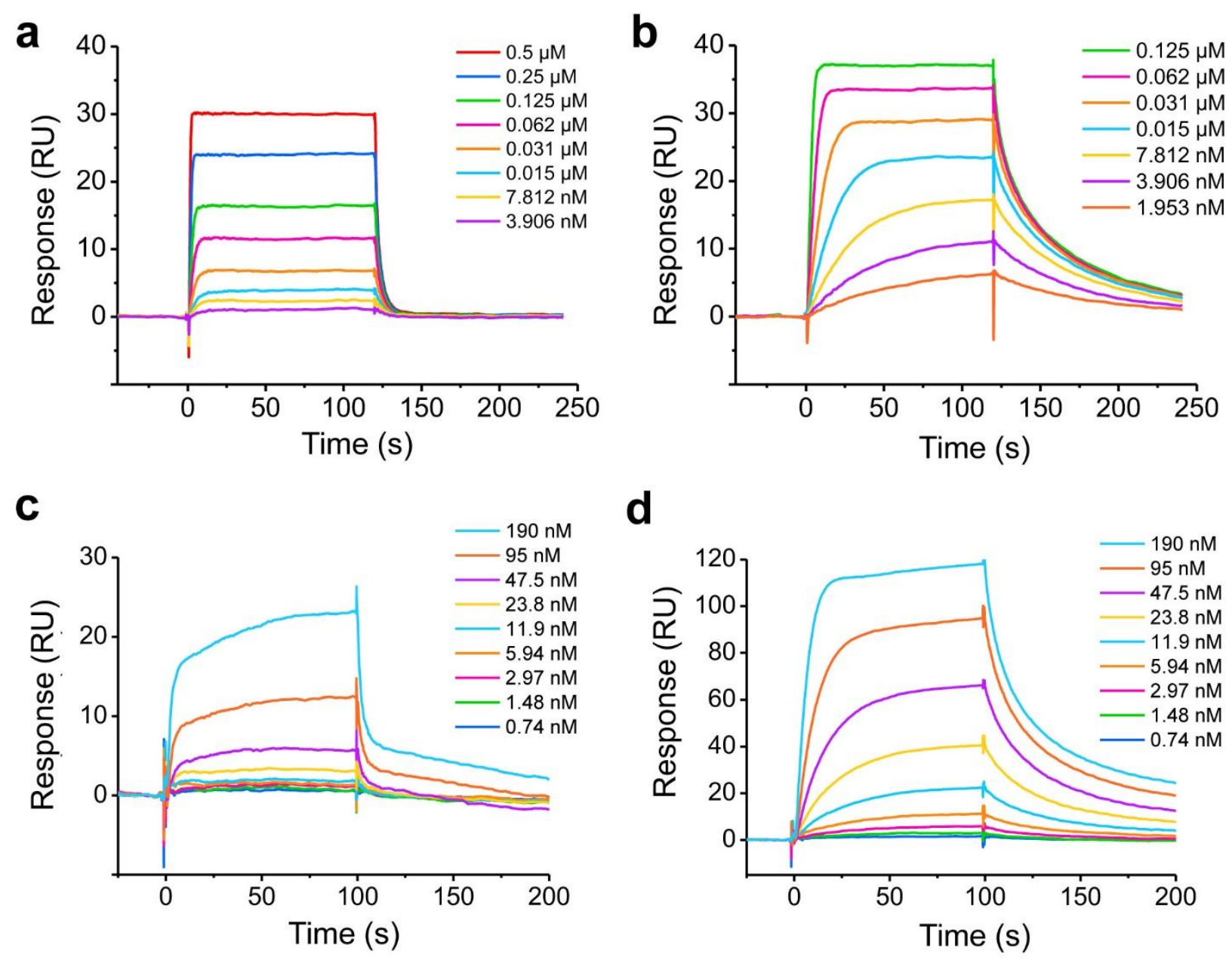

Fig. 5. $\alpha-M e t h y l a t i o n$ enhances binding of ACTR activation domain both to NCBD and full length (270 kDa) CBP. (a,b) Surface plasmon resonance (SPR) binding curves of NCBD to wild type ACTR activation domain and double a-methylated [1055meLeu;1076meLeu]AD1-ACTR variant at $20{ }^{\circ} \mathrm{C}$. Steady state analysis reveals $\sim 10$-times enhanced binding constant for dimethylated variant (see Supplementary Figs. 18, 19 and Supplementary Tables 15, 16 for data at four other temperatures and the estimated values of $k_{\text {on }}, k_{\text {off }}$ and $\left.K_{D}\right)$. (c,d) The same effect is observed for full length $270 \mathrm{kDa} C B P$ with apparent $\mathrm{K}_{\mathrm{D}}$ values indicating an order of magnitude improvement for the $\alpha$-methylated [1055mL;1076mL]AD1-ACTR-variant: $~ 60 \mathrm{nM}$ versus $1.2 \mu \mathrm{M}$ for wild-type (Supplementary Fig. 20; complementary fluorescence polarization measurements are consistent with SPR data, see Supplementary Fig. 21; negative control with weak-binding [1064mL;1071mL] variant shown in Supplementary Fig. 22). 


\section{Supplementary Information}

\section{Enhancing binding affinity of an intrinsically disordered protein by $\alpha$-methylation of key amino acid residues}

Valentin Bauer ${ }^{1 \dagger}$, Boris Schmidtgall ${ }^{1 \dagger}$, Gergő Gógl ${ }^{2 \#}$, Jozica Dolenc ${ }^{3}$, Judit Osz ${ }^{2}$, Yves Nominé ${ }^{2 \#, ~}$ Camille Kostmann ${ }^{2 \#}$, Alexandra Cousido-Siah ${ }^{2 \#}$, André Mitschler ${ }^{2 \#, ~ N a t a c h a ~ R o c h e l ~}{ }^{2}$, Gilles Travé $^{2 \#}$, Bruno Kieffer ${ }^{2}$ and Vladimir Torbeev ${ }^{1 *}$

${ }^{1}$ Institut de Science et d'Ingénierie Supramoléculaires (ISIS), International Center for Frontier Research in Chemistry (icFRC), University of Strasbourg, CNRS (UMR 7006), Strasbourg, France ${ }^{2}$ Department of Integrated Structural Biology, Institut de Génétique et de Biologie Moléculaire et Cellulaire (IGBMC), INSERM (U964), University of Strasbourg, CNRS (UMR 7104), Illkirch, France ${ }^{3}$ Chemistry | Biology | Pharmacy Information Center, ETH Zurich, Zurich, Switzerland

* Correspondence should be addressed to V. T. (torbeev@unistra.fr)

$\dagger$ These authors equally contributed to this work

\# Équipe Labellisée Ligue 2015

Table of contents:

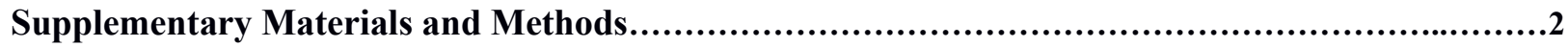

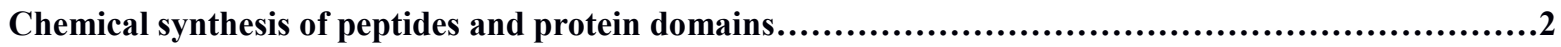

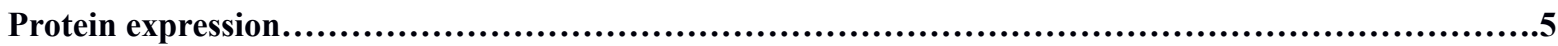

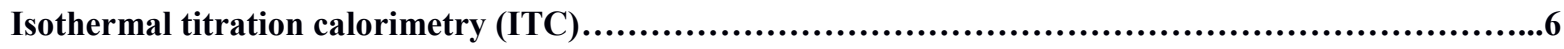

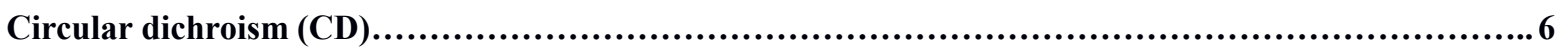

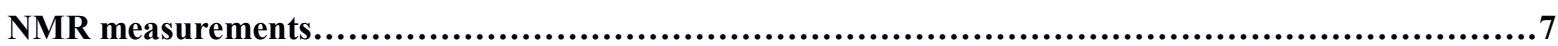

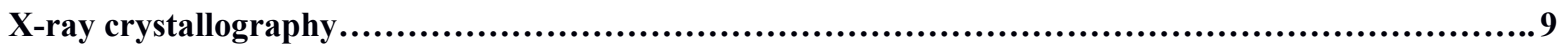

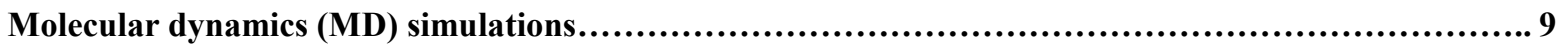

Biomolecular interaction analysis by Surface Plasmon Resonance (SPR) ..............................10

Fluorescence polarization (FP) measurements................................................. 12

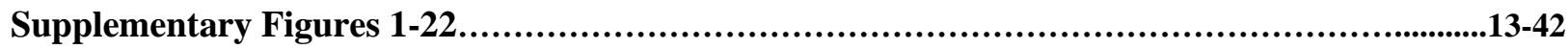

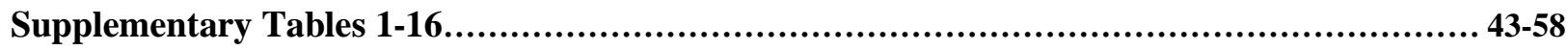

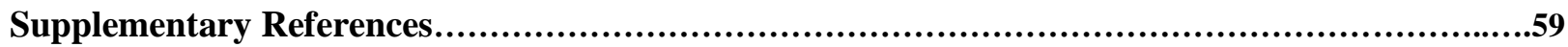




\section{Supplementary Materials and Methods}

\section{Chemical synthesis of peptides and protein domains}

Reagents: Solvents, chemicals and reagents were purchased from commercial sources. Fmoc- $\alpha$ - $L$-amino acids and resins for solid-phase peptide synthesis were purchased from Aapptec, Bachem or Iris Biotech, diisopropylethylamine (DIEA) and piperidine from Sigma-Aldrich, trifluoroacetic acid (Biograde) from Halocarbon. Fmoc-protected $\alpha$-methylated $L$-amino acids were purchased from OKeanos Tech. (China), Iris Biotech and Bachem. The coupling reagents O-(7-azabenzotriazol-1-yl)-N,N,N',N'tetramethyluronium hexafluorophosphate (HATU), O-(benzotriazol-1-yl)-N,N,N',N'-tetramethyluronium hexafluorophosphate (HBTU), N,N'-diisopropylcarbodiimide (DIC) and ethyl cyano(hydroxyimino)acetate (OxymaPure) were obtained from Iris Biotech. Fmoc-Lys(Biotin), Fmoc-NH$(\mathrm{PEG})_{3}-\mathrm{COOH}$ and Fmoc-NH-(PEG) $)_{5}-\mathrm{COOH}$ were purchased from Iris Biotech, and 5-(iodoacetamido)fluorescein from Santa Cruz biotechnology.

Peptide synthesis: The peptide- ${ }^{a}$ thioesters and cysteinyl-peptides were synthesized according to the previously described methods of SPPS and conjugated via native chemical ligation as reported ${ }^{1-4}$. In this work, in addition to two-segment ligation approach, protein domains were synthesized on solid phase in full length (47 residues) using microwave-assisted automated synthesis. The procedures for this approach are detailed below.

Polypeptides corresponding to [1040-1086]-fragment of the ACTR (numbering as in Nature 415, 549553 (2002), which corresponds to [1045-1091]-fragment of sequence Q9Y6Q9 (NCOA3_HUMAN) in UniProtKB) and [2066-2112]-fragment of CBP (CREB-binding protein, UniProtKB - P45481 (CBP_MOUSE)) were assembled using a Liberty Blue microwave-assisted automatic synthesizer (CEM Corporation, USA) on either $0.05,0.1$ or $0.2 \mathrm{mmol}$ scale. Variants of the [1040-1086]-fragment of the ACTR containing $\alpha$-methylated amino acids were synthesized analogously. The following protocol describes a synthesis on $0.1 \mathrm{mmol}$ scale using Fmoc-Lys(Boc)-Wang polystyrene resin, 100-200 mesh with $0.47 \mathrm{mmol} / \mathrm{g}$ loading. To perform standard microwave-assisted coupling reactions the coupling reagent DIC $(1 \mathrm{~mL}, 0.5 \mathrm{M})$, the activator OxymaPure $(0.5 \mathrm{~mL}, 1 \mathrm{M})$ and the amino acid $(2.5 \mathrm{~mL}, 0.2 \mathrm{M})$ were added to the resin and the suspension was treated at $90{ }^{\circ} \mathrm{C}$ for $2 \min (170 \mathrm{~W}$ for $15 \mathrm{~s}, 30 \mathrm{~W}$ for $110 \mathrm{~s})$. For some of the amino acids special conditions were used to achieve complete coupling. For Arg as well as for $\beta$ branched amino acids the coupling under standard microwave conditions was performed twice. The coupling of His was performed twice at $50{ }^{\circ} \mathrm{C}$ for $10 \min (0 \mathrm{~W} 120 \mathrm{~s}, 35 \mathrm{~W} 480 \mathrm{~s})$. The coupling of $\alpha$ methylated amino acids $\left(0.2 \mathrm{M}\right.$ solution) was performed at $90{ }^{\circ} \mathrm{C}$ for $4 \mathrm{~min}$. Fmoc-deprotections were performed by adding $20 \%(\mathrm{v} / \mathrm{v}) 4$-methylpiperidine $(3 \mathrm{~mL})$ to the resin and treating the suspension for 1 $\min$ at $90{ }^{\circ} \mathrm{C}(155 \mathrm{~W} 15 \mathrm{~s}, 32 \mathrm{~W} 50 \mathrm{~s})$. 
The peptides with sequences $(H)$-DERALLDQLHTLLSN- $\left(\mathrm{NH}_{2}\right)$ and $(H)$-DERALLDQLHT-meLeuLSN-( $\left.\mathrm{NH}_{2}\right)$ (meLeu $=\alpha$-methyl- $L$-leucine) corresponding to [1045-1059]-fragment of ACTR were also assembled by a microwave-assisted SPPS using Fmoc-Rink-Amide-AM polystyrene resin with 0.71 $\mathrm{mmol} / \mathrm{g}$ loading. Shorter peptides corresponding to the LXXLL motif of AD1-ACTR with two flanking additional amino acids, $(\mathrm{H})$-QLHTLLS- $\left(\mathrm{NH}_{2}\right)$ and $(\mathrm{H})$-QLHT-meLeu-LS- $\left(\mathrm{NH}_{2}\right)$ were prepared in the same manner.

Biotinylated peptides needed for surface plasmon resonance (SPR) measurements were synthesized on a $0.05 \mathrm{mmol}$ scale using Rink-Amide ChemMatrix resin (0.49 mmol/g loading). First, Fmoc-Lys(Biotin) was coupled to the resin followed by Fmoc-NH-(PEG) $)_{3}-\mathrm{COOH}$ (Iris Biotech, art. no.: PEG4370, chemical structure depicted below) and subsequently three glycine residues. Then, the actual sequence of the corresponding AD1-ACTR variant was assembled.

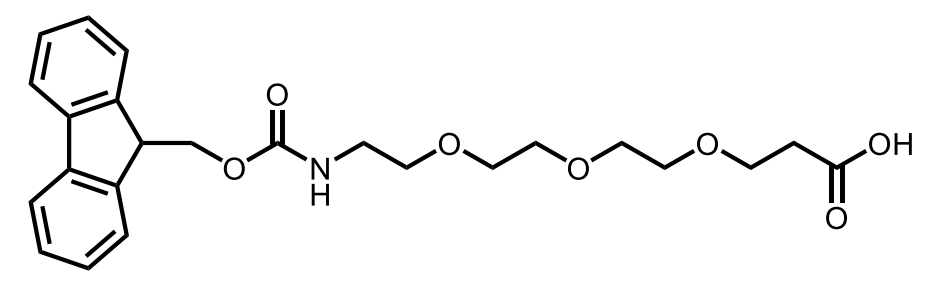

Fluoresceine-labeled AD1-ACTR peptides: cysteinyl-peptides were synthetized using microwaveassisted peptide synthesis as described above. The $\mathrm{N}$-terminal cysteine was separated from the peptide sequence using a (PEG) 5 linker. After purification on a C4 Jupiter column (same method as other AD1ACTR, see on p.4) Cys-(PEG) 5 -WT-AD1-ACTR and Cys-(PEG) 5 -[1055meLeu;1076meLeu]AD1-ACTR were labeled using the thiol reactive 5-(iodoacetamido)fluorescein. To do so, two solutions were prepared. First $2 \mathrm{mg}$ of peptide ( $1 \mathrm{eq}, 3.7 \times 10^{-7}$ moles) were dissolved in $300 \mu \mathrm{L}$ of $100 \mathrm{mM} \mathrm{NaHCO}{ }_{3} 5 \mathrm{mM} \mathrm{TCEP}$ at $\mathrm{pH}$ 7.5. Then, protected from light, $1 \mathrm{mg}$ of 5-(iodoacetamido)fluorescein (5 eq) were dissolved in $300 \mu \mathrm{L}$ of anhydrous DMF. The two solutions were mixed, quickly stirred and allowed to react for $10 \mathrm{~min}$ at room temperature. The reaction mixture was further purified on a C4 Jupiter column (same method as other AD1ACTR, see on p.4) and pure fractions were combined and lyophilized yielding a green-yellowish powder (1.3 mg, 59\%). The structure of the dye and spacer are shown below:

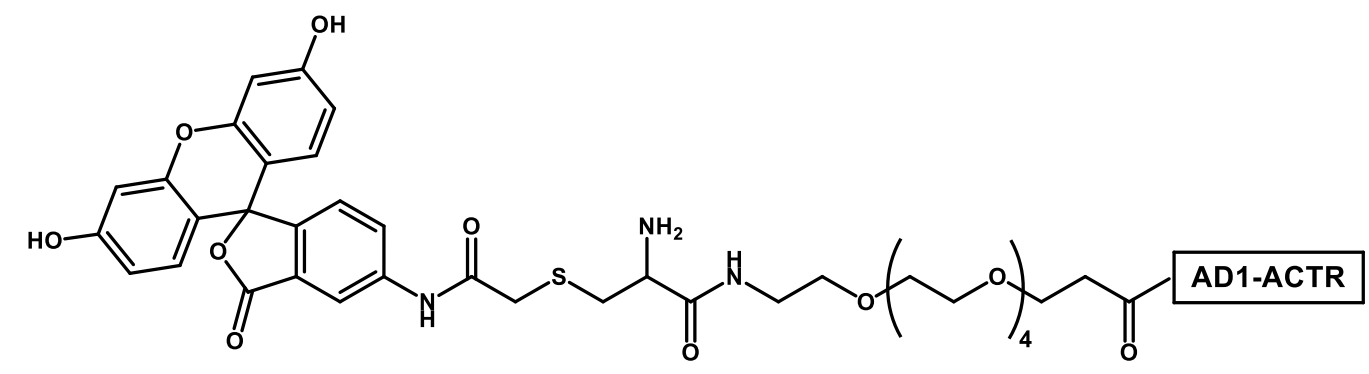


Analytical HPLC: Analytical reversed phase HPLC of all peptides and proteins was performed on a Dionex Ultimate 3000 (Thermo Fisher) equipped with a UV detector, a column heater set to $40{ }^{\circ} \mathrm{C}$ and an autosampler. Analyzes were performed on a Kinetex EVO C18 column (Phenomenex, particle size $2.6 \mu \mathrm{m}$, pore size $100 \AA$, dimensions $50 \times 2.1 \mathrm{~mm}$ ) or a Kinetex XB C18 column (Phenomenex, particle size 2.6 $\mu \mathrm{m}$, pore size $100 \AA$, dimensions $50 \times 2.1 \mathrm{~mm}$ ) at a flow rate of $1 \mathrm{~mL} / \mathrm{min}$ and a gradient of $2-50 \%$ of eluent $\mathrm{B}(0.08 \%$ TFA in acetonitrile $)$ in eluent $\mathrm{A}\left(0.1 \%\right.$ TFA in $\left.\mathrm{H}_{2} \mathrm{O}\right)$ within 4 min.

Preparative HPLC: Preparative reversed phase HPLC was performed on a Shimadzu instrument equipped with a CBM-20A communication module, a SPD-M20A UV detector, a SIL-10AP autosampler and a FRC$10 \mathrm{~A}$ fraction collector.

Wild type AD1-ACTR and its $\alpha$-methylated variants were injected onto a Jupiter C4 column (Phenomenex, particle size $10 \mu \mathrm{m}$, pore size $300 \AA$, dimensions $250 \times 21 \mathrm{~mm}$ ) at a flow rate of $10 \mathrm{~mL} / \mathrm{min}$ and a gradient of $10-46 \%$ of eluent $\mathrm{B}(0.08 \%$ TFA in acetonitrile $)$ in eluent $\mathrm{A}\left(0.1 \%\right.$ TFA in $\left.\mathrm{H}_{2} \mathrm{O}\right)$ within 70 min. After purification, pure fractions were identified by analytical HPLC and LC/MS, combined and lyophilized.

NCBD protein was purified two times on a Jupiter C4 column (Phenomenex, particle size $10 \mu \mathrm{m}$, pore size $300 \AA$, dimensions $250 \times 21 \mathrm{~mm}$ ) at a flow rate of $10 \mathrm{~mL} / \mathrm{min}$ and a gradient of $10-40 \%$ of eluent $\mathrm{B}$ $\left(0.08 \%\right.$ TFA in acetonitrile) in eluent $\mathrm{A}\left(0.1 \%\right.$ TFA in $\left.\mathrm{H}_{2} \mathrm{O}\right)$ within 85 min. After purification, pure fractions were identified by analytical HPLC and LC/MS, combined and lyophilized.

Peptides $(H)$-DERALLDQLHTLLSN- $\left(\mathrm{NH}_{2}\right)$ and $(\mathrm{H})$-DERALLDQLHTL-meLeu-SN- $\left(\mathrm{NH}_{2}\right)(\mathrm{meLeu}=$ $\alpha$-methyl-L-leucine) and shorter LXXLL motif containing peptides (see above) were purified on a C18 column (Phenomenex, particle size $10 \mu \mathrm{m}$, pore size $300 \AA$, dimensions $250 \times 21.00 \mathrm{~mm}$ ) at a flow rate of $10 \mathrm{~mL} / \mathrm{min}$ and a gradient of $5-30 \%$ of eluent $\mathrm{B}\left(0.08 \%\right.$ TFA in acetonitrile) in eluent $\mathrm{A}\left(0.1 \% \mathrm{TFA}\right.$ in $\left.\mathrm{H}_{2} \mathrm{O}\right)$ within $40 \mathrm{~min}$. After purification, pure fractions were identified by analytical HPLC and LC/MS, combined and lyophilized.

Mass-spectrometry: Peptide masses were determined using a LC/MS instrument containing a Thermo Scientific Accela UHPLC (Hypers II GOLD column, $50 \times 2.1 \mathrm{~mm}, 1.9 \mu \mathrm{m}$ ) integrated with a Thermo Scientific LCQ Fleet ion trap. Deconvolution of experimental data was performed using the Zscore algorithm with the help of MagTran 1.03 software.

Supplementary Tables 1 and 2 provide the list of sequences of the peptides studied in this work and the corresponding mass-spectrometry data. 


\section{Protein expression}

Maltose binding protein (MBP)-NCBD: MBP-NCBD construct was over-expressed in E. coli BL21(DE3) overnight at $16^{\circ} \mathrm{C}$. The construct was purified by amylose affinity chromatography in buffer A (50 mM Tris $\mathrm{pH} \mathrm{8,} 400 \mathrm{mM} \mathrm{NaCl}, 1 \mathrm{mM}$ DTT). In order to remove soluble oligomers, the purified sample was ultracentrifuged overnight at 40,000 RPM in a swing SW41 rotor (Beckman) at $4{ }^{\circ} \mathrm{C}$. Then the resulting MBP-NCBD sample was concentrated and loaded onto a Superdex 200 pg HiLoad 26/60 gel filtration column (GE Healthcare) equilibrated in buffer A.

CREB-binding protein (CBP): The full length hsCBP (1-2442 aa) cloned into pDEST10 plasmid with Nterminal His-tag and C-terminal Flag and Myc-tag was a kind gift of Dr. P. Tompa (Flanders Institute for Biotechnology, Belgium). The protein was expressed in Sf21 insect cells for $48 \mathrm{~h}$. To avoid the intracellular proteolytic degradation, 1 tablet of Roche cOmplete EDTA free protease inhibitor dissolved in ultrapure sterile water was added to the expression culture after $24 \mathrm{~h}$ of culture. The purification of the protein was performed as described in Bekesi et al. ${ }^{5}$ with small modifications. The cell pellet of $1 \mathrm{~L}$ expression culture was resuspended in $50 \mathrm{mM}$ Tris $\mathrm{pH} 7.5,300 \mathrm{mM} \mathrm{NaCl}, 2 \mathrm{mM} \mathrm{MgCl} 2,5 \%$ glycerol, $1 \mathrm{mM}$ DTT, $5 \mu \mathrm{g} / \mathrm{ml}$ DNase I, $5 \mu \mathrm{g} / \mathrm{ml}$ RNase A. The cell suspension was homogenized in Dounce homogenizer, sonicated (2 min, $40 \%$ amplitude, 0.5 cycle, in ice) and homogenized. The lysate was ultracentrifuged for $1 \mathrm{~h}$ at 125000 $\mathrm{g}$ and the supernatant was filtered with $0.45 \mu \mathrm{M}$ pore-size filter. The purification was performed in 3 steps: a Ni-affinity using Ni-cOmplete resin (Roche), a Flag affinity step in batch chromatography followed by a size-exclusion chromatography on Superose 6 Increase column (GE Healthcare Life Sciences) using Akta systems and $50 \mathrm{mM}$ Tris $\mathrm{pH}$ 7.5, $300 \mathrm{mM} \mathrm{NaCl}, 1 \mathrm{mM}$ TCEP buffer. All steps were carried out in presence of the protease inhibitors: Roche cOmplete EDTA free, pepstatin A, bestatin, Pefabloc and E64, $25 \mu \mathrm{M}$ Pefabloc and $2 \mu \mathrm{g} / \mathrm{ml} \mathrm{E64,} \mathrm{and} \mathrm{performed} \mathrm{at} 4{ }^{\circ} \mathrm{C}$. The SDS PAGE confirmed molecular weight of recombinant CBP:

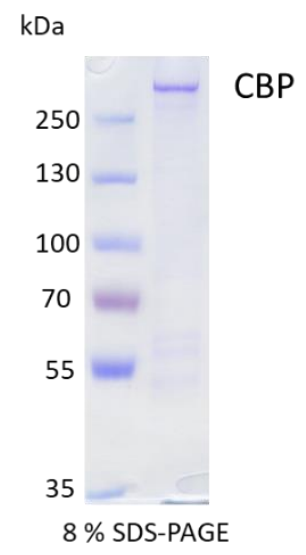




\section{Isothermal titration calorimetry (ITC)}

Most ITC measurements were performed according to the previously described procedure using an iTC 200 microcalorimeter (GE Healthcare) ${ }^{1}$. To analyze and visualize the data NITPIC, SEDPHAT/ITCsy, and GUSSI software were used ${ }^{6-8}$. For each AD1-ACTR variant two titrations and two control experiments (i.e., titration of buffer into buffer, and the NCBD into buffer) were performed. The data depicted in Supplementary Fig. 1 (panels 1-36) show only one representative titration with baseline subtracted. The observed positive signal on the right side of the titration curves is due to the slight buffer mismatch and heat of NCBD dilution that were corrected by subtraction of control titrations. For each AD1-ACTR variant the two recorded titration curves were fitted globally. The error estimation for $K_{D}$ and $\Delta H$ values were $\pm 20 \%$ and $\pm 5-8 \%$, respectively.

For weak binding AD1-ACTR variants such as $[1064 \mathrm{~mL} ; 1071 \mathrm{~mL}]$, as well as $(H)$ -

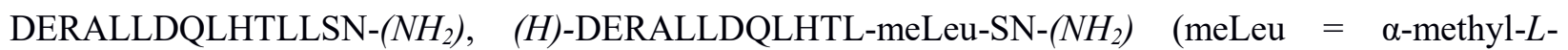
leucine), $(\mathrm{H})$-QLHTLLS-( $\left.\mathrm{NH}_{2}\right)$ and $(\mathrm{H})$-QLHT-meLeu-LS- $\left(\mathrm{NH}_{2}\right)$ peptides a PEAK ITC microcalorimeter (Malvern Instruments) was used. To avoid aggregation of NCBD protein at high concentrations, 25-60 $\mu \mathrm{M}$ of NCBD was in a sample cell (titrant) and the corresponding ACTR derived variants were in the syringe (titrators) at 250-600 $\mu \mathrm{M}$ concentrations. The solutions of AD1-ACTR variants were dialyzed for $48 \mathrm{~h}$ before measurements against a $10 \mathrm{mM}$ Tris, $50 \mathrm{mM} \mathrm{NaCl}, 0.05 \%(\mathrm{w} / \mathrm{v}) \mathrm{NaN}_{3}$ buffer at $\mathrm{pH} 6.9$ and room temperature. The titration parameters were set as following, temperature $31^{\circ} \mathrm{C}$, reference power $10 \mu \mathrm{cal} / \mathrm{s}$, feedback=high, stirring speed $750 \mathrm{RPM}$, initial delay $60 \mathrm{~s}$, first injection $0.4 \mu \mathrm{L}$ in $0.8 \mathrm{~s}$ and the remaining 19 injections were $2 \mu \mathrm{L}$ in $4 \mathrm{~s}$ with $120 \mathrm{~s}$ of spacing. The initial fitting was performed using the analysis software from Malvern with subtraction of three control experiments (i.e., titration of buffer into buffer, buffer into NCBD solution and the ACTR variants into buffer) and a correction of concentration taking into account precise concentration measurements by analytical HPLC using calibration curve at OD $220 \mathrm{~nm}$. For $[1064 \mathrm{~mL} ; 1071 \mathrm{~mL}] \mathrm{AD} 1-\mathrm{ACTR}$ analogue previously used fitting protocol was applied to report the thermodynamic parameters listed in Supplementary Table 3. The inversion of the analytes and method of fitting are not significantly affecting the thermodynamics parameters: the control titrations of the WT AD1ACTR and $[1055 \mathrm{~mL}] \mathrm{AD} 1-\mathrm{ACTR}$ variants were performed using these settings resulting in similar $\mathrm{K}_{\mathrm{D}}$ values of $0.208 \mu \mathrm{M}$ and $0.072 \mu \mathrm{M}$ compared to values of $0.204 \mu \mathrm{M}^{1}$ and $0.075 \mu \mathrm{M}$ (Supplementary Table 3), obtained by the first method.

\section{Circular dichroism (CD)}

CD spectra were recorded using a J-1500 (Jasco) spectrophotometer. All samples were prepared in a quartz cuvette (thickness of $1 \mathrm{~mm}$ and a volume of $300 \mu \mathrm{L}$ ). For every measurement protein or protein 
complexes were dissolved in a buffered solution (20 mM phosphate, $\mathrm{pH} 7.4)$ at a concentration of $25 \mu \mathrm{M}$. For data collection the following parameters were set: scan range $280-185 \mathrm{~nm}$, band width $1.00 \mathrm{~nm}$, scanning speed $100 \mathrm{~nm} / \mathrm{min}$, data pitch $0.1 \mathrm{~nm}$. Every CD curve was obtained by averaging of 5 scans and subtracting the background signal. The data are depicted in Supplementary Fig. 3.

The thermal stability of complexes of several AD1-ACTR variants with NCBD (concentration of complex $50 \mu \mathrm{M}$ ) was evaluated by monitoring the ellipticity at $222 \mathrm{~nm}$ as a function of temperature from 20 to $90{ }^{\circ} \mathrm{C}$. Rate of heating / cooling was $1{ }^{\circ} \mathrm{C} / \mathrm{min}$. The thermal denaturation was found to be highly reversible. The thermal denaturation curves are depicted in Supplementary Fig. 5 and the apparent melting temperatures are listed in Supplementary Table 4.

For free AD1-ACTR protein variants, the ratio of ellipticities $\left(\theta_{222} / \theta_{199}\right)$ was calculated in order to compare their helical contents $^{9}$ (Supplementary Fig. 4a). For their complexes with NCBD, the other ratio $\left(\theta_{222} / \theta_{208}\right)$ was derived (Supplementary Fig. $\left.4 b\right)$, which may serve as a readout of helix-helix interactions ${ }^{10}$. All obtained values are summarized in Supplementary Tables 5 and 6, respectively.

\section{NMR measurements}

All NMR spectra were recorded on a $700 \mathrm{MHz}$ Bruker spectrometer equipped with TCI cryo-probe at $304 \mathrm{~K}$ in $3 \mathrm{~mm}$ NMR tubes. The proton frequencies were referenced using DSS (2,2-dimethyl-2silapentane-5-sufonate) as external reference and carbon frequencies were referenced using the indirect $\operatorname{method}^{11}$.

Sample preparation: Proteins samples were obtained by dissolving the appropriate amount of each protein in $200 \mu \mathrm{L} 90 \% \mathrm{H}_{2} \mathrm{O}, 10 \% \mathrm{D}_{2} \mathrm{O}, 20 \mathrm{mM}$ sodium phosphate, $0.05 \% \mathrm{NaN}_{3}$ buffer at $\mathrm{pH}$ 7.2. The exact concentrations were measured by analytical HPLC using a calibration curve and adjusted to $1.4 \mathrm{mM}$. For NMR experiments in $\mathrm{D}_{2} \mathrm{O}, 200 \mu \mathrm{L}$ of the samples described above were lyophilized for at least $48 \mathrm{~h}$. The resulting powder was then re-dissolved in $200 \mu \mathrm{L}$ of pure $\mathrm{D}_{2} \mathrm{O}$ just before the experiment.

Spectra acquisition: The ${ }^{1} \mathrm{H}-{ }^{13} \mathrm{C}$ HSQC spectra were recorded using the gradient-selected coherence transfer pulse-sequence of the Bruker standard library. A resolution of 2 and $12 \mathrm{~Hz}$ in the ${ }^{1} \mathrm{H}$ and ${ }^{13} \mathrm{C}$ dimensions, respectively, were used with relaxation delays set to $1.2 \mathrm{~s}$ for a total experimental time of approximately $3.5 \mathrm{~h}$. $60 \mathrm{kHz}$ Chirp pulses of $500 \mu$ s and a $\mathrm{B}_{1}$-field of $8 \mathrm{kHz}$ were used for ${ }^{13} \mathrm{C}$ resonance inversion.

The measurements of the ${ }^{13} \mathrm{C} \mathrm{R}_{1}$ and $\mathrm{R}_{2}$ relaxation rates were performed using refocused ${ }^{1} \mathrm{H}-{ }^{13} \mathrm{C}$ HSQC type experiments incorporating ${ }^{13} \mathrm{C}$ relaxation time ${ }^{12}$. For the $\mathrm{R}_{1}$ relaxation experiment proton decoupling was applied with 180 degree pulses every $2.5 \mathrm{~ms}$. The following $\mathrm{T}_{1}$ delays were used: 10, 50, 100, 200, $300,400,600,800 \mathrm{~ms}$. Additional points $(50,500 \mathrm{~ms})$ were recorded for wild type and [1055meLeu]AD1- 
ACTR variant samples to estimate the experimental uncertainty on peak volumes. For the $\mathrm{R}_{2}$ relaxation, a CPMG pulse sequence was used during the carbon relaxation time with $300 \mu$ s half-echo delay and a $\mathrm{B}_{1}$ field of $10 \mathrm{kHz}$. The $\mathrm{T}_{2}$ delays were 35, 70, 140, 176, 211, 246, 317, $387 \mathrm{~ms}$. Additional points (105, 211 $\mathrm{ms}$ ) were recorded for wild-type and [1055mL]AD1-ACTR variant to estimate the experimental uncertainty on peak volumes. The relaxation delay was set to $2.5 \mathrm{~s}$ and total acquisition time was approximately 25 hours for each set of relaxation experiments.

The ${ }^{1} \mathrm{H}$ homonuclear TOCSY and NOESY experiments were recorded using 4096 and 600 points in the direct and indirect dimensions, respectively. The spectral width was set to $7.8 \mathrm{kHz}$ and the relaxation delay to $2 \mathrm{~s}$. The mixing times were $80 \mathrm{~ms}$ and $500 \mathrm{~ms}$ for the TOCSY and the NOESY, respectively. A $\mathrm{B}_{1^{-}}$ field of $9 \mathrm{kHz}$ was used for the TOCSY spin-lock. ${ }^{1} \mathrm{H}-{ }^{13} \mathrm{C}$ HSQC-TOCSY were recorded with a resolution of 4 and $24 \mathrm{~Hz}$ for the ${ }^{1} \mathrm{H}$ and ${ }^{13} \mathrm{C}$ dimensions, respectively, a relaxation time of $1.2 \mathrm{~s}$ and a TOCSY mixing time of $80 \mathrm{~ms}\left(\mathrm{~B}_{1}\right.$-field of $9 \mathrm{kHz}$ ) for a total experiment time of $14 \mathrm{~h}$. The ${ }^{1} \mathrm{H}-{ }^{13} \mathrm{C}$ HMBC experiment was recorded with carrier frequency centered on the carbonyl resonances (174 ppm) to correlate the carbonyl with the adjacent $\mathrm{H} \alpha$ proton frequencies using the gradient-selected coherence transfer pulse-sequence of the Bruker standard library. The delay for long-range magnetization transfer was set to $89.3 \mathrm{~ms}\left({ }^{2} J_{\mathrm{CO}-\mathrm{H} \alpha} 5.6\right.$ $\mathrm{Hz}$ ). The resolution were $4 \mathrm{~Hz}$ and $7 \mathrm{~Hz}$ for the proton and carbon dimensions, respectively. The relaxation time was set to $2 \mathrm{~s}$ for a total measurement time of $32 \mathrm{~h}$.

Manual assignment of ${ }^{1} \boldsymbol{H}-{ }^{13} \boldsymbol{C H S Q C}$ : Spin systems were manually identified using ${ }^{1} \mathrm{H}-{ }^{1} \mathrm{H}$ TOCSY (80 ms mixing time) and the sequential assignment was based on the inter-residue correlations identified in the ${ }^{1} \mathrm{H}-{ }^{1} \mathrm{H}$ NOESY (500 ms mixing time). $\mathrm{C} \alpha$ carbon assignments were obtained using high-resolution ${ }^{1} \mathrm{H}-{ }^{13} \mathrm{C}$ HSQC experiment. Ambiguities in the ${ }^{1} \mathrm{H}-{ }^{13} \mathrm{C}$ HSQC were solved using ${ }^{1} \mathrm{H}-{ }^{13} \mathrm{C}$ HSQC-TOCSY (80 ms mixing time) experiment. In two cases (N1058 and N1078) HMBC experiment was used to resolve the ambiguities of the assignment. When the WT AD1-ACTR protein was fully assigned, the chemical shifts being mostly the same, except for some residues, were used to assign the signals of [1055meLeu] and [1055meLeu;1076meLeu] AD1-ACTR analogues.

Data processing was performed using TopSpin software 2.1. All spectral analysis including frequency assignments and relaxation rate measurements were performed using ccpNmr (version 2.4.2) ${ }^{13}$. For relaxation measurements, time dependent evolutions of the peak intensities were fitted using a single exponential model and the estimate of the uncertainty of the fitted parameters was obtained using the covariance method implemented in ccpNmr.

Chemical shifts for wild-type AD1-ACTR, [1055meLeu]AD1-ACTR and [1055meLeu;1076meLeu]AD1-ACTR analogues are listed in Supplementary Tables 7-9. Relaxation rates $\mathrm{R}_{1}$ and $\mathrm{R}_{2}$ and experimental uncertainties are tabulated in Supplementary Tables 10 and 11. 
Secondary chemical shifts: POTENCI program ${ }^{14}$ was used to create a neighbor-corrected list of the random coil chemical shifts of the wild-type AD1-ACTR sequence including the effect of temperature, $\mathrm{pH}$ and ionic strength to be subtracted from the experimental chemical shifts.

\section{X-ray crystallography}

Crystallization, data collection and structure refinement: The NCBD-ACTR complexes were reconstituted by mixing MBP-NCBD construct and synthetic wild-type AD1-ACTR, [1055meLeu] or [1055meLeu;1076meLeu] in a 1:1 stoichiometric ratio in buffer B (10 mM Tris pH 8, $100 \mathrm{mM} \mathrm{NaCl}, 1 \mathrm{mM}$ DTT, $5 \mathrm{mM}$ Maltose) and concentrated to $85 \mathrm{mg} / \mathrm{mL}$ prior to crystallization. Crystallization conditions were screened using commercially available kits (Qiagen, Hampton Research, Emerald Biosystems) by the sitting-drop vapor-diffusion method in 96-well MRC 2-drop plates (SWISSCI), using a Mosquito robot (TTP Labtech). After 3 weeks a crystal grew for a complex of MBP-NCBD with [1055meLeu;1076meLeu] variant in a drop made from $200 \mathrm{~nL}$ of protein solution at $85 \mathrm{mg} / \mathrm{mL}$ and $100 \mathrm{~nL}$ of reservoir solution containing 20\% polyethylene glycol 6000, $100 \mathrm{mM}$ Tris $\mathrm{pH} 8$ and $10 \mathrm{mM} \mathrm{ZnCl}$. The crystals were flashcooled in a cryoprotectant solution containing 30\% Ethylene Glycol and stored in liquid nitrogen.

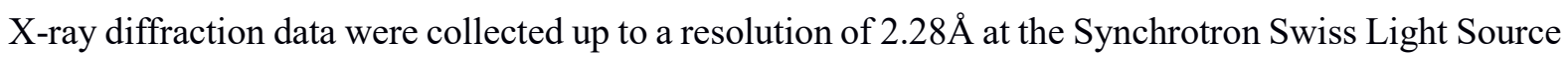
(SLS) (Switzerland) on the X06DA beamline and processed with the program $\mathrm{XDS}^{15}$. The crystal structure was solved by molecular replacement with a high resolution crystal structure of MBP (PDB entry 5H7Q ${ }^{16}$ ) using Phaser ${ }^{17}$ and structure refinement was carried out with PHENIX ${ }^{18}$. Building of the unnatural meLeu residues were achieved using $\mathrm{eLBOW}^{19}$. TLS refinement was applied during the refinement ${ }^{20}$. The crystallographic parameters and the statistics of data collection and refinement are shown in Supplementary Table 12. The refined model and the structure factor amplitudes have been deposited in the PDB under PDB entry: 6SQC.

\section{Molecular dynamics (MD) simulations}

Molecular dynamics simulations were carried out with the GROMOS biomolecular simulation package $^{21,22}$ and the GROMOS force-field parameter set $54 \mathrm{~A} 7^{23,24}$. The initial coordinates for AD1ACTR/NCBD, [1055meLeu]AD1-ACTR/NCBD and [1055meLeu;1076meLeu]AD1-ACTR/NCBD complexes were derived from the solution NMR structure of the ACTR-NCBD complex (PDB ID 1KBH, model 1) and sequence has been matched to the experimentally studied sequence from this work. In the NCBD sequence methionine 2098 was replaced by norleucine. Each complex was solvated in approximately 8400 simple point charge $(\mathrm{SPC})^{25}$ water molecules. Rectangular periodic boundary conditions were used and $26 \mathrm{Na}^{+}$and $24 \mathrm{Cl}^{-}$ions were added to each simulation box to neutralize the negative charge and to mimic the ionic strength of $0.15 \mathrm{M}$. The dimensions of the box were determined by 
a minimum solute-wall distance of $1.2 \mathrm{~nm}$ and a minimum solute-solvent atom-atom distance of $0.23 \mathrm{~nm}$. In order to relax unfavorable contacts between atoms of the solute and the solvent, the systems were relaxed by performing a steepest-descent energy minimization with harmonic positional restraints on all solute atoms (force constant $2.5 \times 10^{4} \mathrm{~kJ} \mathrm{~mol}^{-1} \mathrm{~nm}^{-2}$ ), followed by an equilibration period of $1 \mathrm{~ns}$ in which the strength of the positional restraints was gradually released from $2.5 \times 10^{4}$ to $0.0 \mathrm{~kJ} \mathrm{~mol}^{-1} \mathrm{~nm}^{-2}$, and the temperature was raised from 60 to $300 \mathrm{~K}$. Initial velocities for the MD simulations were taken from a Maxwell-Boltzmann distribution. Solvent and solute were weakly coupled to separate temperature baths ${ }^{26}$ with a relaxation time of $0.1 \mathrm{ps}$. After equilibration, the systems were also coupled to a pressure bath ${ }^{26}$ with a relaxation time of $0.5 \mathrm{ps}$ and an isothermal compressibility of $0.4575 \times 10^{-3}\left(\mathrm{kJmol}^{-1} \mathrm{~nm}^{-3}\right)^{-1}$. Bond lengths of the solute and the geometry of the solvent molecules were constrained using the SHAKE algorithm ${ }^{27}$ with a relative geometric tolerance of $10^{-4}$, so the leapfrog integration time step could be set to 2 fs. The non-bonded van der Waals and electrostatic interactions were calculated using a triple-range cutoff scheme. Nonbonded interactions were truncated at a distance of $1.4 \mathrm{~nm}$ and recalculated every time step in the range 0.0-0.8 $\mathrm{nm}$ and every five time steps in the range $0.8-1.4 \mathrm{~nm}$. The long-range electrostatic interactions beyond the outer cutoff of $1.4 \mathrm{~nm}$ were represented by a reaction field ${ }^{28}$ with a relative dielectric permittivity of 61 for water ${ }^{29}$. The motion of the center of mass was removed every 2 ps. The simulations were carried out for $200 \mathrm{~ns}$ at a constant pressure of $1 \mathrm{~atm}$ and a constant temperature of $300 \mathrm{~K}$.

The coordinate trajectories were saved at 1 ps intervals and were analyzed using the GROMOS++ set of programs $\mathrm{s}^{30}$. The first $50 \mathrm{~ns}$ of every simulation were considered as equilibration time and were omitted from the analysis. Atom-positional root-mean-square deviation (RMSD) and atom-positional root-meansquare fluctuations (RMSF) were calculated for the backbone atoms N, C, O and C $\alpha$ using the energyminimized initial structure as a reference. Conformational clustering analysis was performed with the approach of Daura et al. ${ }^{31}$ using as a criterion a backbone atom-positional RMSD of less than $0.2 \mathrm{~nm}$.

\section{Biomolecular interaction analysis by Surface Plasmon Resonance (SPR)}

The SPR measurements were performed on a Biacore T200 instrument (GE Healthcare - Biacore). Kinetics of NCBD binding to WT AD1-ACTR as well as to [1055meLeu;1076meLeu]AD1-ACTR, [1076meLeu]AD1-ACTR and [1055meLeu]AD1-ACTR variants were measured at five different temperatures $\left(20,22,25,27\right.$ and $\left.31^{\circ} \mathrm{C}\right)$. The buffer consisted of $10 \mathrm{mM}$ HEPES, $500 \mathrm{mM} \mathrm{NaCl}$ and $0.005 \%$ (v/v) 10\% P20 surfactant (GE Healthcare) at pH 7.5. The capture of biotinylated peptides on the chip was performed with the Biotin CAPture kit, Series S (GE Healthcare-Biacore). The oligo-streptavidin diluted 5 times in the running buffer was injected on all 4 channels at flow rate $2 \mu \mathrm{L} / \mathrm{min}$ for $300 \mathrm{sec}$. The first channel was always kept as a reference for subtraction of non-specific binding of NCBD to the chip surface. On the remaining 3 channels biotinylated AD1-ACTR variants at a concentration of $100 \mathrm{nM}$ were injected at a 
flow rate of $20 \mu \mathrm{L} / \mathrm{min}$ for $10 \mathrm{sec}$ yielding around 25 to $35 \mathrm{RU}$. For regeneration between each sensogram recording a solution of $6 \mathrm{M}$ guanidine- $\mathrm{HCl}, 250 \mathrm{mM} \mathrm{NaOH}$ was injected into all channels at $5 \mu \mathrm{L} / \mathrm{min}$ for $60 \mathrm{sec}$. The parameters for the binding measurement were set as follows: temperature varied from 20 to 31 ${ }^{\circ} \mathrm{C}$, initial delay $60 \mathrm{sec}$, injection of NCBD $120 \mathrm{sec}$ at $50 \mu \mathrm{L} / \mathrm{min}$, dissociation $120 \mathrm{sec}$. NCBD solutions were prepared with a two-fold cascade dilution with a range of concentrations from $1 \mu \mathrm{M}$ to $1.95 \mathrm{nM}$ (10 dilutions).

Data analysis was performed using BiaEvaluation 3.2 software (GE Healthcare). After subtraction of the background signal from the reference channel, the curves were fitted assuming a simple 1:1 binding isotherm model. More advanced "two state" kinetic model involving a conformational change did not improve the fitting. The apparent dissociation constants $\left(\mathrm{K}_{\mathrm{D}}\right)$, as well as association and dissociation kinetics ( $k_{\mathrm{on}}$ and $k_{\mathrm{off}}$ ) obtained upon fitting the data are provided in Supplementary Table 15 . These values are listed in order to make a qualitative comparison (rather than quantitative) of binding properties by four different AD1-ACTR variants, given the complexity of coupled binding and folding and difficulties to obtain the exact fitting of the experimental curves.

Steady-state analysis was made to obtain dissociation constants and the corresponding experimental uncertainties (Supplementary Fig. 19) ${ }^{32}$. The steady-state binding $\left(R_{\mathrm{eq}}\right)$ was derived by averaging the signals at equilibrium. Subsequently, steady-state analysis using in-house Python scripts was performed by fitting the average signal $R_{\text {eq }}$ as a function of analyte concentration, assuming a simple 1:1 interaction binding isotherm model, leading to 3 fitted parameters: the minimal signal $\left(R_{\min }\right)$, the maximum capacity of the surface $\left(R_{\max }\right)$ and the affinity $\left(\mathrm{K}_{\mathrm{D}}\right)$. A Monte Carlo approach was further used in order to estimate the values and uncertainties of the $R_{\max }$ and $\mathrm{K}_{\mathrm{D}}$ fitted parameters (Supplementary Table 16). This method consists of reproducing the fit using 1000 datasets in which noise fluctuations were introduced based on experimental uncertainty, and then the mean and the standard deviation of the fitted parameters were calculated.

The SPR measurements with full length $270 \mathrm{kDa}$ CBP were also performed using Biotin CAPture kit, Series S (GE Healthcare-Biacore) on a Biacore T200 instrument (GE Healthcare - Biacore). The running buffer was $50 \mathrm{mM}$ Tris, pH 7.5, $300 \mathrm{mM} \mathrm{NaCl}, 1 \mathrm{mM}$ TCEP, 0.01\% P20 supplemented with Roche Complete EDTA free protease inhibitor and the running temperature was set to $10{ }^{\circ} \mathrm{C}$. First, the Biotin capture reagent was immobilized on the chip surface followed by the immobilization of the biotinylated ACTR variants (WT, [1055mL;1076mL]AD1-ACTR and [1064mL;1071mL]AD1-ACTR) as ligands. Interactions of the hCBP full length protein with the WT and AD1-ACTR analogues were analyzed in the manner of dose response using twofold dilution series of hCBP ranging from 200 to $0.75 \mathrm{nM}$. The association and dissociation phase were $100 \mathrm{~s}$ and the analyte flow rate $40 \mu \mathrm{l} / \mathrm{min}$. For regeneration, a solution of $6 \mathrm{M}$ guanidine- $\mathrm{HCl}, 250 \mathrm{mM} \mathrm{NaOH}$ was injected into all channels at $5 \mu \mathrm{L} / \mathrm{min}$ for $60 \mathrm{sec}$. After 
subtracting the reference and buffer signal, the data were fit to a steady state binding model to define the apparent $\mathrm{K}_{\mathrm{D}}$.

Equilibrium signals were extracted from experimental SPR data for both systems and subsequently fitted with a 1:1 binding model. Since the data recorded for WT ACTR / hCBP interaction are so far from saturation, the fitting has been done in two steps: a first one by fitting the equilibrium data for the ACTR doubly methylated variant, leading, among others, to the maximum capacity $R_{\max }$ value; then a second step in which the previous $R_{\max }$ value has been used as forced parameter into the fit of the wild-type AD1-ACTR data, assuming that the saturation level is the same for both the wild type and the doubly methylated analogue (Supplementary Fig. 20).

\section{Fluorescence polarization (FP) measurements}

The fluorescein labeled AD1-ACTR (WT and [1055meLeu;1076meLeu] variant) was diluted at $5 \mathrm{nM}$ in the assay buffer ( $25 \mathrm{mM}$ Hepes $\mathrm{pH} 7.5,150 \mathrm{mM} \mathrm{NaCl}, 1 \mathrm{mM}$ TCEP, 0.05\% Tween-20) and mixed with increasing concentration of hCBP $(0.03-470 \mathrm{nM})$. The triplicates of the mixtures were transferred into 384 well black microplate (PS, F-bottom; Greiner Bio-one) and let incubate for $10 \mathrm{~min}$ at $25^{\circ} \mathrm{C}$ in the dark. The FP was recorded by PHERAstar Plus (BMG LABTECH) at $25^{\circ} \mathrm{C}$, using excitation and emission filters of 485 and $520 \mathrm{~nm}$, respectively. Graphpad Prism 8 software was used to calculate the dissociation constant $\left(\mathrm{K}_{\mathrm{D}}\right)$ by fitting a curve with the one site binding model (Supplementary Fig. 21). 


\section{Supplementary Figures}

Supplementary Fig. 1: Isothermal titration calorimetry of binding of AD1-ACTR variants to NCBD (consists of 36 panels on p. 13-21).

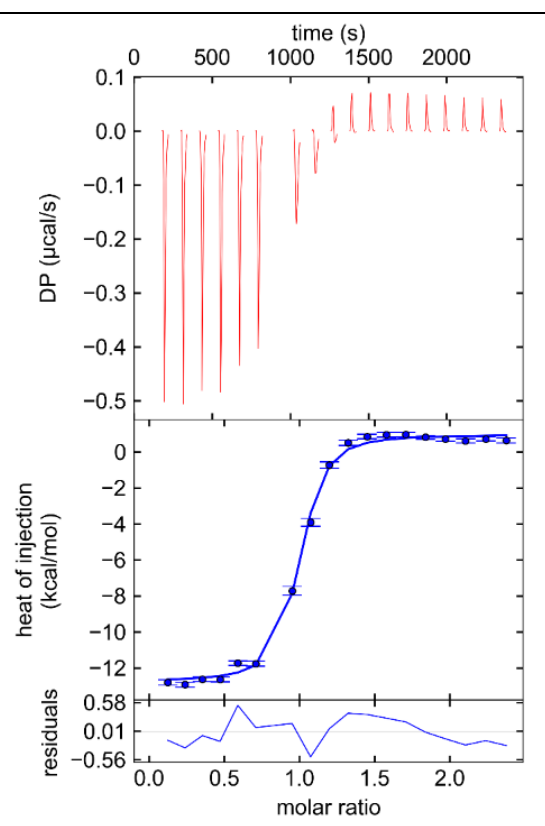

Panel 1: Binding of [S1043M;D1050E;T1054Q] AD1ACTR to NCBD

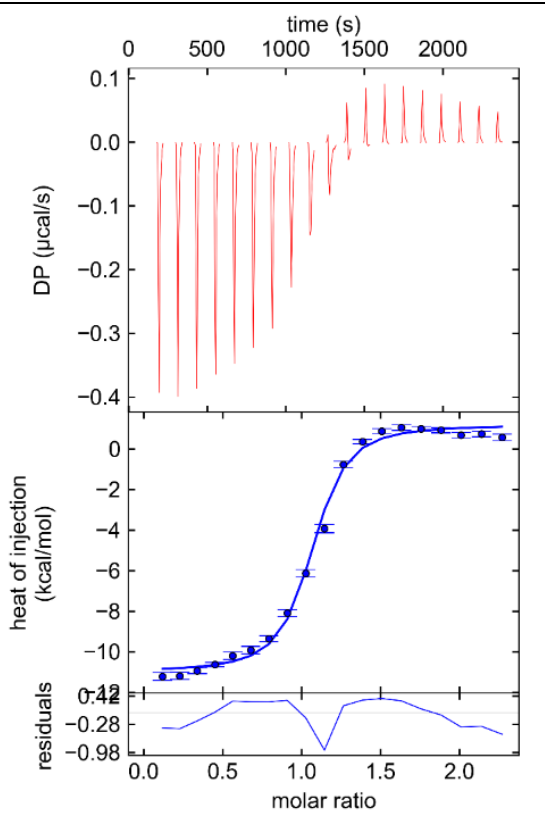

Panel 3: Binding of [1048mL] AD1-ACTR to NCBD

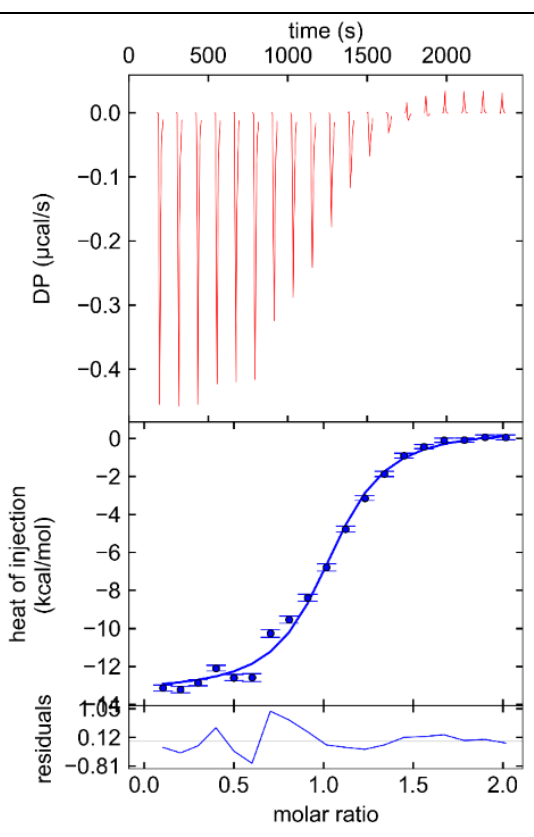

Panel 2: Binding of [A1047G] AD1-ACTR to NCBD

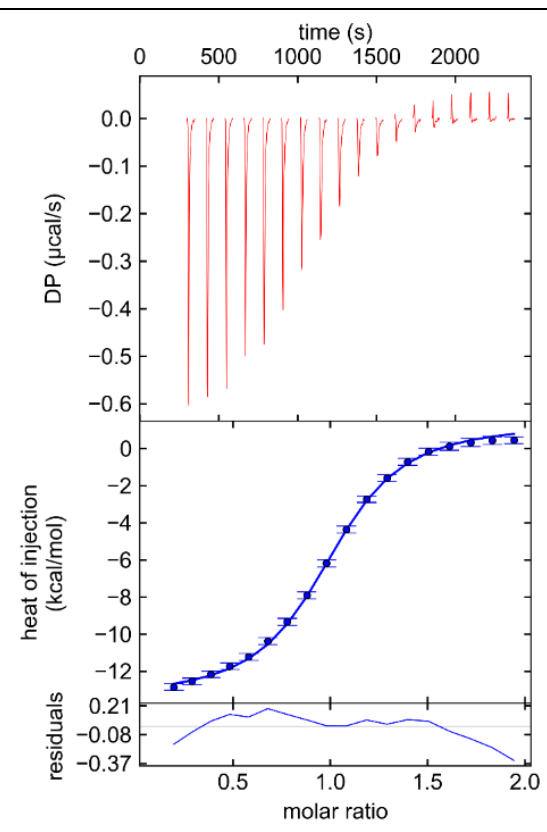

Panel 4: Binding of [1049mL] AD1-ACTR to NCBD 
Supplementary Fig. 1: Isothermal titration calorimetry of binding of AD1-ACTR variants to NCBD (continued from p. 13).

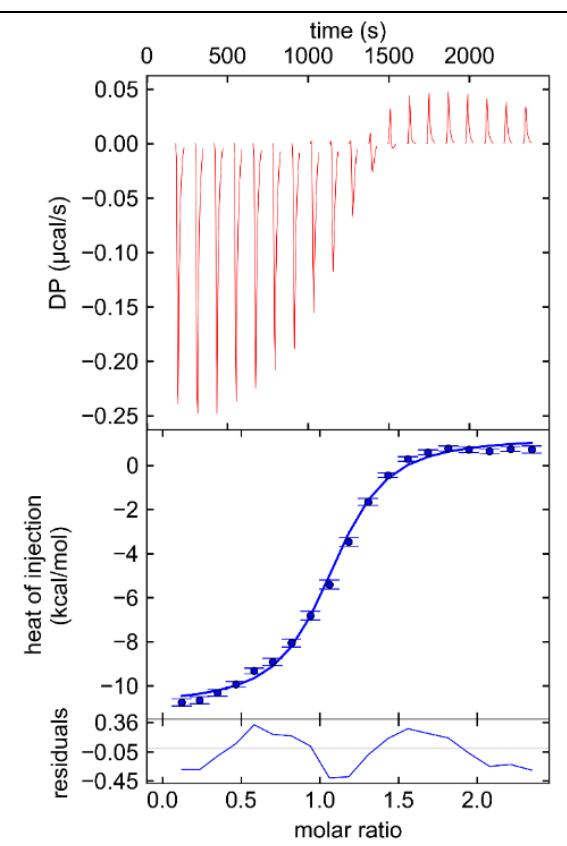

Panel 5: Binding of [1052mL] AD1-ACTR to NCBD

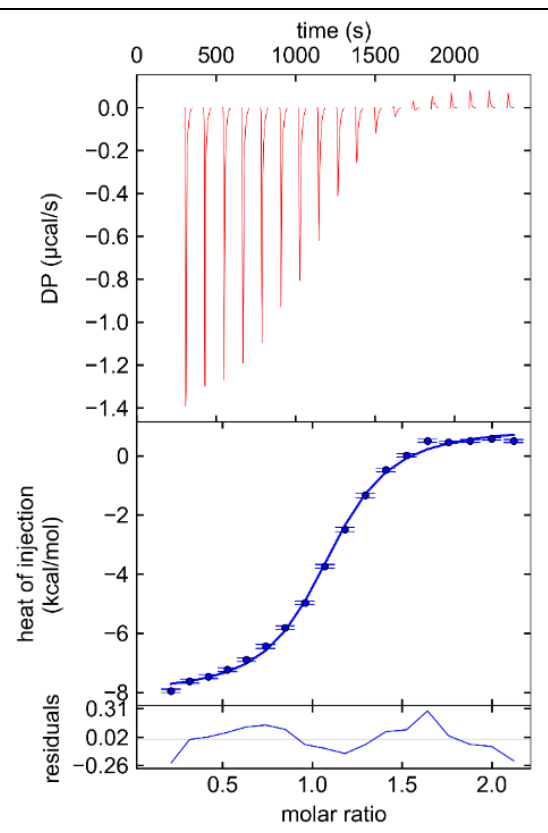

Panel 7: Binding of [1056mL] AD1-ACTR to NCBD

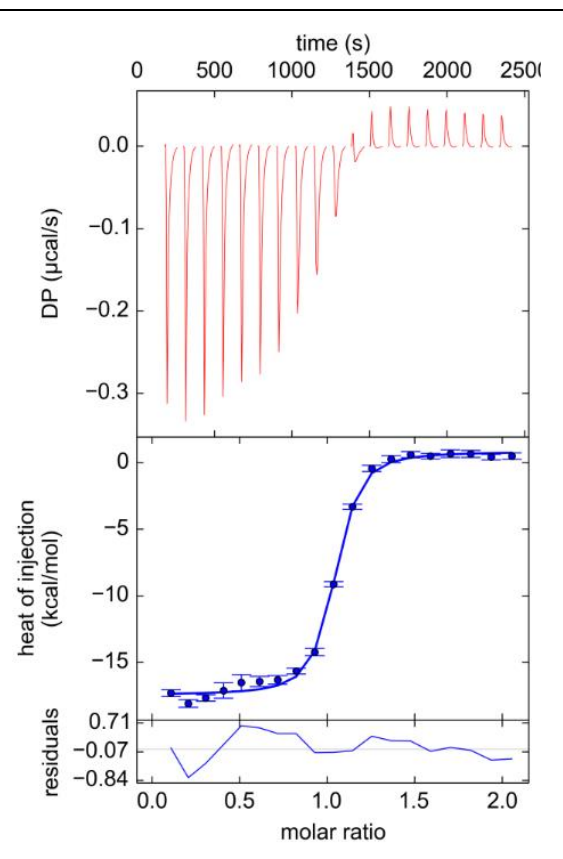

Panel 6: Binding of [1055mL] AD1-ACTR to NCBD

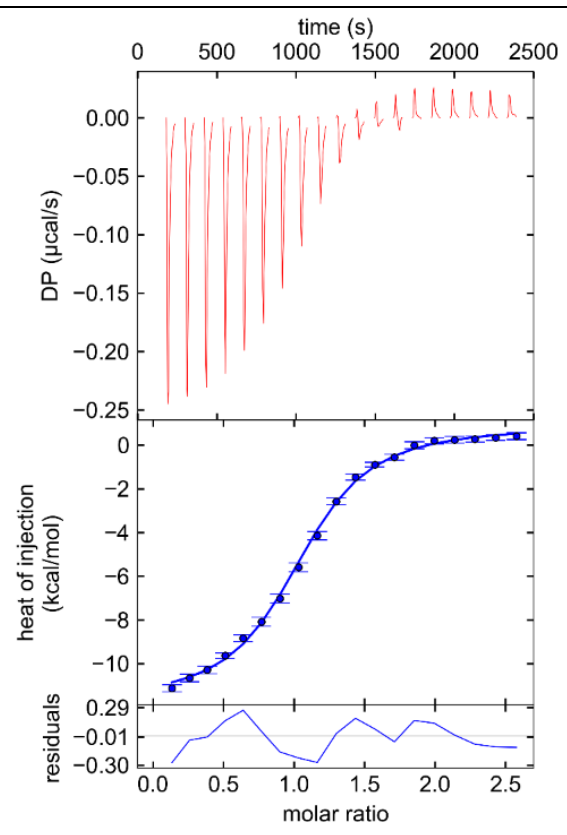

Panel 8: Binding of [1064mL] AD1-ACTR to NCBD 
Supplementary Fig. 1: Isothermal titration calorimetry of binding of AD1-ACTR variants to NCBD (continued from p. 14).

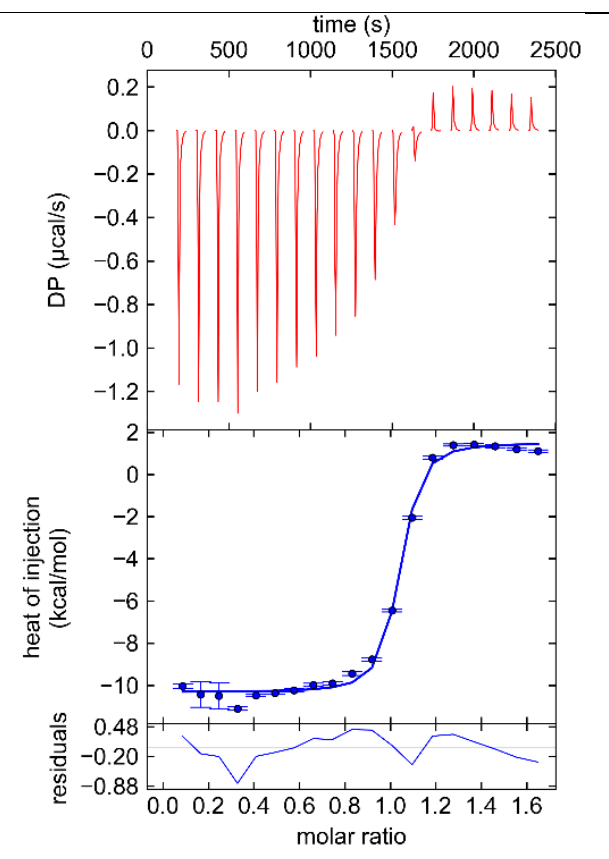

Panel 9: Binding of [1072mA] AD1-ACTR to NCBD

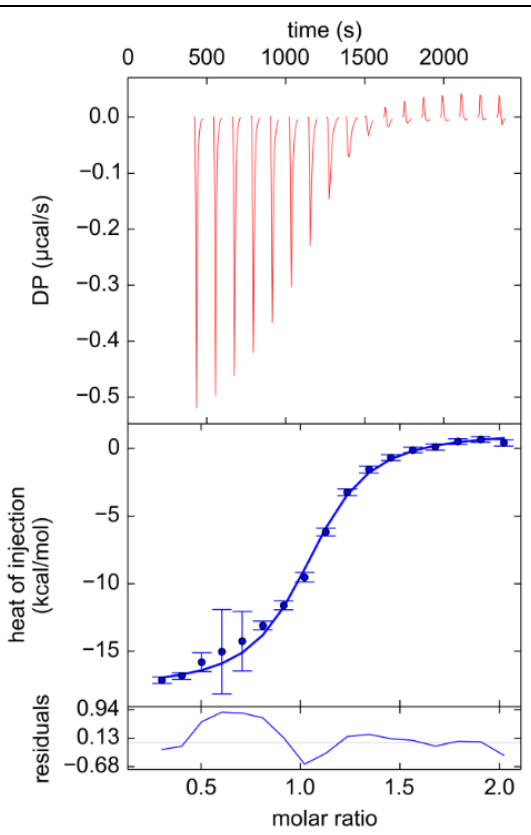

Panel 11: Binding of [1080mA] AD1-ACTR to NCBD

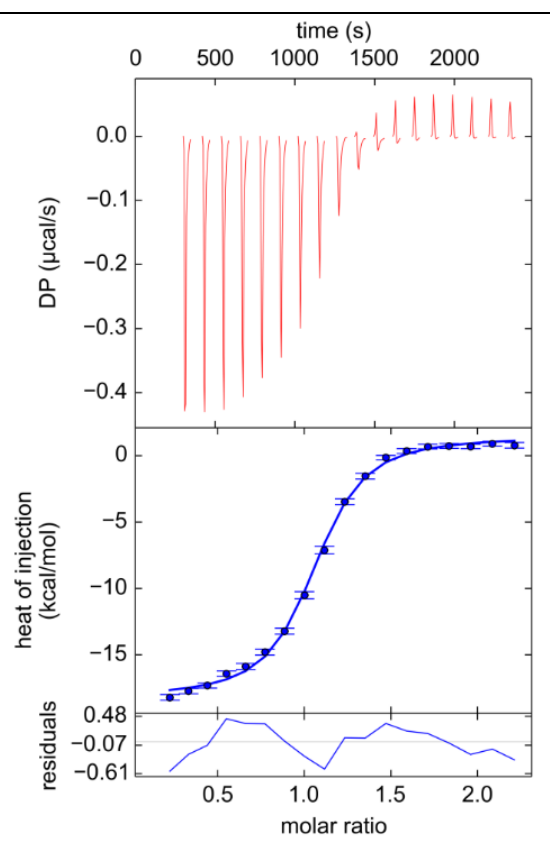

Panel 10: Binding of [1077mL] AD1-ACTR to NCBD

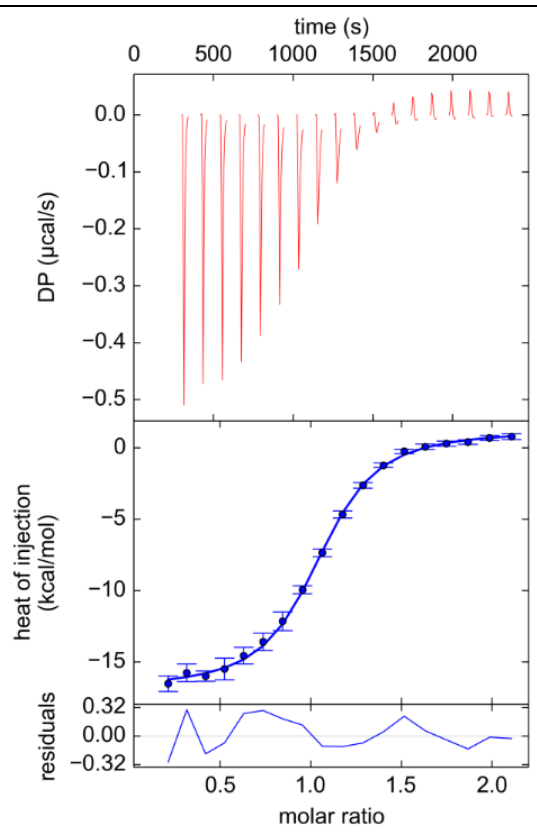

Panel 12: Binding of [1082mA] AD1-ACTR to NCBD 
Supplementary Fig. 1: Isothermal titration calorimetry of binding of AD1-ACTR variants to NCBD (continued from p. 15).

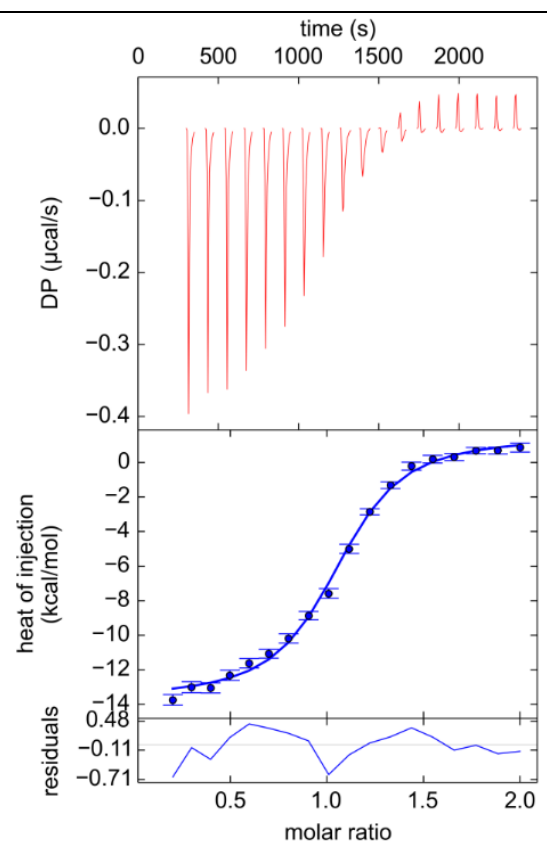

Panel 13: Binding of [1047mA;1072mA] AD1-ACTR to NCBD

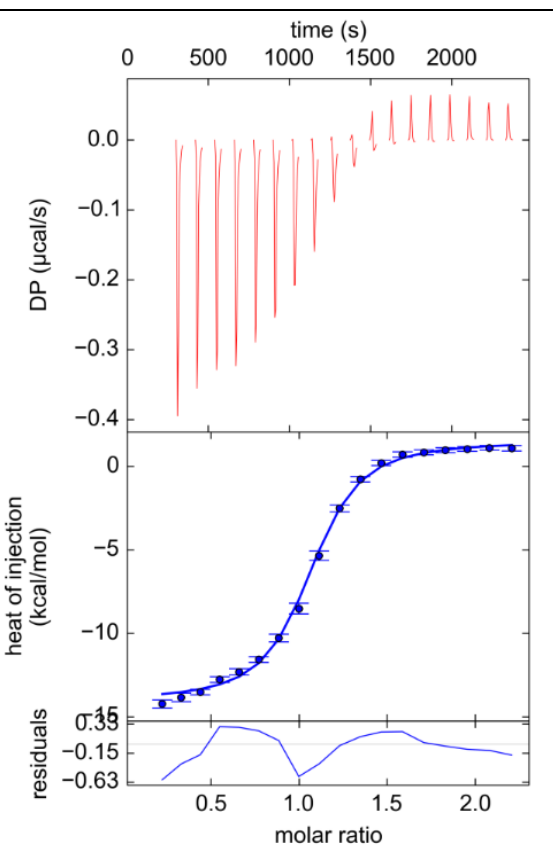

Panel 15: Binding of [1048mL;1076mL] AD1-ACTR to NCBD

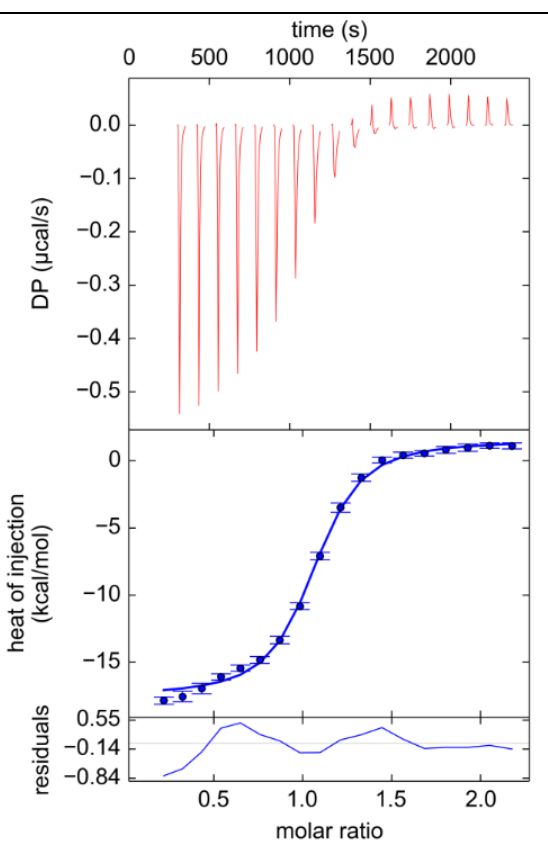

Panel 14: Binding of [1047mA;1077mV] AD1-ACTR to NCBD

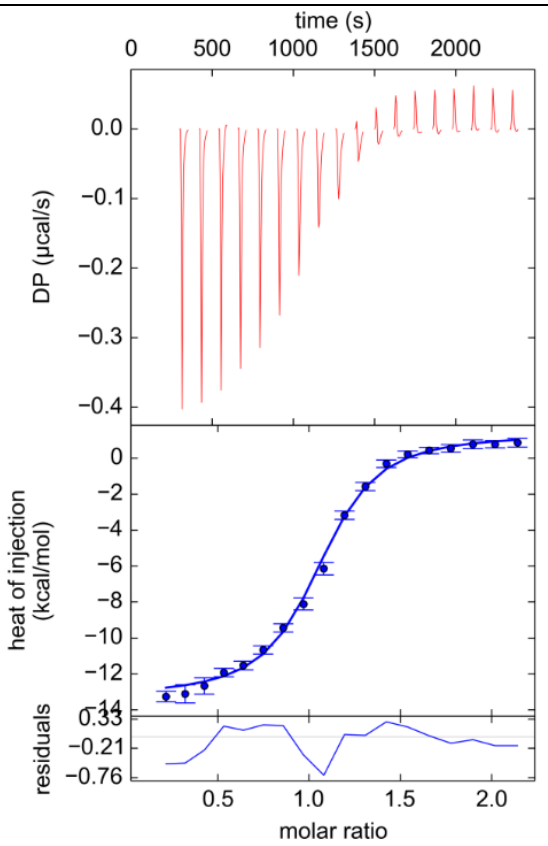

Panel 16: Binding of [1048mL;1077mV] AD1-ACTR to NCBD 
Supplementary Fig. 1: Isothermal titration calorimetry of binding of AD1-ACTR variants to NCBD (continued from p. 16).

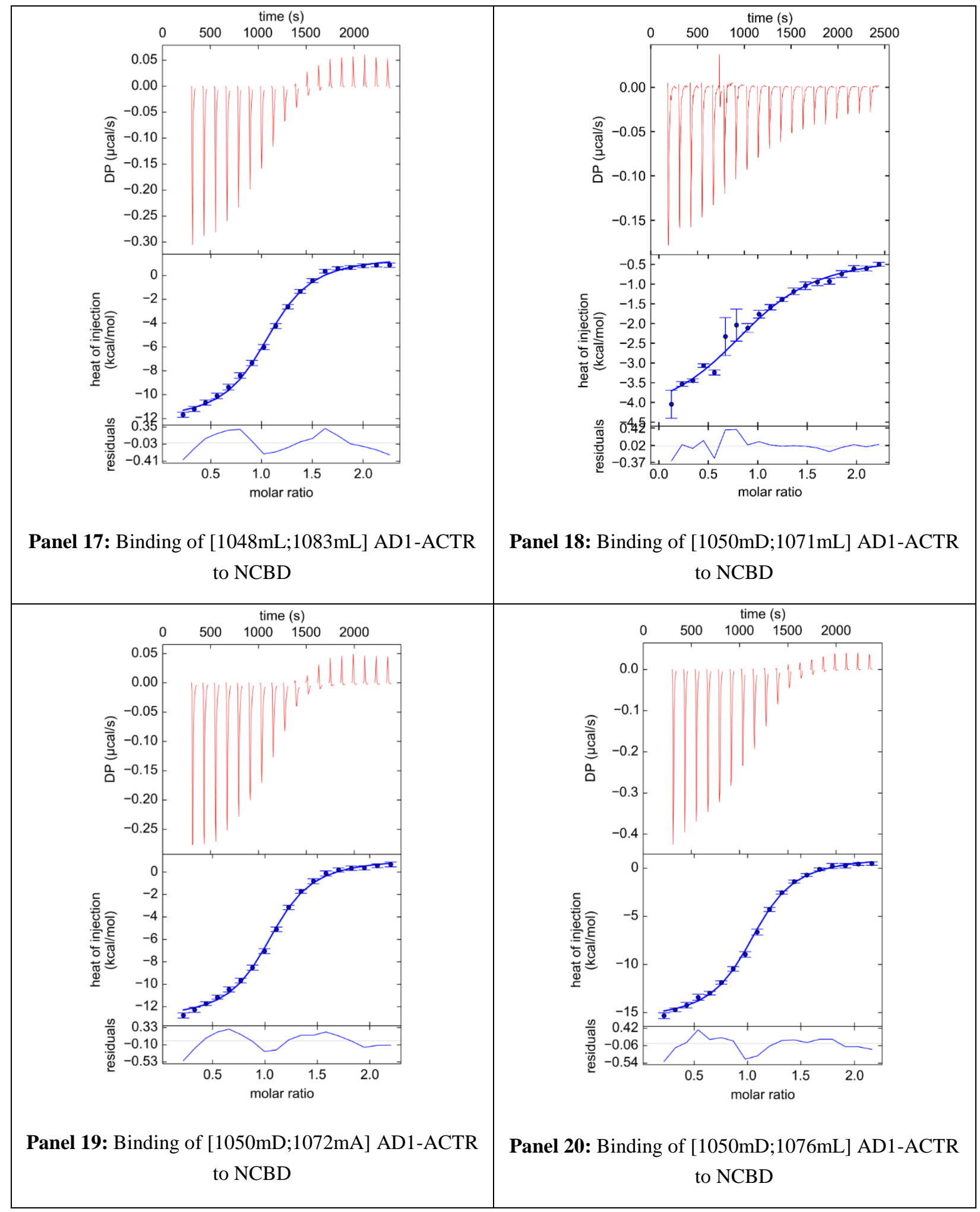


Supplementary Fig. 1: Isothermal titration calorimetry of binding of AD1-ACTR variants to NCBD (continued from p. 17).

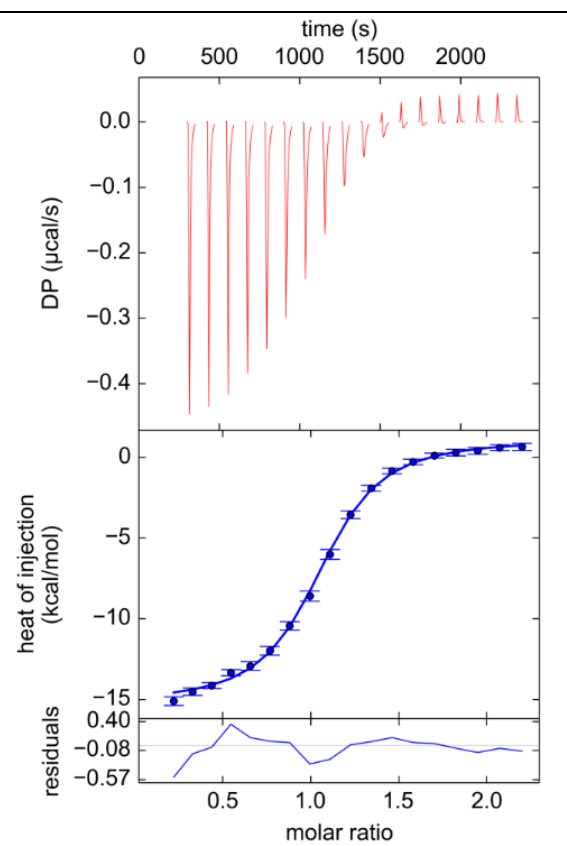

Panel 21: Binding of [1050mD; $1077 \mathrm{mV}]$ AD1-ACTR to NCBD

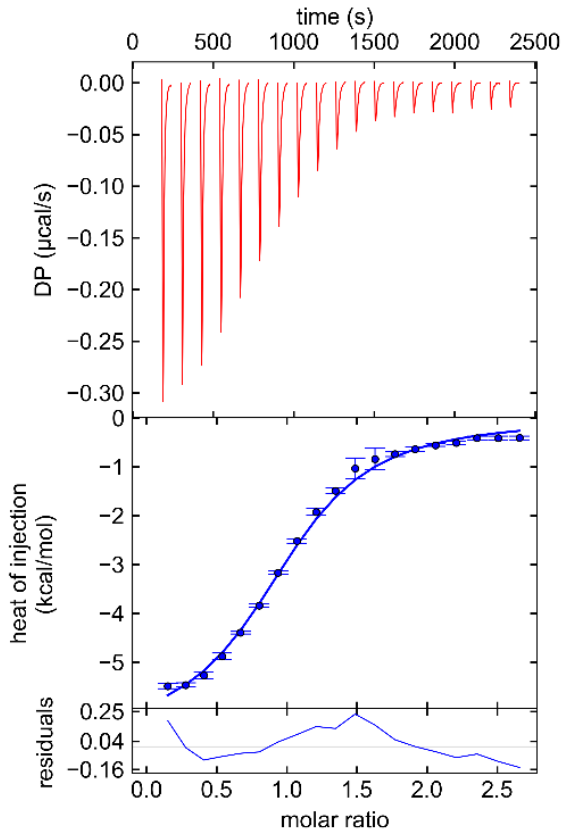

Panel 23: Binding of [1061mA;1071mL] AD1-ACTR to NCBD

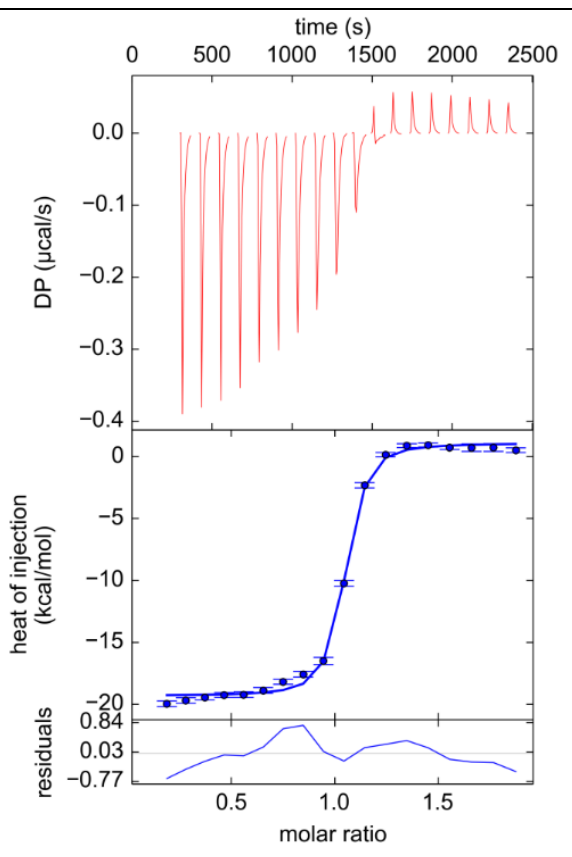

Panel 22: Binding of [1055mA;1076mL] AD1-ACTR to NCBD

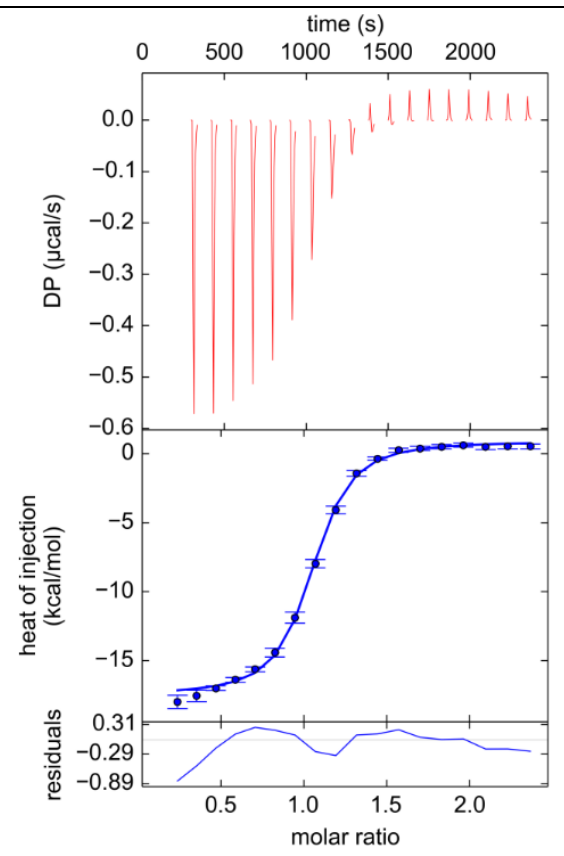

Panel 24: Binding of [1061mA;1077mV] AD1-ACTR to NCBD 
Supplementary Fig. 1: Isothermal titration calorimetry of binding of AD1-ACTR variants to NCBD (continued from p. 18).

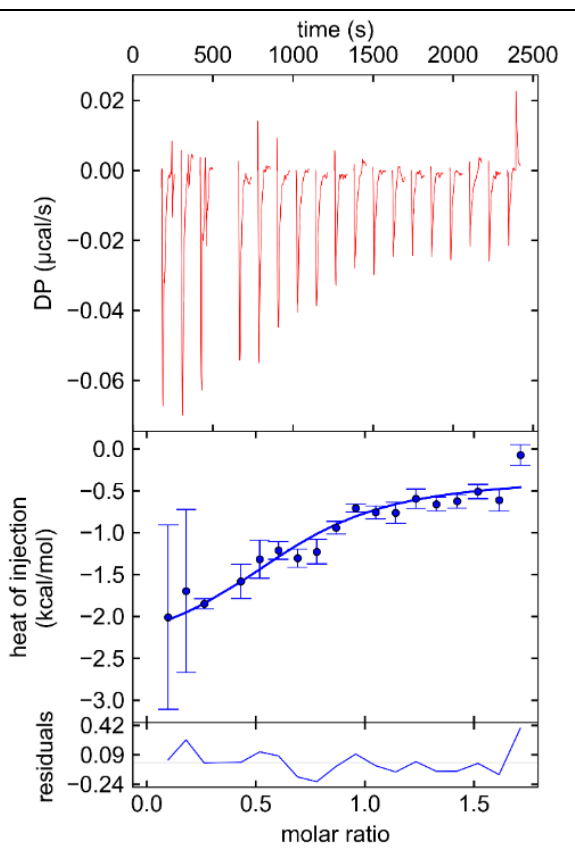

Panel 25: Binding of [1064mL;1071mL] AD1-ACTR to NCBD

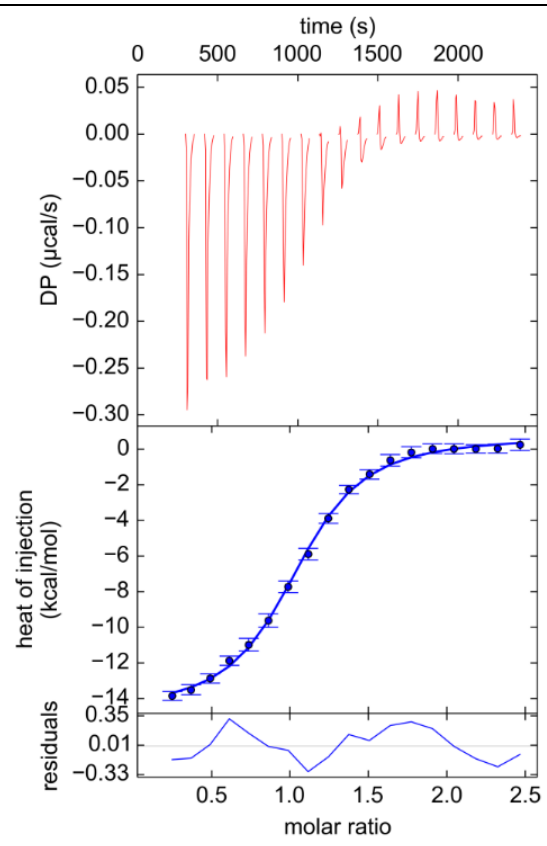

Panel 27: Binding of [1064mL;1077mV] AD1-ACTR to NCBD

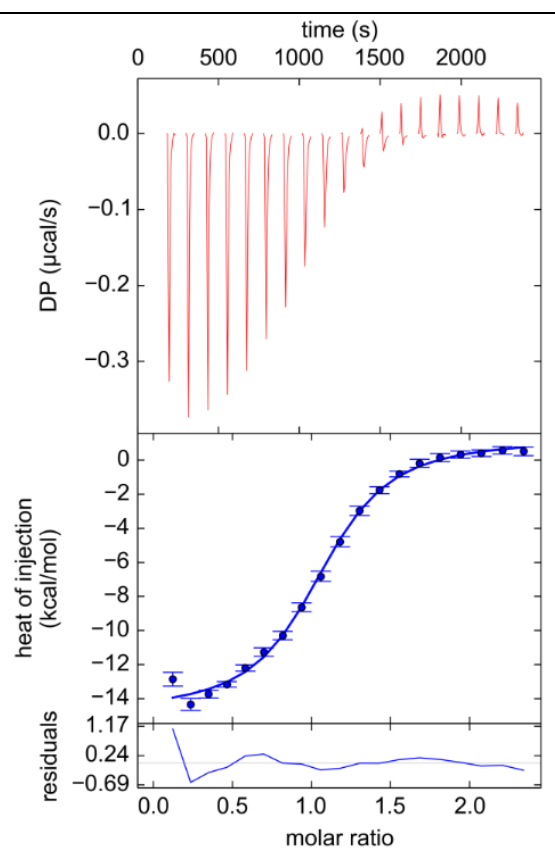

Panel 26: Binding of [1064mL;1076mL] AD1-ACTR to NCBD

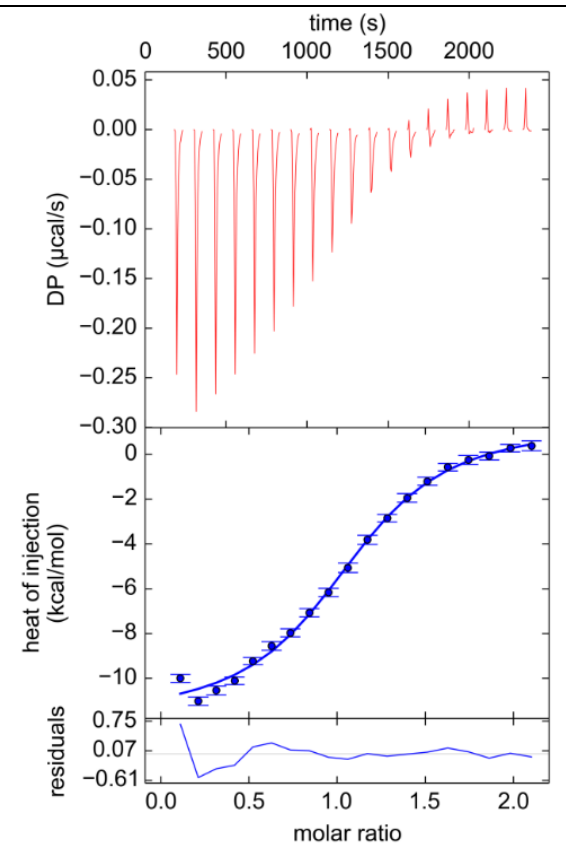

Panel 28: Binding of [1064mL;1083mL] AD1-ACTR to $\mathrm{NCBD}$ 
Supplementary Fig. 1: Isothermal titration calorimetry of binding of AD1-ACTR variants to NCBD (continued from p. 19).

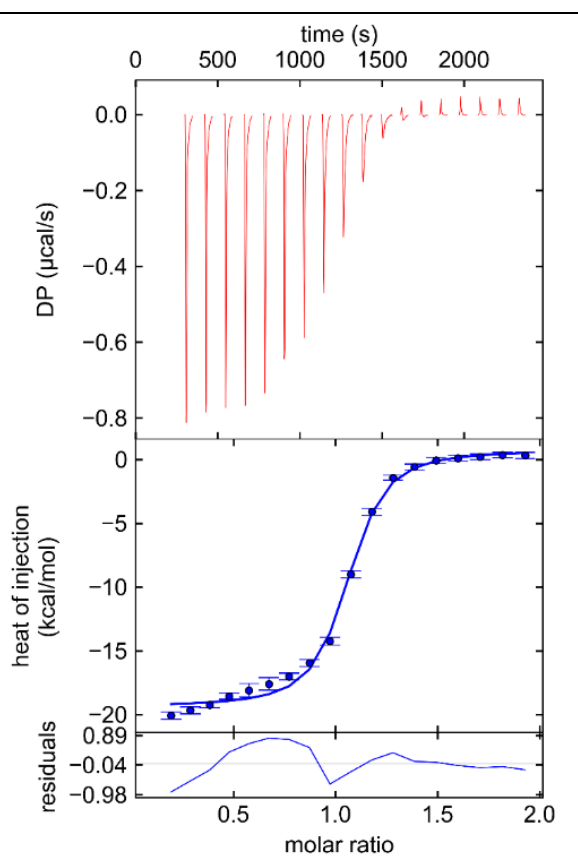

Panel 29: Binding of [1047mA;1055mL;1061mA] AD1-ACTR to NCBD

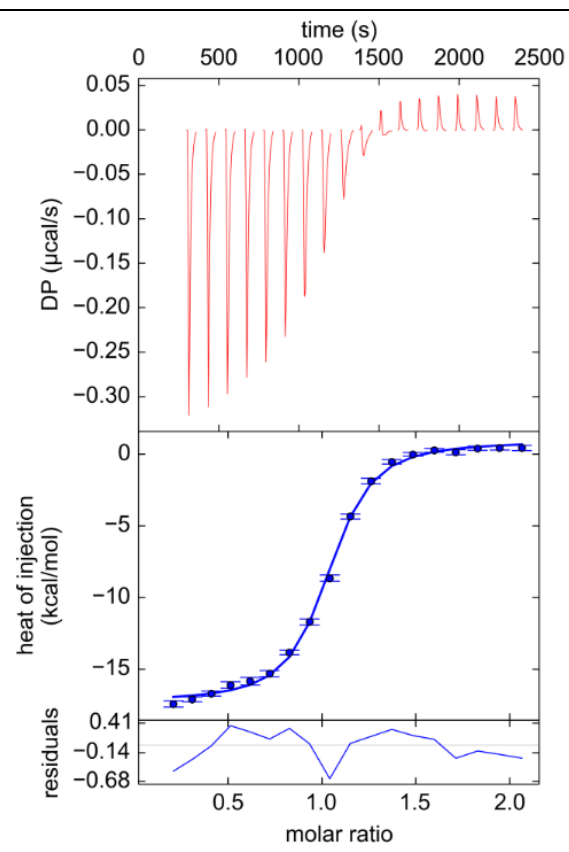

Panel 31: Binding of

[1047mA;1050mD;1061mA;1076mL] AD1-ACTR to NCBD

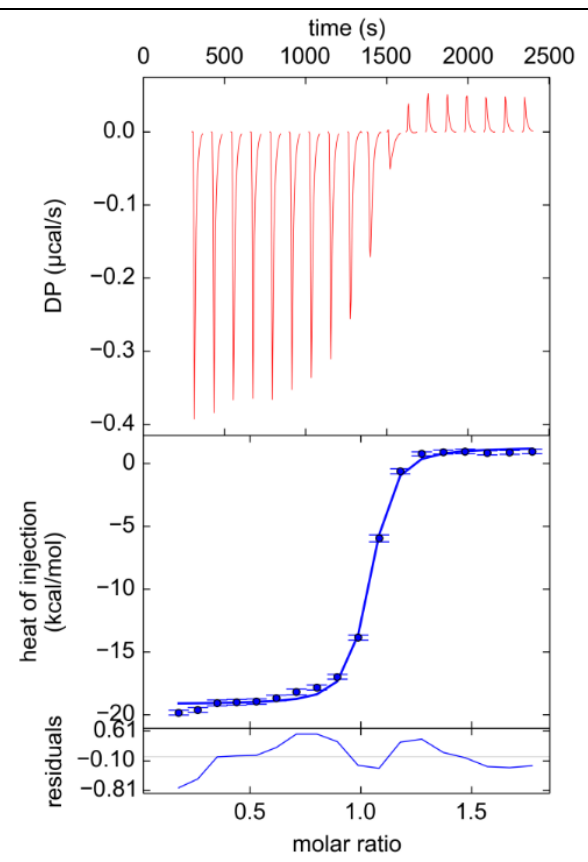

Panel 30: Binding of [1055mL;1076mL;1083mL] AD1-ACTR to NCBD

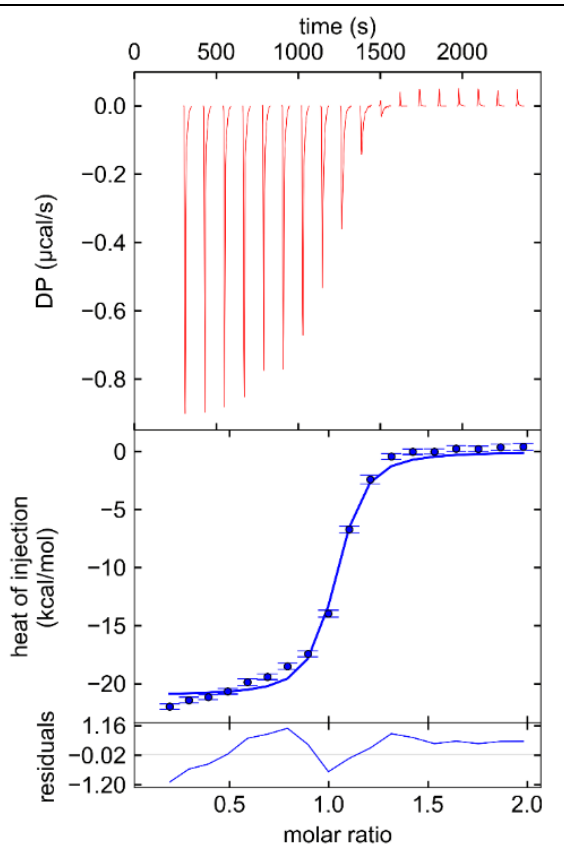

Panel 32: Binding of

[1047mA;1055mL;1061mA;1076mL] AD1-ACTR to NCBD 
Supplementary Fig. 1: Isothermal titration calorimetry of binding of AD1-ACTR variants to NCBD (continued from p. 20).

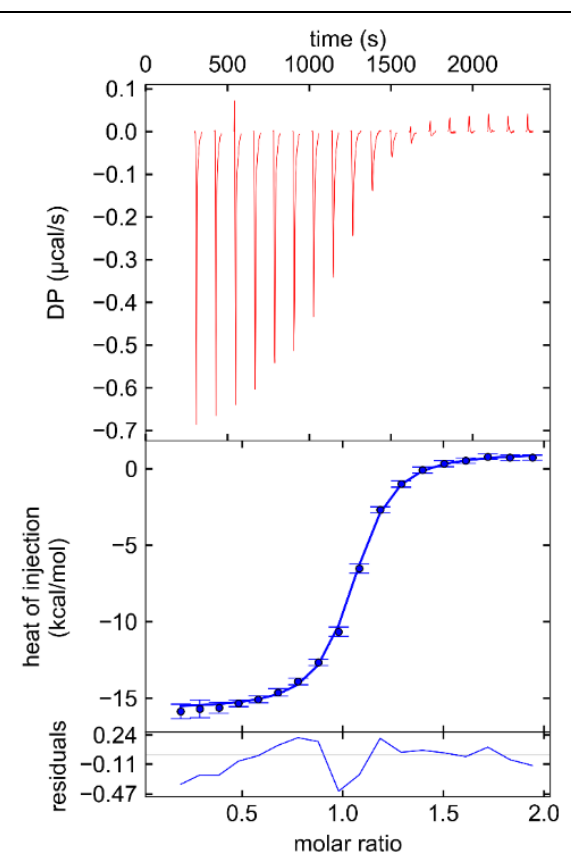

Panel 33: Binding of

[1047mA;1055mL;1076mL;1083mL] AD1-ACTR to NCBD

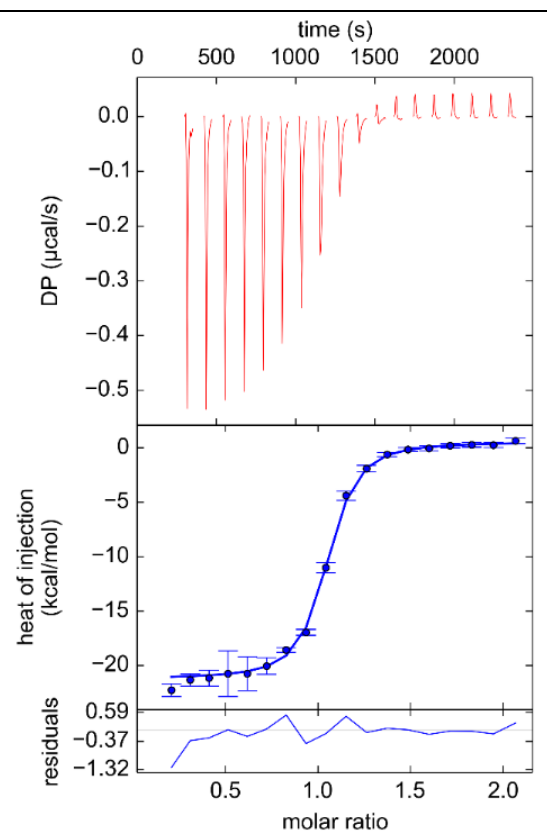

Panel 35: Binding of

[1047mA;1055mL;1061mA;1076mL;1083mL] AD1ACTR to NCBD

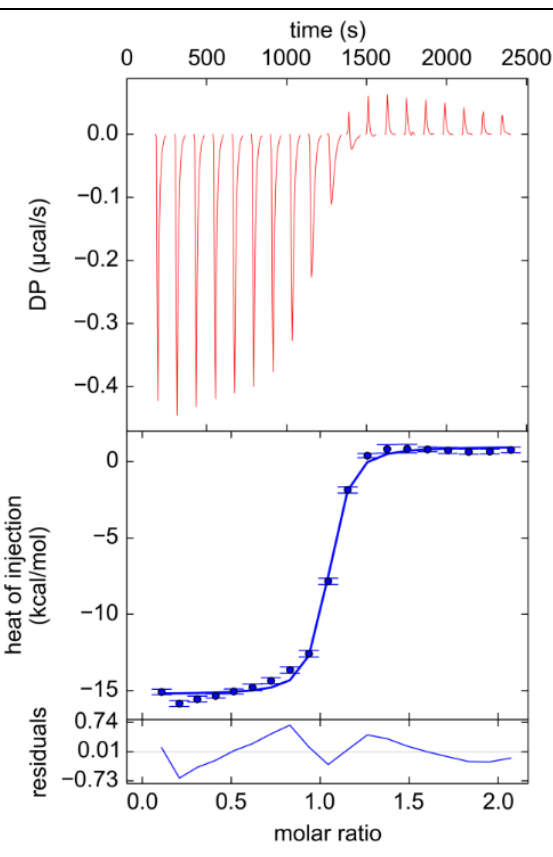

Panel 34: Binding of

[1047mA;1061mA;1076mL;1083mL] AD1-ACTR to NCBD

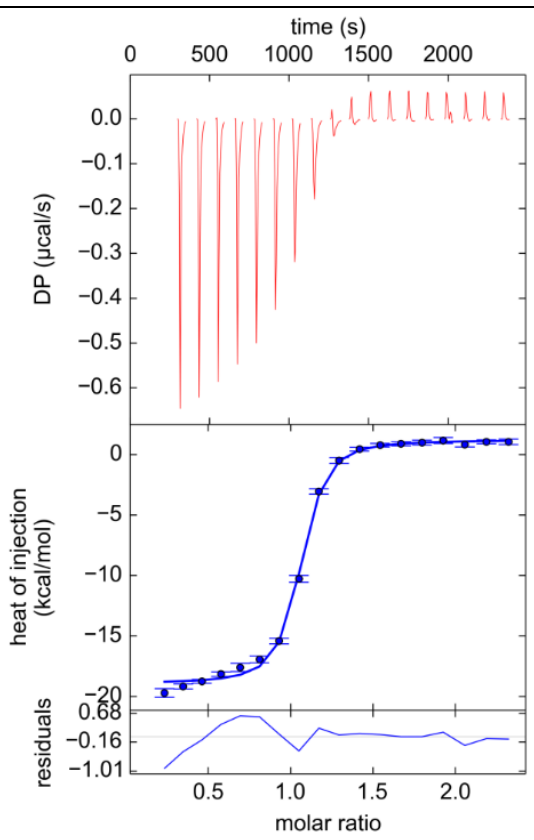

Panel 36: Binding of

[1047mA;1055mL;1061mA;1076mL;1083mL;1085mP] AD1-ACTR to NCBD 


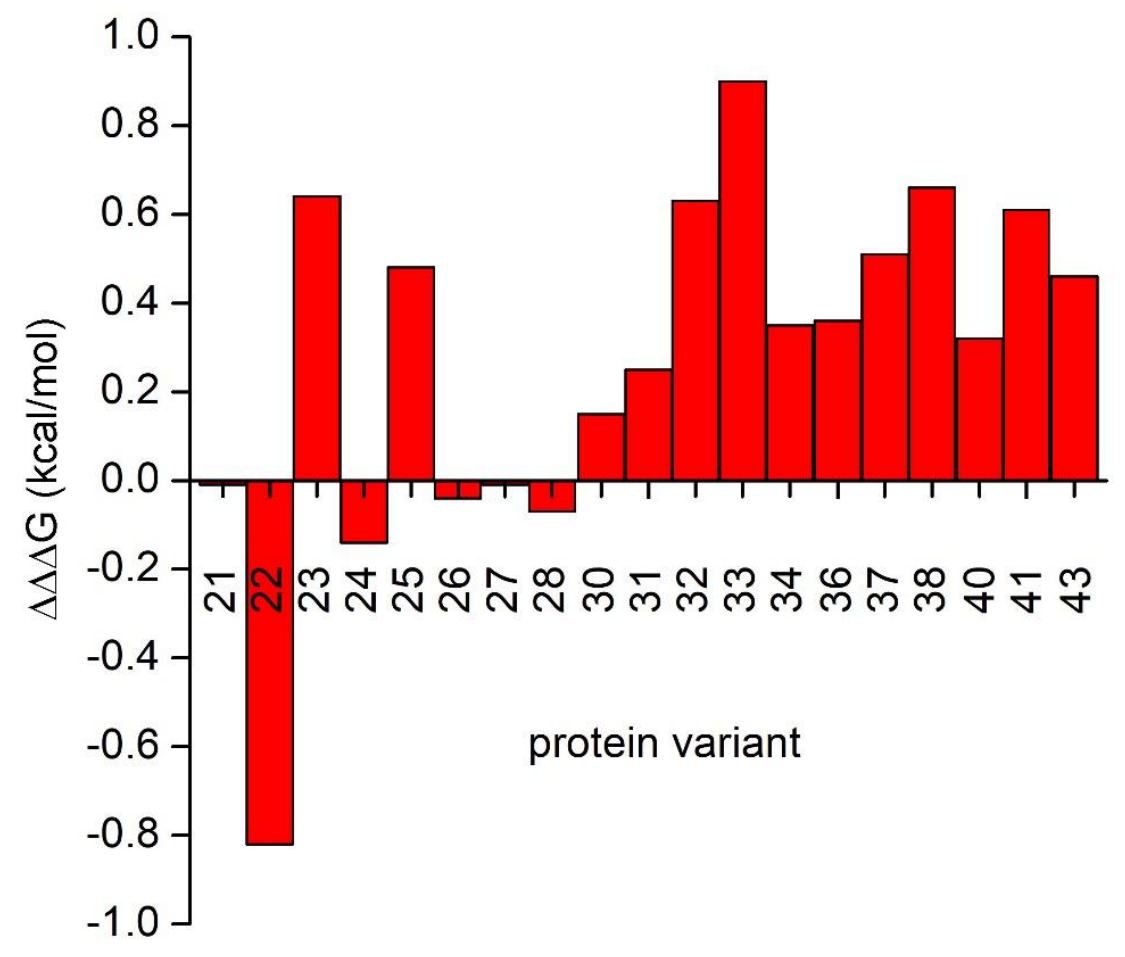

Supplementary Fig. 2. "Double mutant cycle" analysis for Gibbs free energy of complex formation for AD1-ACTR variants with two $\alpha$-methylations according to relationship: $\Delta \Delta \Delta \mathrm{G}=\Delta \Delta \mathrm{G}_{\text {variant-X}}+\Delta \Delta \mathrm{G}_{\text {variant-Y }}-\Delta \Delta \mathrm{G}_{\text {double-XY}}$, where $\Delta \Delta \mathrm{G}_{\text {variant }}$ is the variation in Gibbs free energy for a singly modified ACTR variant and $\Delta \Delta \mathrm{G}_{\text {double-XY }}$ is the variation in Gibbs free energy for the doubly $\alpha$-methylated protein. The numbering of protein variants is provided in Supplementary Table 1. 
a
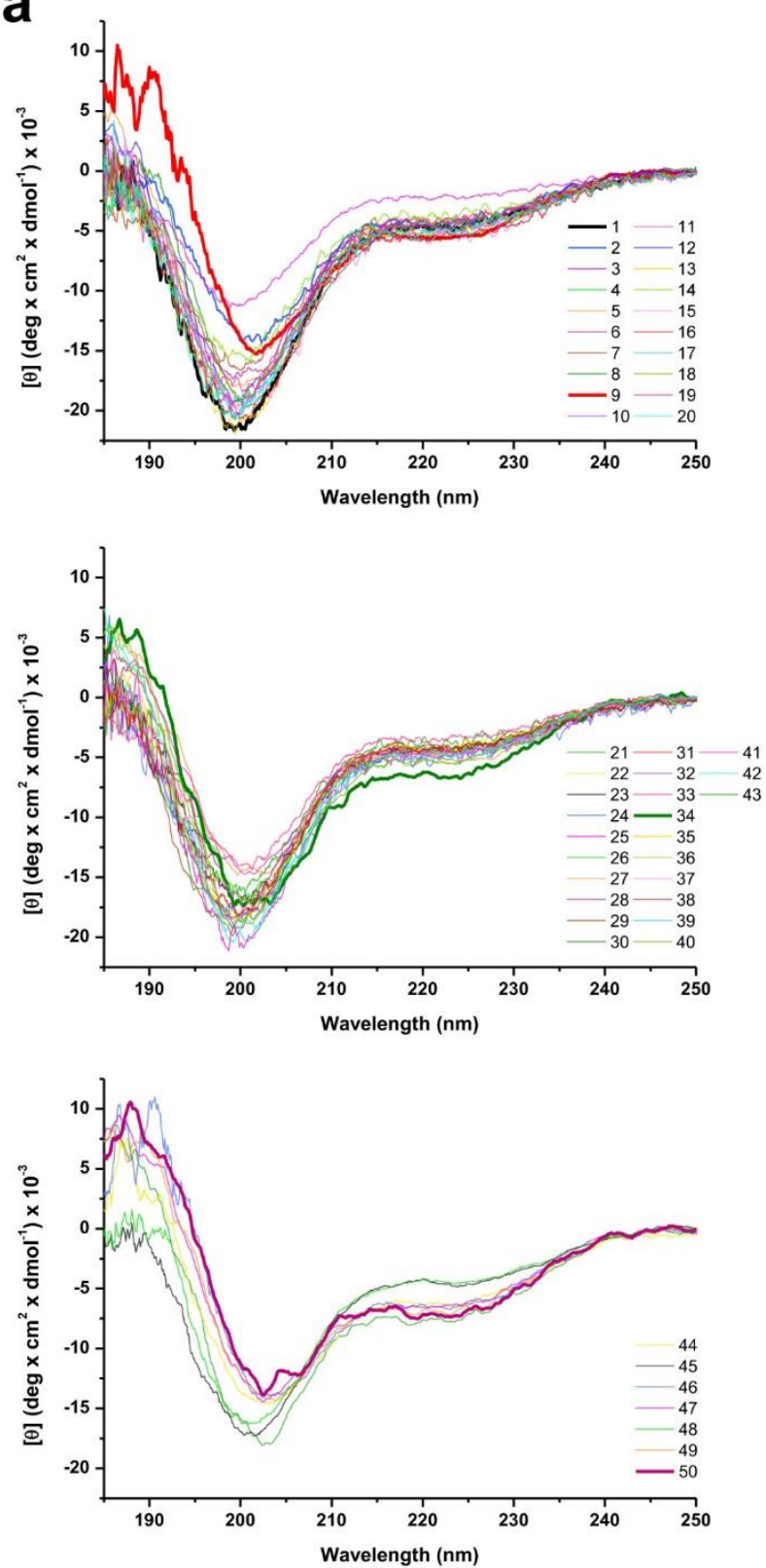

b
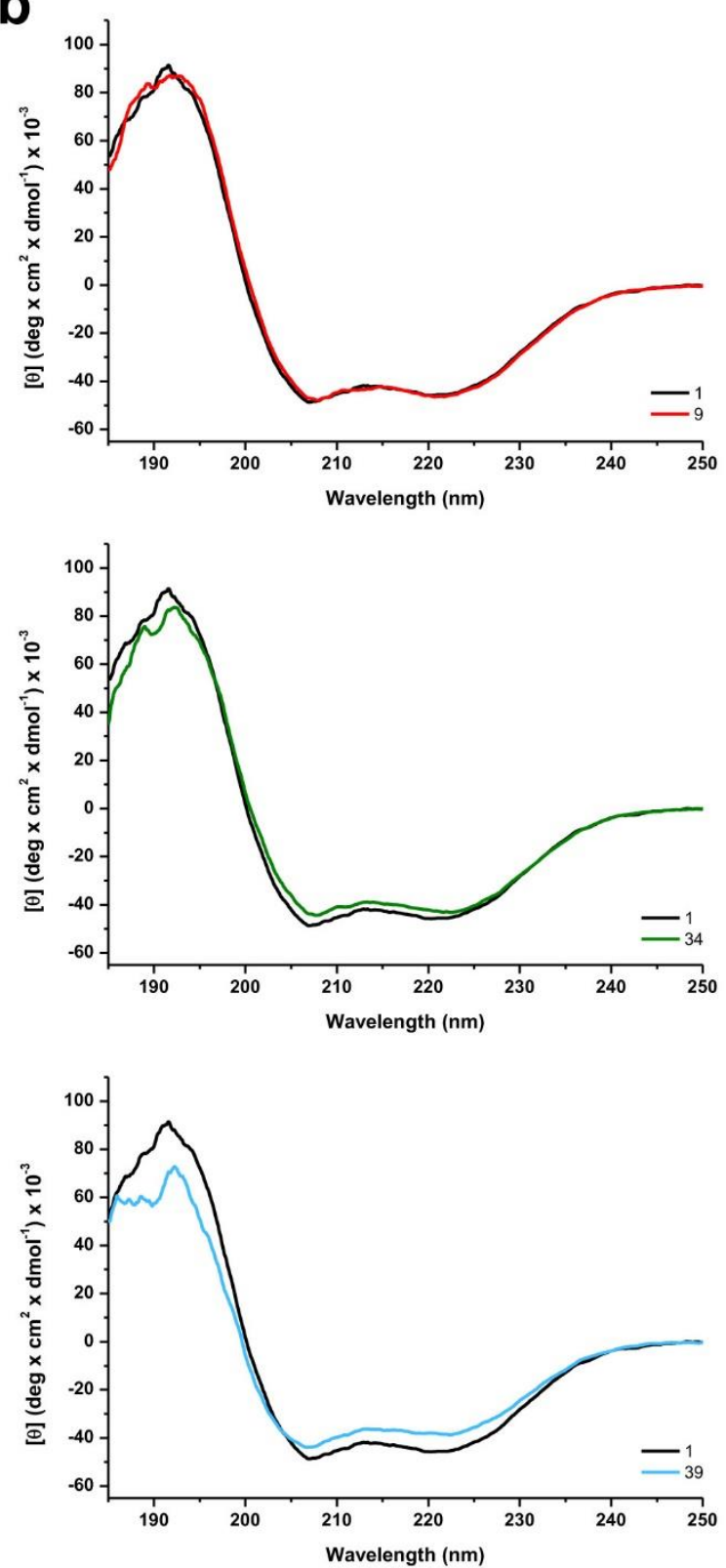

Supplementary Fig. 3. Circular dichroism (CD) spectra of AD1-ACTR variants and their complexes with NCBD. (a) Top panel: two control variants [S1043M;D1050E;T1054Q] (2) and [A1047G] (3) and protein analogues containing one $\alpha$-methylated residue overlaid onto spectrum of wild-type (1); middle: analogues with two $\alpha$-methylated amino acids, and bottom: containing multiple $\alpha$-methylated residues. (b) Representative CD spectra of stabilized [1055mL] (9) (top panel), [1055mL;1076mL] (34) (middle panel), and destabilized [1064mL;1071mL] (39) (bottom panel) variants complexed with NCBD overlaid onto the corresponding spectrum of wild type complex. 


\section{a}

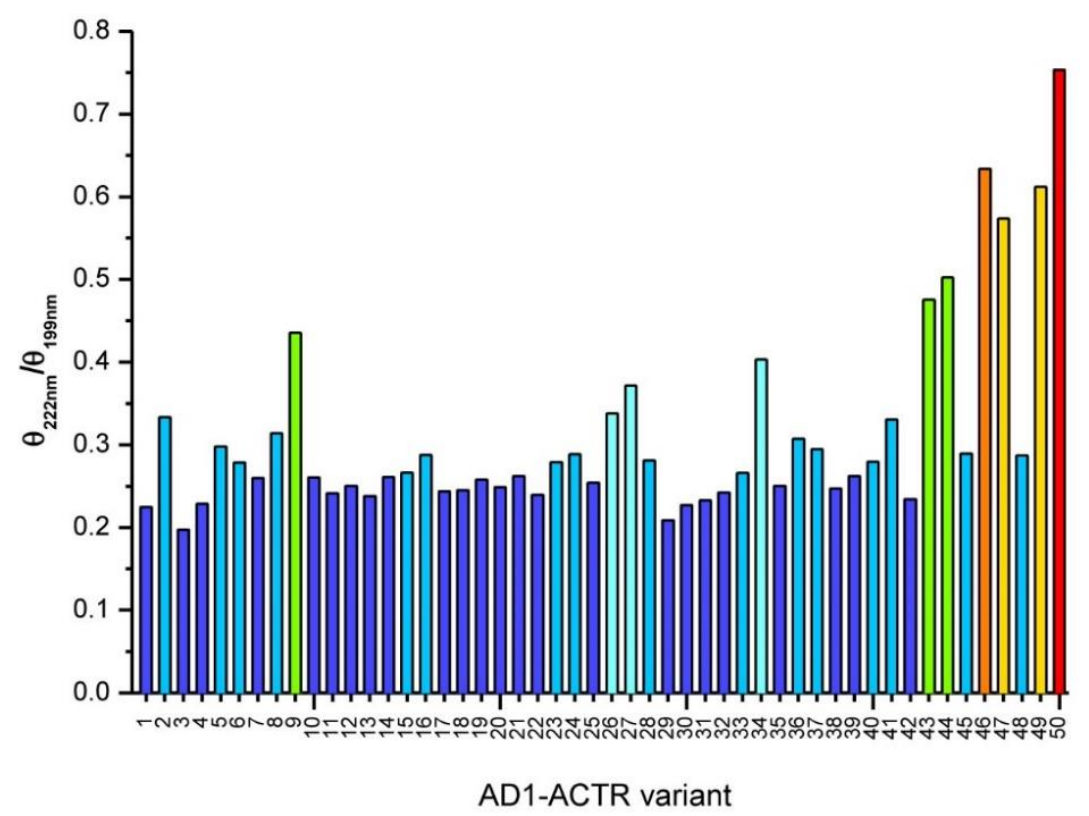

b

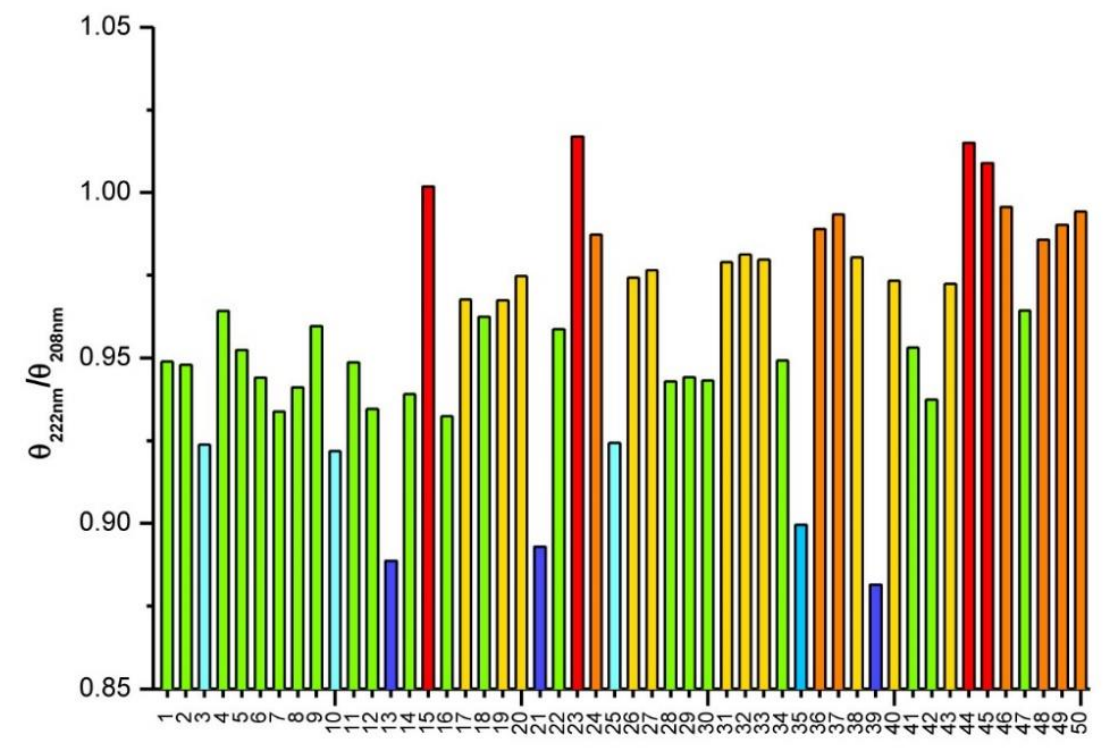

AD1-ACTR variant / NCBD complex

Supplementary Fig. 4: (a) Ellipticity ratio $\theta_{222} / \theta_{199}$ of AD1-ACTR protein variants illustrating different helical content $^{9}$, which increases upon multiple $\alpha$-methylation. (b) Ellipticity ratio $\theta_{222} / \theta_{208}$ of complexes of AD1-ACTR with NCBD suggesting non-identical secondary/tertiary structure in different complexes ${ }^{10}$. Note especially diminished values for analogues $\mathbf{1 3}, \mathbf{2 1}, \mathbf{3 5}$ and $\mathbf{3 9}$, all containing $1071 \mathrm{~mL}$ residue and the least stable in the library, although there is no straightforward correlation between helicity and stability. Different colors are used to highlight differences in values (blue correspond to lower values, red to higher values). 


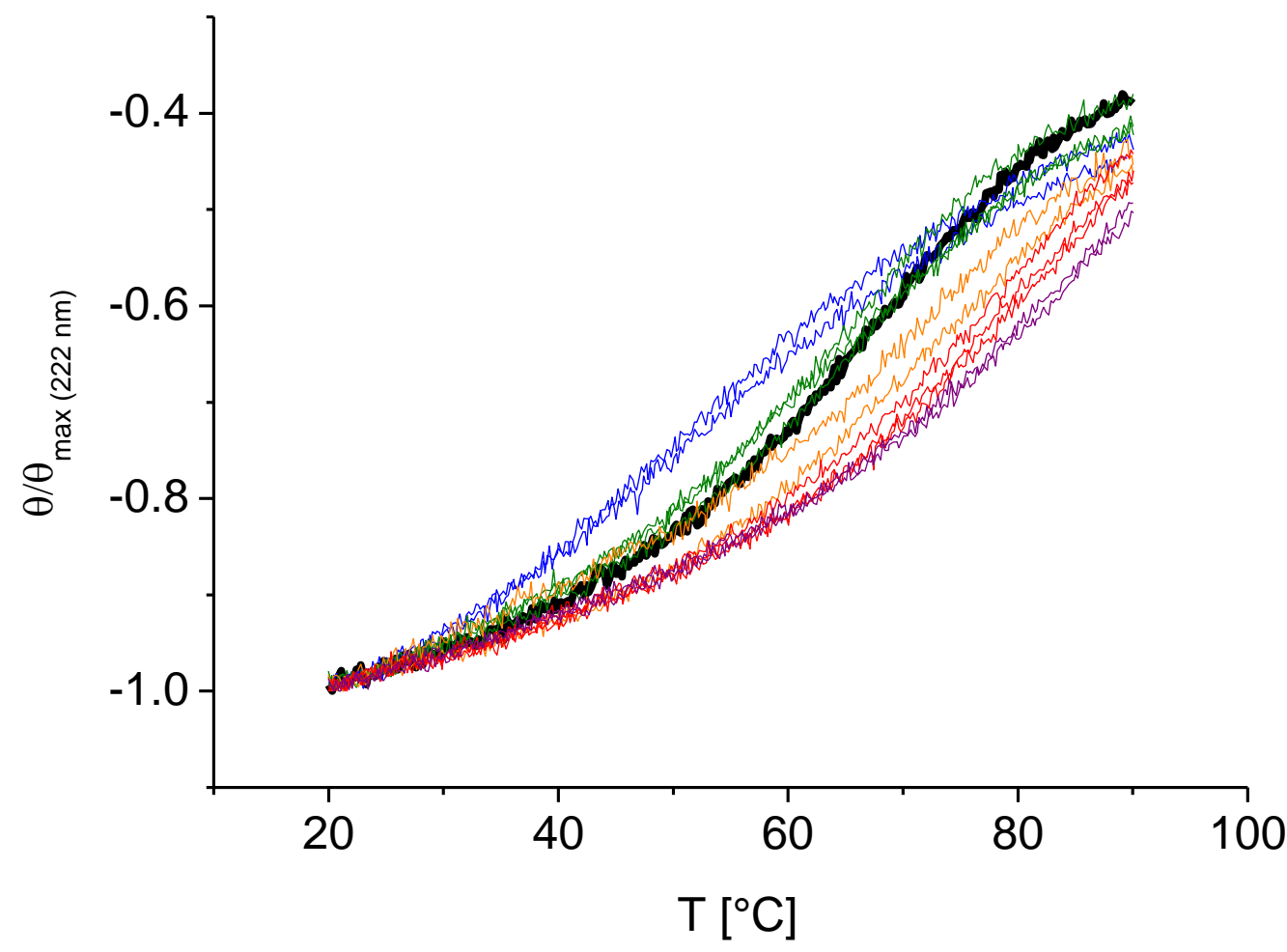

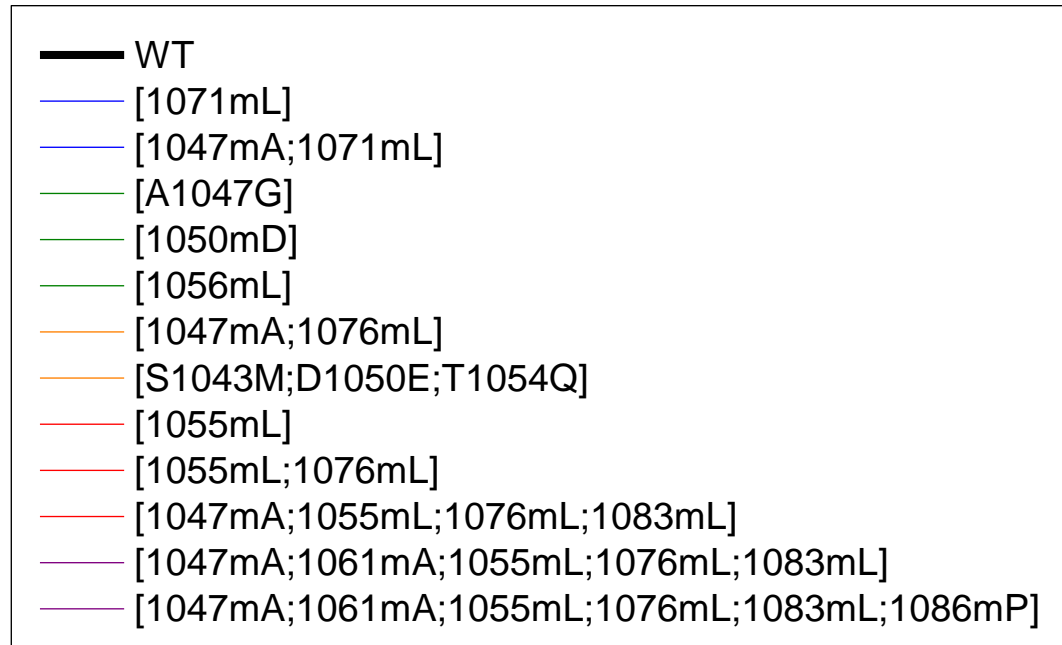

Supplementary Fig. 5: Thermal stability of AD1-ACTR/NCBD complexes evaluated by CD spectroscopy. Ellipticity at $222 \mathrm{~nm}$ was monitored as a function of temperature. The signal fully restores upon cooling after heating, i.e., termal denaturation is reversible. Apparent melting points are provided in Supplementary Table 4 and are in agreement with relative order of thermodynamic stabilities $(\Delta \mathrm{G})$ of the protein variants obtained by isothermal titration calorimetry (ITC). 


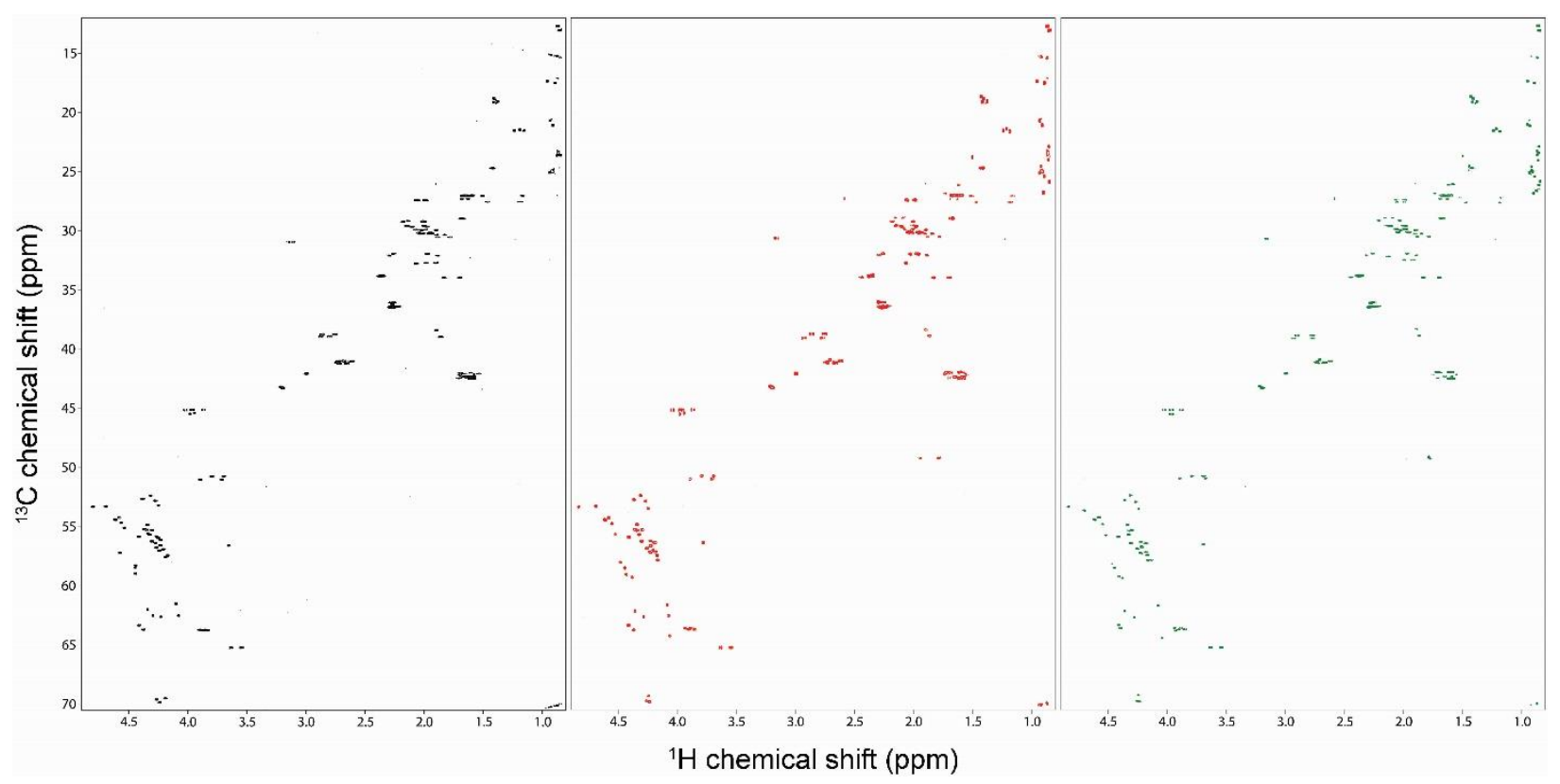

b

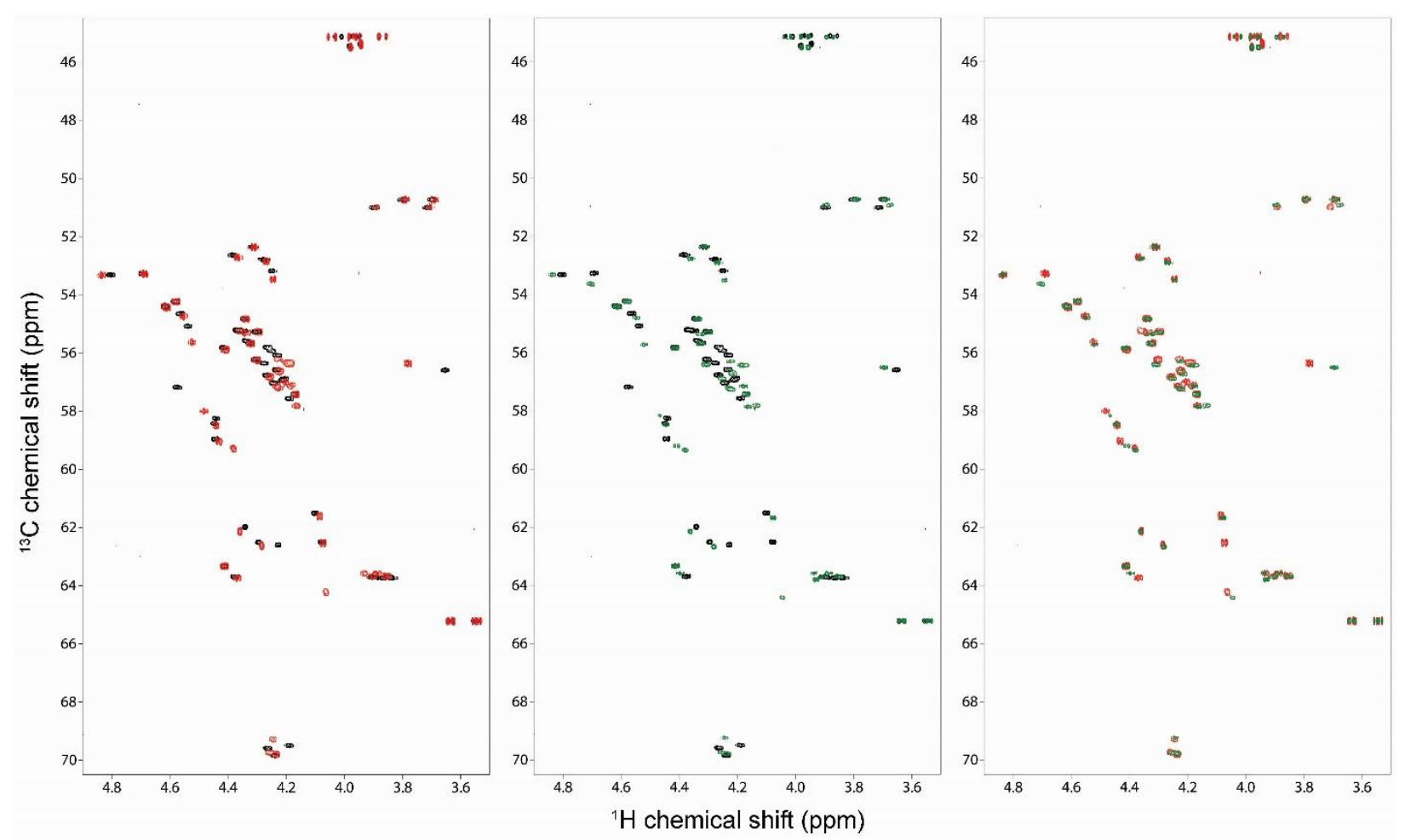

Supplementary Fig. 6: A comparison of ${ }^{13} \mathrm{C}-\mathrm{HSQC}$ spectra in $\mathrm{D}_{2} \mathrm{O}$. (a) ${ }^{13} \mathrm{C}-\mathrm{HSQC}$ spectra acquired in $\mathrm{D}_{2} \mathrm{O}$ for wild type (WT) AD1-ACTR (in black) and two [1055meLeu] (in red) and [1055meLeu;1076meLeu] (in green) variants. (b) Pairwise superposition of the spectral regions corresponding to $\mathrm{C} \alpha-\mathrm{H} \alpha$ correlations with the same color-coding as in (a). 

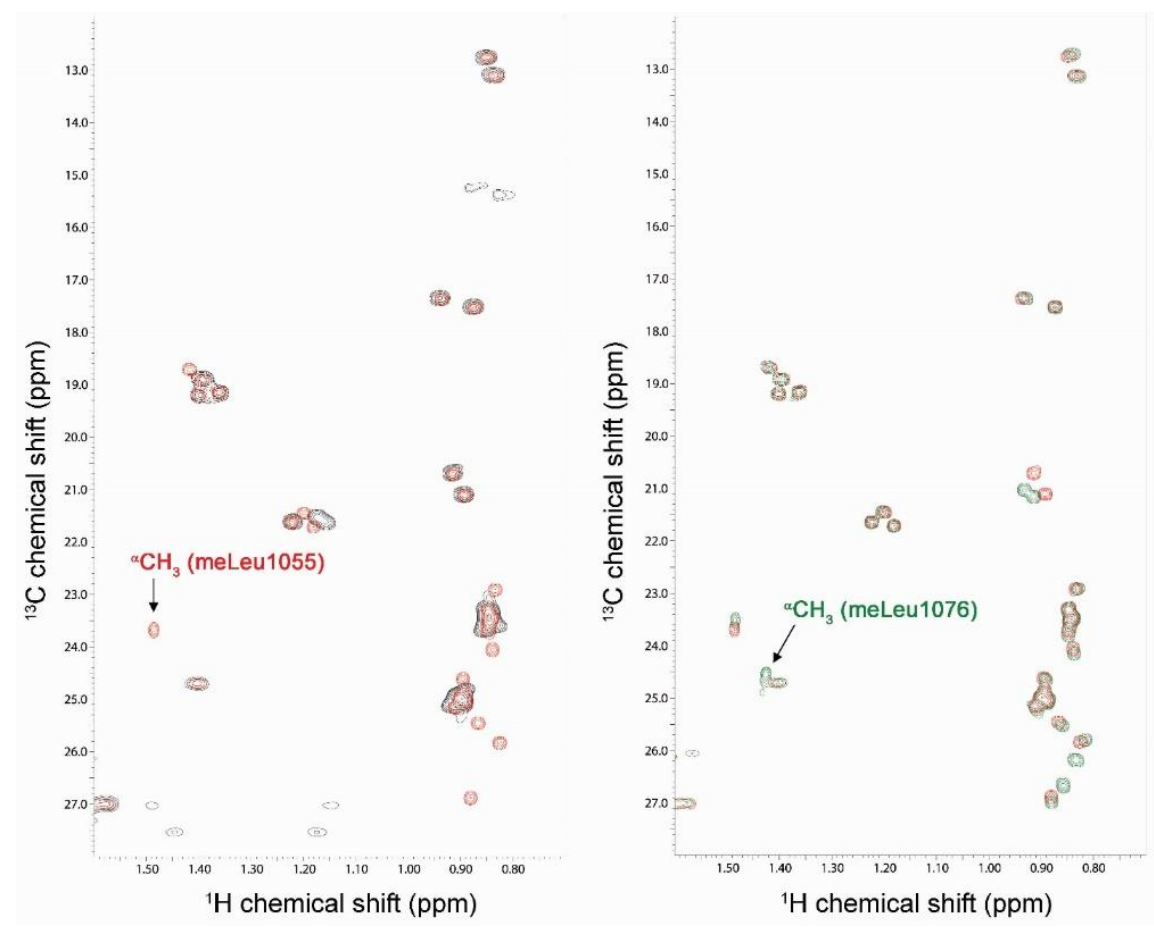

Supplementary Fig. 7: A comparison of ${ }^{13} \mathrm{C}-\mathrm{HSQC}$ spectra in $\mathrm{D}_{2} \mathrm{O}$. The excerpts of the ${ }^{13} \mathrm{C}-\mathrm{HSQC}$ spectra of WT AD1-ACTR (in black), [1055meLeu] variant (in red) and [1055meLeu;1076meLeu] variant (in green) recorded in $\mathrm{D}_{2} \mathrm{O}$. The spectra are overlaid in a pairwise manner to illustrate the additional peaks for $\alpha$-methyl groups of residues meLeu1055 and meLeu1076 in the corresponding proteins.

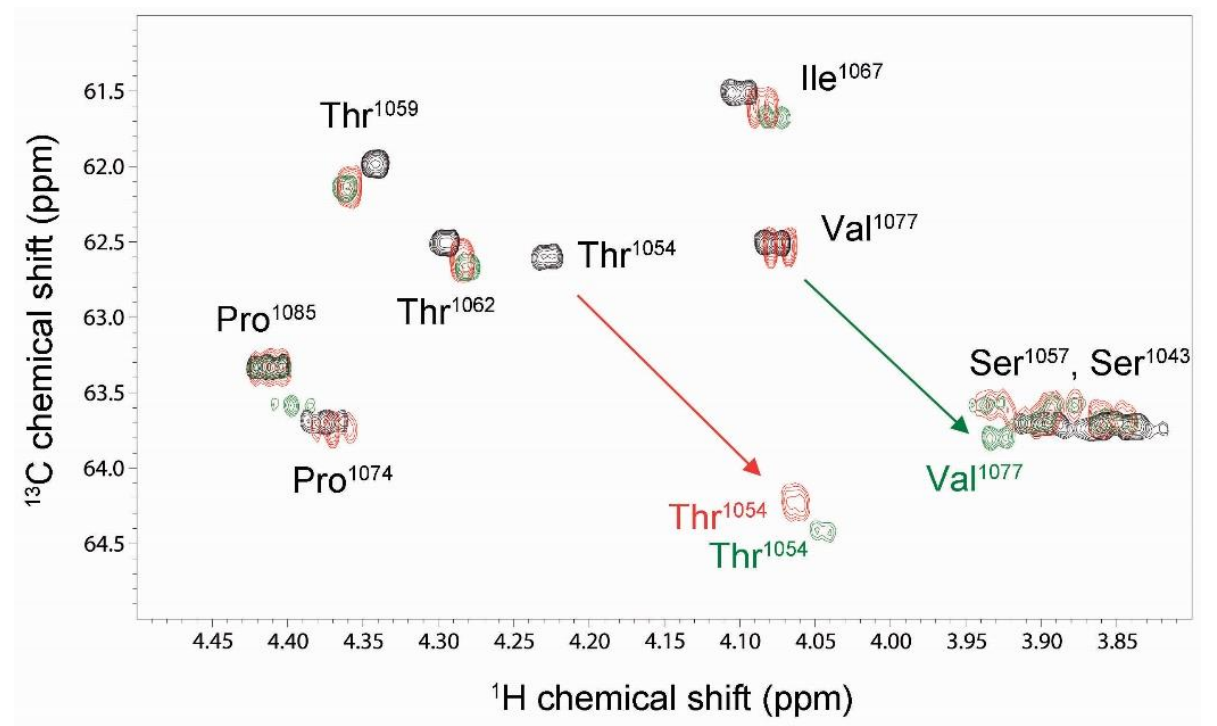

Supplementary Fig. 8: Superposition of the region of ${ }^{13} \mathrm{C}-\mathrm{HSQC}$ spectra of WT AD1-ACTR (in black), [1055meLeu] variant (in red) and [1055meLeu; $1076 \mathrm{meLeu}$ variant (in green) recorded in $\mathrm{D}_{2} \mathrm{O}$ shown to illustrate the changes of chemical shifts for $\mathrm{CH} \alpha$ groups for residues Thr1054 and Val1077, which are in close proximity to helix-stabilizing meLeu1055 and meLeu1076, respectively. 


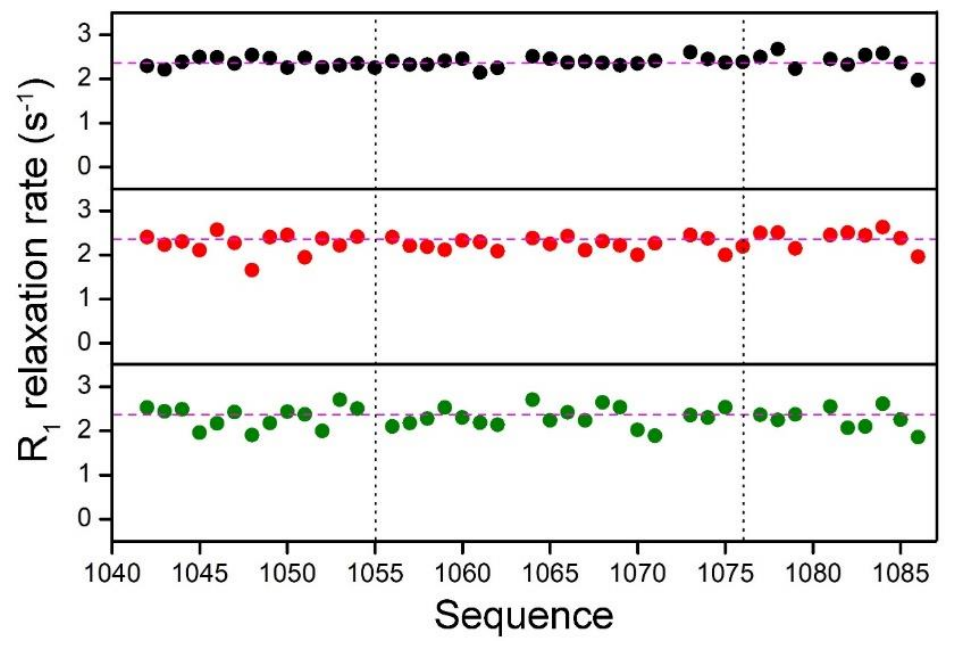

Supplementary Fig. 9: Spin-lattice relaxation rates $\left(\mathrm{R}_{1}\right)$ are not perturbed significantly in two studied $\alpha$-methylated [1055meLeu] (in red) and [1055meLeu;1076meLeu] (in green) variants of AD1-ACTR in comparison to wild type (in black). The vertical dashed lines in black indicate positions for $\alpha$-methylation (1055 and 1076). The horizontal dashed lines (in magenta) in all three panels indicate the average $\mathrm{R}_{1}$ value for WT AD1-ACTR. The $\mathrm{R}_{1}$ values and the experimental uncertainties are listed in Supplementary Table 10.
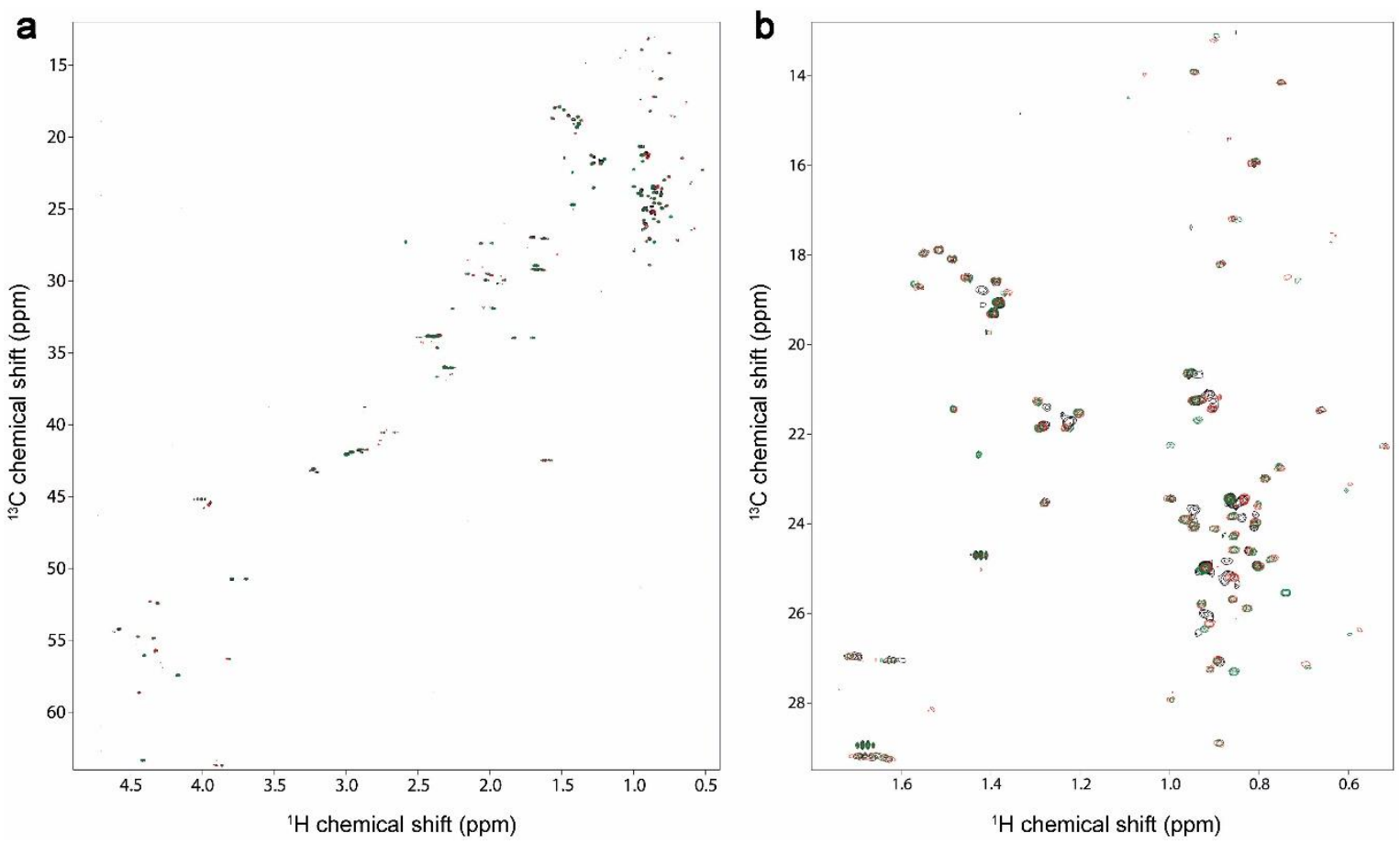

Supplementary Fig. 10: A comparison of ${ }^{13} \mathrm{C}-\mathrm{HSQC}$ spectra of complexes with NCBD. (a) Overlay of ${ }^{13} \mathrm{C}-\mathrm{HSQC}$ spectra of complexes of NCBD with WT AD1-ACTR (depicted in black) and two analogues [1055meLeu] and [1055meLeu;1076meLeu] (in red and green, respectively). (b) The methyl region of the corresponding spectra showing that most of the structural differences in the complexes are for the aliphatic side-chains. The signal intensities for the $\mathrm{CH} \alpha$ region are attenuated in the complexes in comparison to spectra of free AD1-ACTR domains presumably due to accelerated transverse relaxation. 


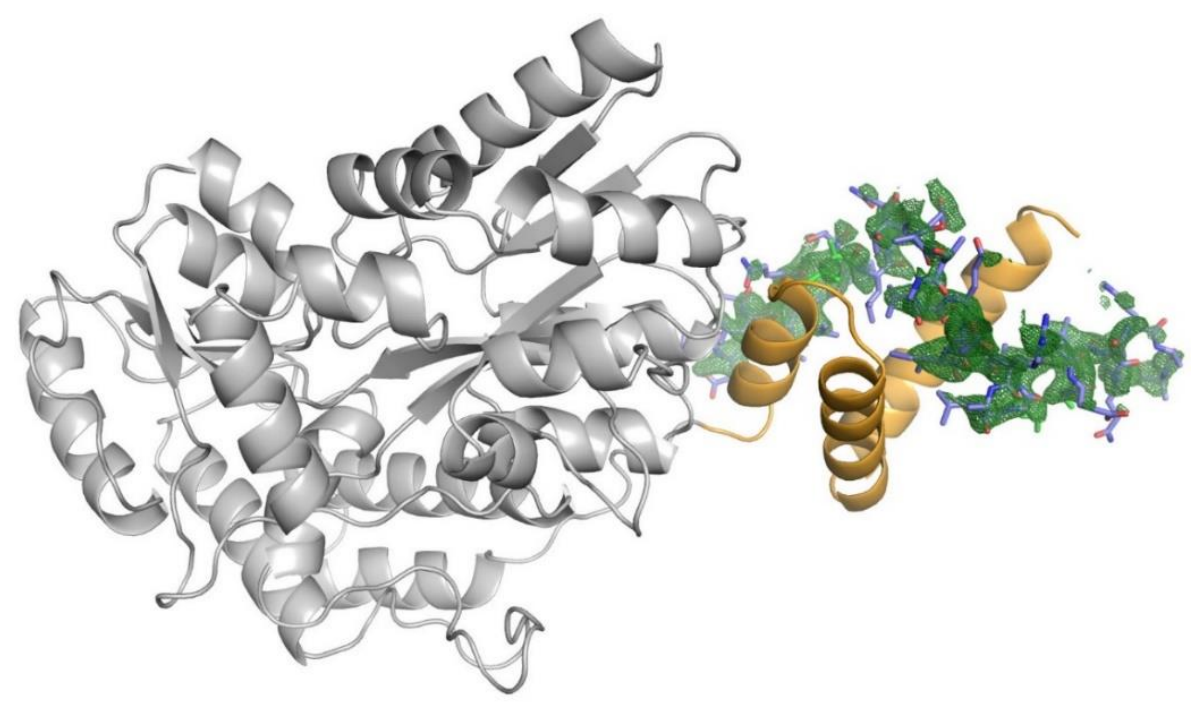

Supplementary Fig. 11: Fo-Fc simulated annealing omit map (contoured at 2 $\sigma$ ) calculated for ACTR activation domain.
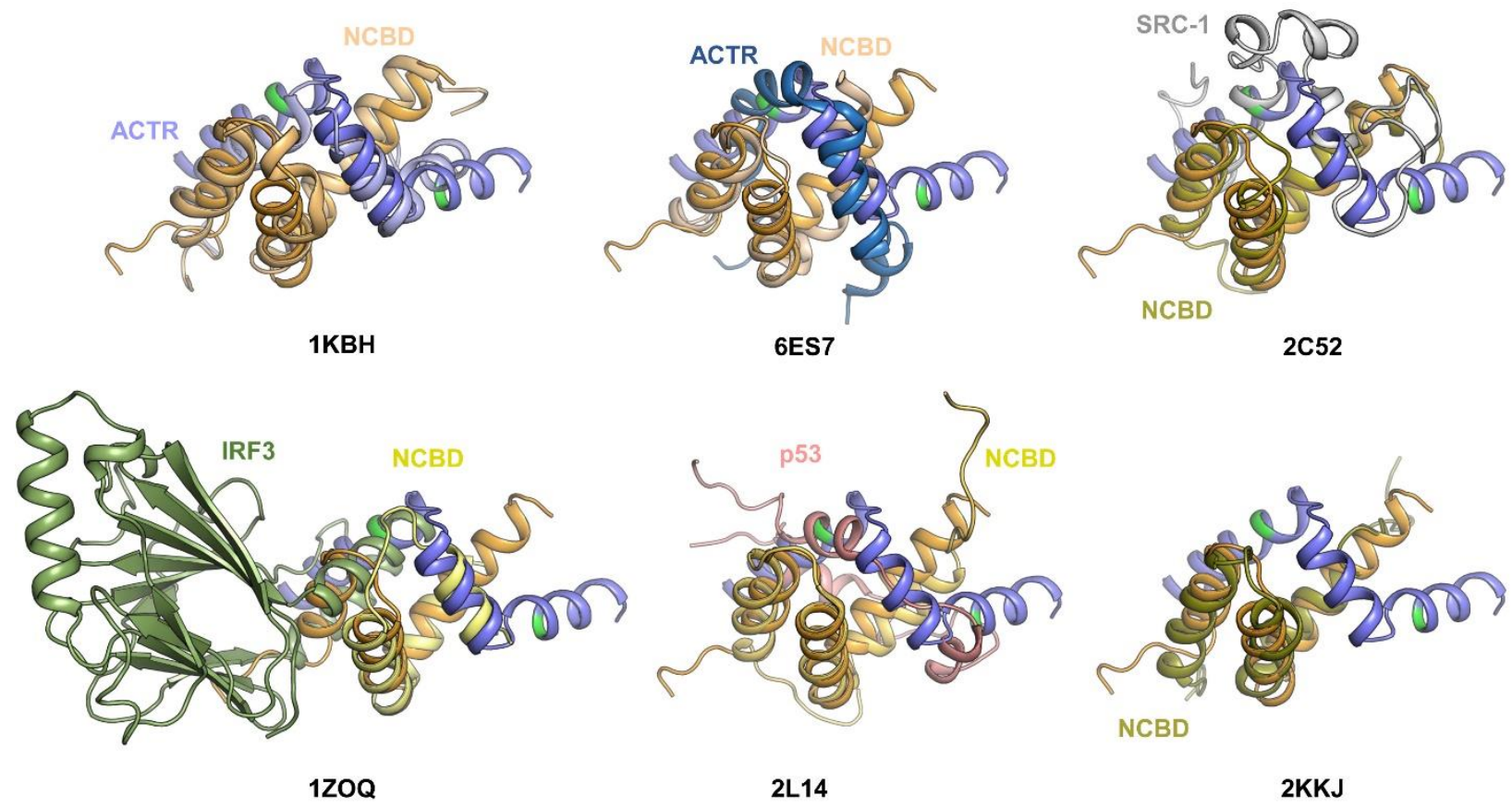

Supplementary Fig. 12: Comparison with the previously reported structures. The X-ray structure of $\alpha$-methylated [1055meLeu;1076meLeu]AD1-ACTR variant complexed with NCBD of CBP shows similar arrangement of six $\alpha$ helices with previously solved NMR structure $(1 \mathrm{KBH})$ and significant deviations from the other reported structure (6ES7). For comparison, other known structures containing NCBD are superimposed onto new X-ray structure. These include SRC-1 isoform of p160 (2C52), complex with IRF3 (1ZOQ), transactivation domain (TAD) of p53 (2L14), and free NCBD $(2 \mathrm{KKJ})$. 

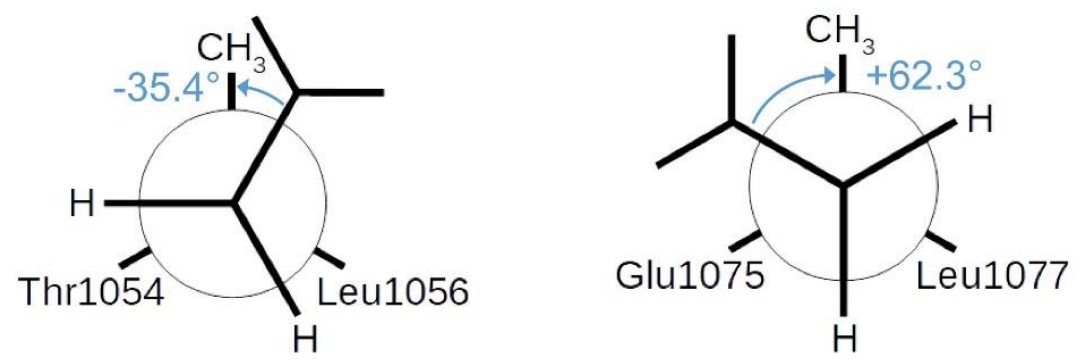

Supplementary Fig. 13: Stereochemical Newman projections for residues 1055meLeu (left) and 1076 meLeu (right) in the X-ray structure of [1055meLeu;1076meLeu] AD1-ACTR / NCBD complex. Torsional angles $\mathrm{C} \gamma-\mathrm{C} \beta-\mathrm{C} \alpha-\mathrm{C} \beta$ (methyl) are depicted.

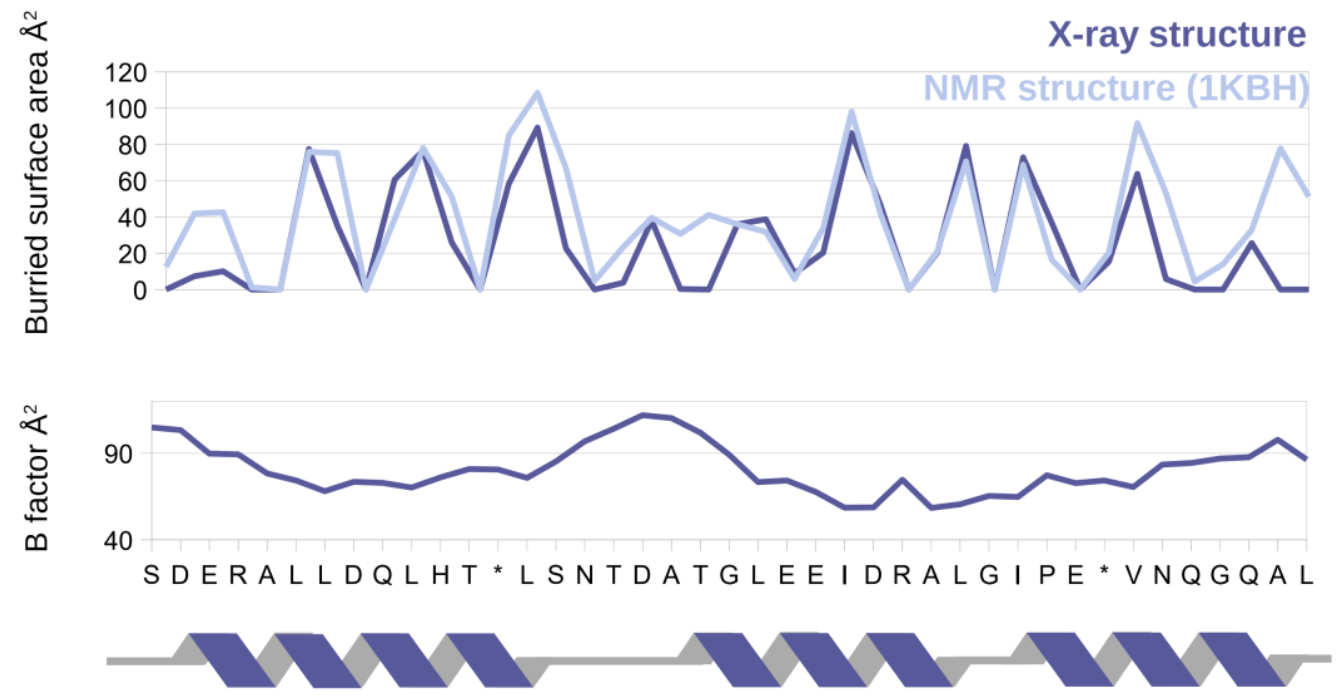

Supplementary Fig. 14: The protein-protein interface is less tight than in the NMR complex (1KBH). The overall buried surface area decreased from 1655 to $1066 \AA^{2}$. The trend is similar and the highest difference is between residues 1059-1064 (linker between helix 1 and 2), which shows high flexibility in the crystal and the C-terminal helix which no longer makes close interactions with NCBD. Star $\left(^{*}\right)$ indicates $\alpha$-methyl-Leu residues in the sequence. 

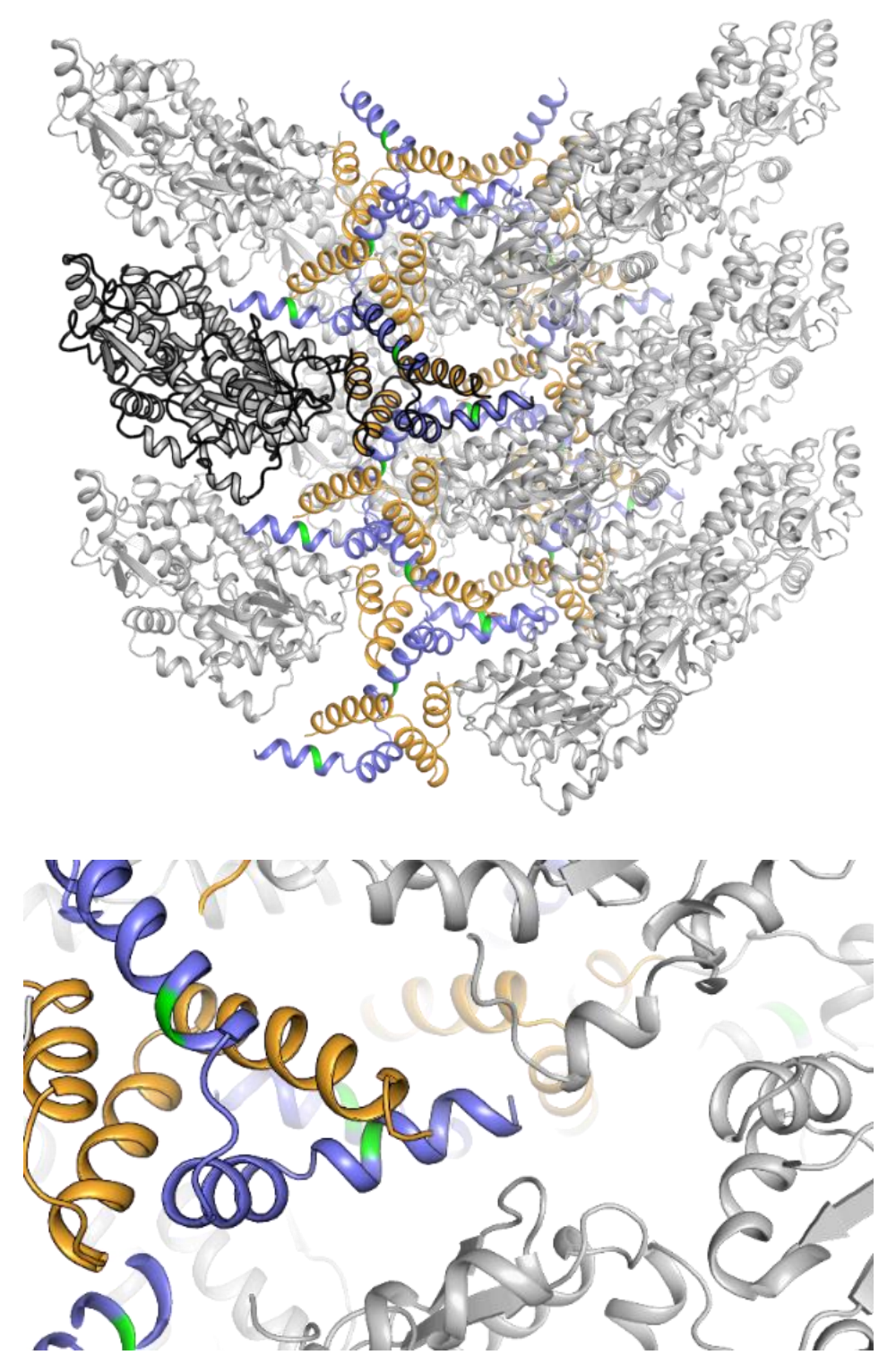

Supplementary Fig. 15: Visualization of molecular interactions in the crystal. Crystal packing does not affect the orientation of $\alpha$-helices in the [1055meLeu;1076meLeu]AD1-ACTR / NCBD complex. 
a

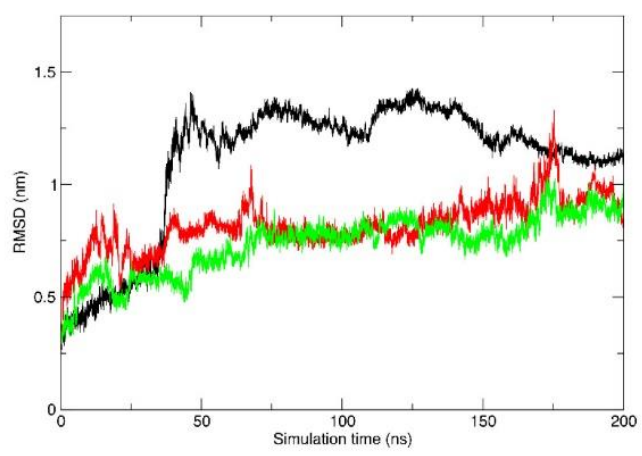

b

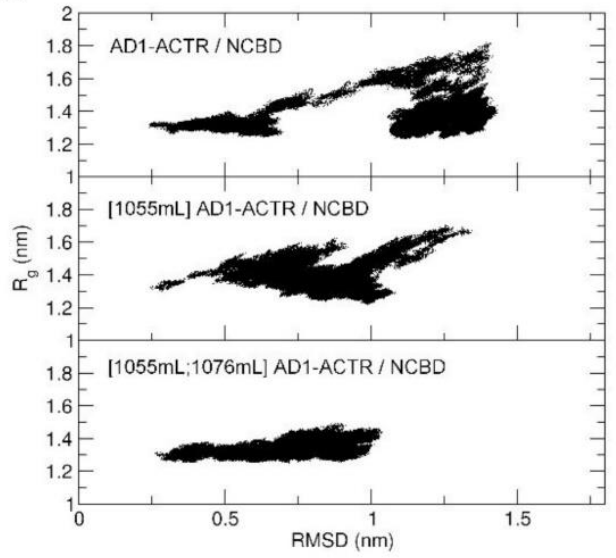

C
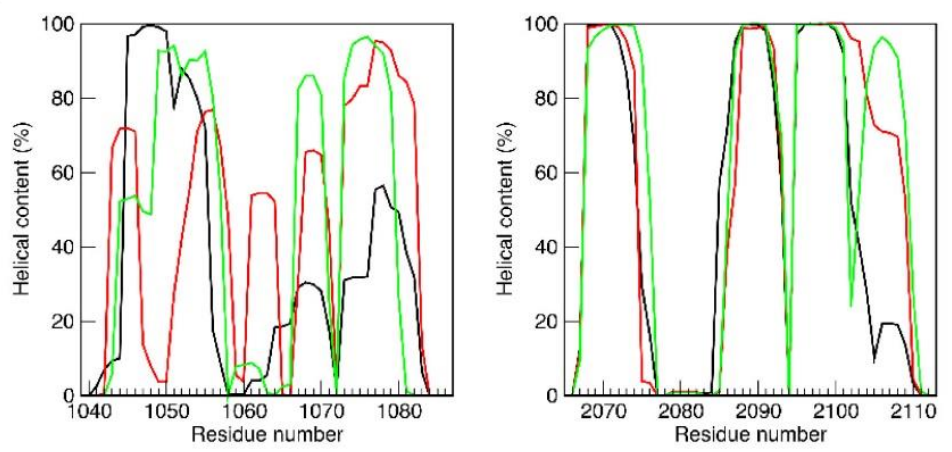

d

Thr 1054

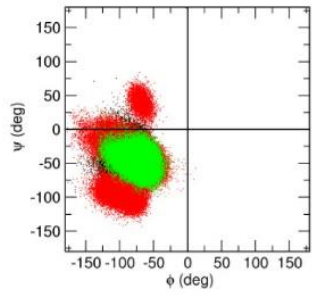

Leu1056

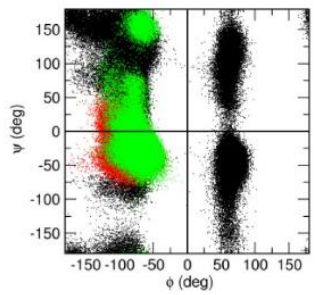

Glu1075

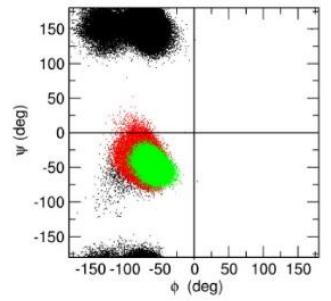

Val1077

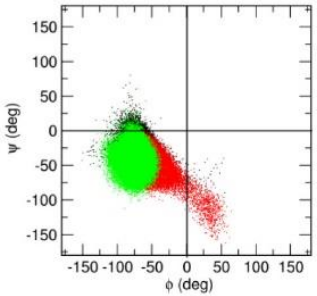

Supplementary Fig. 16: Molecular dynamics (MD) simulations of WT AD1-ACTR / NCBD complex and of the corresponding analogues [1055meLeu] and [1055meLeu;1076meLeu]. (a) Backbone atom-positional root-meansquare deviations (RMSD) of complexes from its initial structure indicate a large structural change around $37 \mathrm{~ns}$. The RMSF analysis, Ramachandran plots, hydrogen bonding and salt-bridge analysis therefore exclude the first $50 \mathrm{ns.}$ Black line: WT complex, red line: [1055meLeu]AD1-ACTR/NCBD complex, green line: [1055meLeu;1076meLeu] AD1-ACTR/NCBD complex. (b) Changes in the radii of gyration of the complexes show that the [1055meLeu;1076meLeu]AD1- ACTR/NCBD complex has the most compact structure. (c) The analysis of helical content per residue shows the overall increase of helicity in the ACTR chain that occurs upon $\alpha$-methylation of Leu1055 and Leu1076. The pre-organization of ACTR analogues into segments with helical conformations was also observed in CD and NMR experiments on free AD1-ACTR proteins. The secondary structural analysis was performed using the DSSP program as implemented in $\operatorname{GROMOS}^{30}$. The helical content per residue was calculated as the sum of the occurrences for $3_{10}$-helix, $\alpha$-helix and $\pi$-helix. For this analysis the entire trajectory was used. (d) The conformational distribution of the neighboring residues Thr1054, Leu1056, Glu1075 and Val1077 also gets reduced upon $\alpha$ methylation of Leu1055 and Leu1076. First $50 \mathrm{~ns}$ were omitted from the latter analysis. 
a

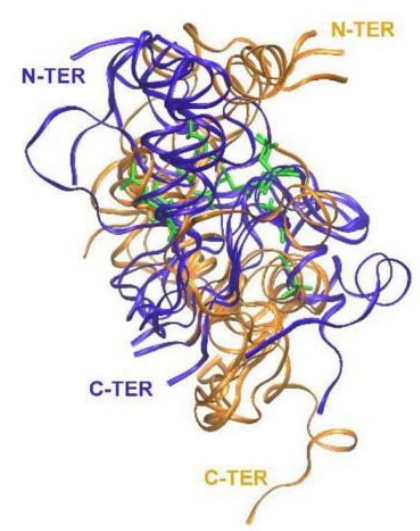

b

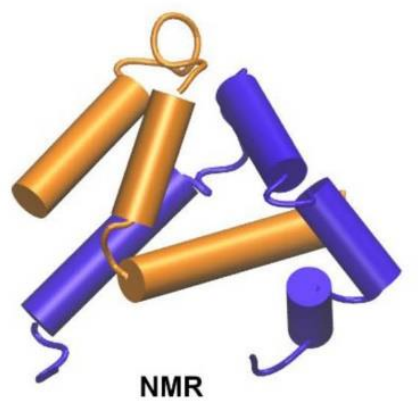

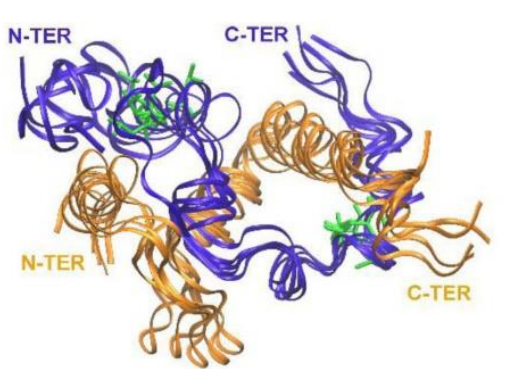
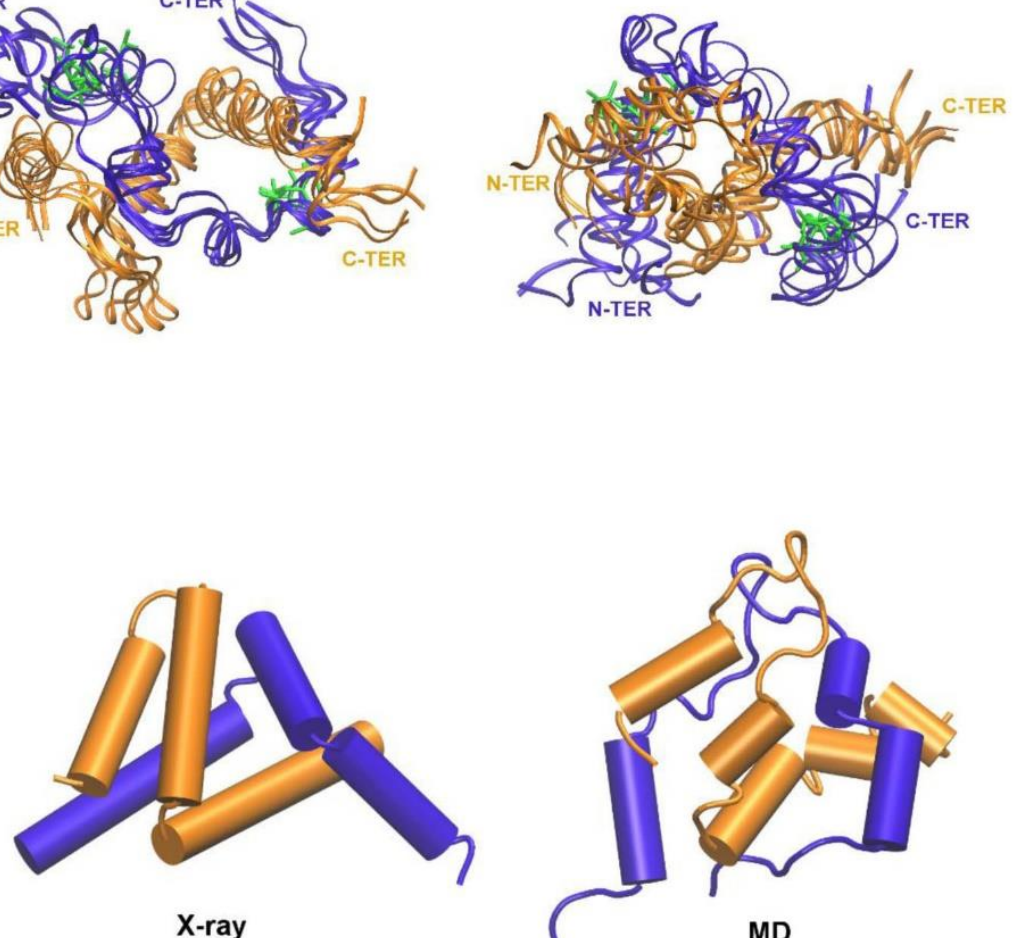

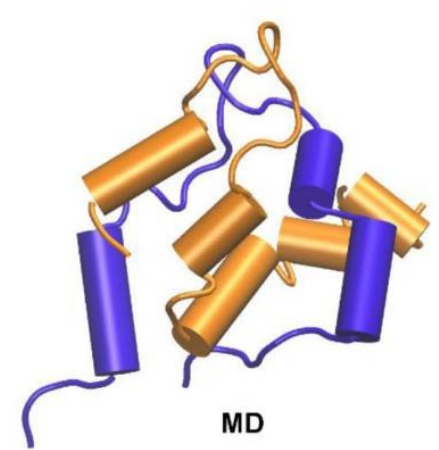

Supplementary Fig. 17: (a) Overlay of five representative conformations (first five central member structures from the conformational clustering) for MD simulation of wild-type AD1-ACTR/NCBD (left), [1055 meLeu]AD1ACTR/NCBD (center) and [1055meLeu;1076meLeu]AD1-ACTR/NCBD (right) complexes. In all plots, chain corresponding to ACTR is colored in purple and for NCBD in orange, while residues 1055 and 1076 are highlighted in green. Evident are the structural differences between the complexes and structural variations within each ensemble. Those are the largest for wild type complex and smallest for [1055meLeu]AD1-ACTR/NCBD complex. (b) Comparison of orientation of helices in the structure of wild-type complex determined by NMR (PDB ID: 1KBH), of the [1055meLeu;1076meLeu]AD1-ACTR/NCBD complex determined by X-ray crystallography in this study (PDB ID: 6SQC) and of the first central member structure from the conformational clustering of the corresponding MD simulation. 
Supplementary Fig. 18 (consists of 6 panels on pp. 34-38): Surface plasmon resonance binding data for WT AD1-ACTR, [1055meLeu]AD1-ACTR, [1076meLeu]AD1-ACTR and [1055meLeu;1076meLeu] AD1-ACTR at $20^{\circ} \mathrm{C}(293 \mathrm{~K})$ (curves in black correspond to fitting to 1:1 association model).

\section{Panel 1:}

WT AD1-ACTR:


Supplementary Fig. 18: (continued from p. 34) Surface plasmon resonance binding data for WT AD1ACTR, [1055meLeu]AD1-ACTR, [1076meLeu]AD1-ACTR and [1055meLeu;1076meLeu]AD1-ACTR at $22{ }^{\circ} \mathrm{C}(295 \mathrm{~K})$ (curves in black correspond to fitting to $1: 1$ association model).

Panel 2:

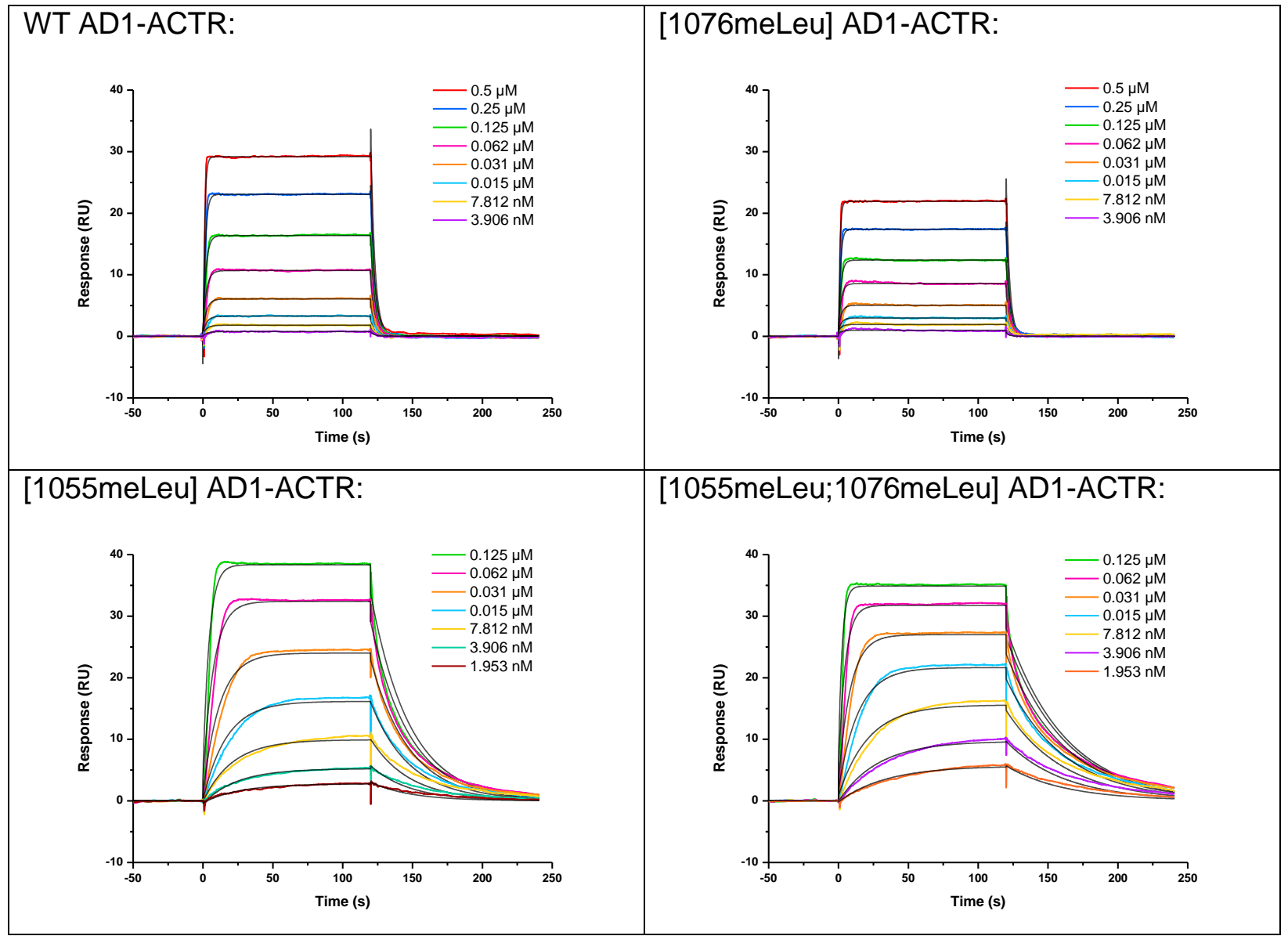


Supplementary Fig. 18: (continued from p. 35) Surface plasmon resonance binding data for WT AD1ACTR, [1055meLeu]AD1-ACTR, [1076meLeu]AD1-ACTR and [1055meLeu;1076meLeu]AD1-ACTR at $25^{\circ} \mathrm{C}(298 \mathrm{~K})$.

Panel 3:

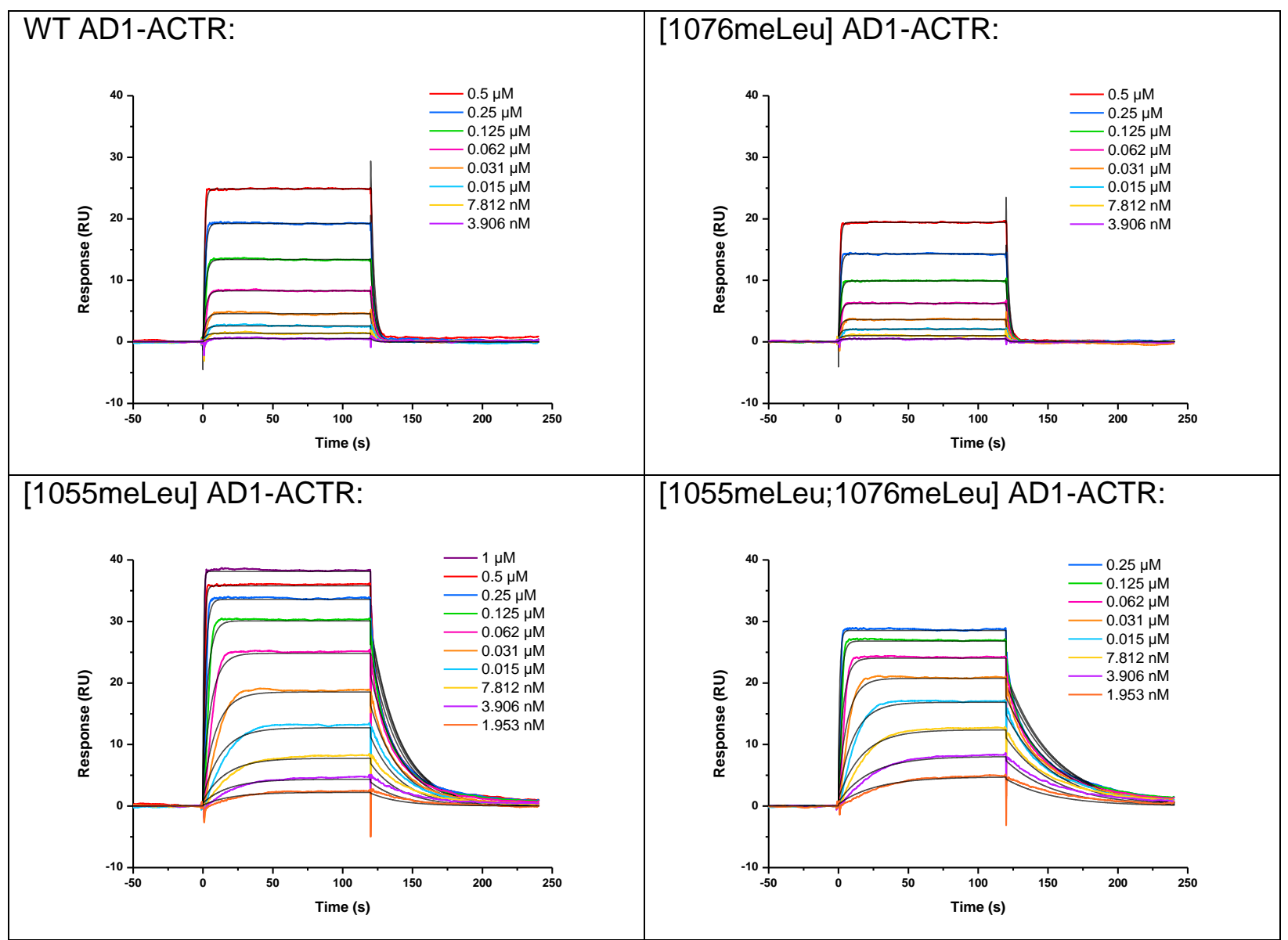


Supplementary Fig. 18: (continued from p. 36) Surface plasmon resonance binding data for WT AD1ACTR, [1055meLeu]AD1-ACTR, [1076meLeu]AD1-ACTR and [1055meLeu;1076meLeu]AD1-ACTR at $27^{\circ} \mathrm{C}(300 \mathrm{~K})$ (curves in black correspond to fitting to $1: 1$ association model).

\section{Panel 4:}

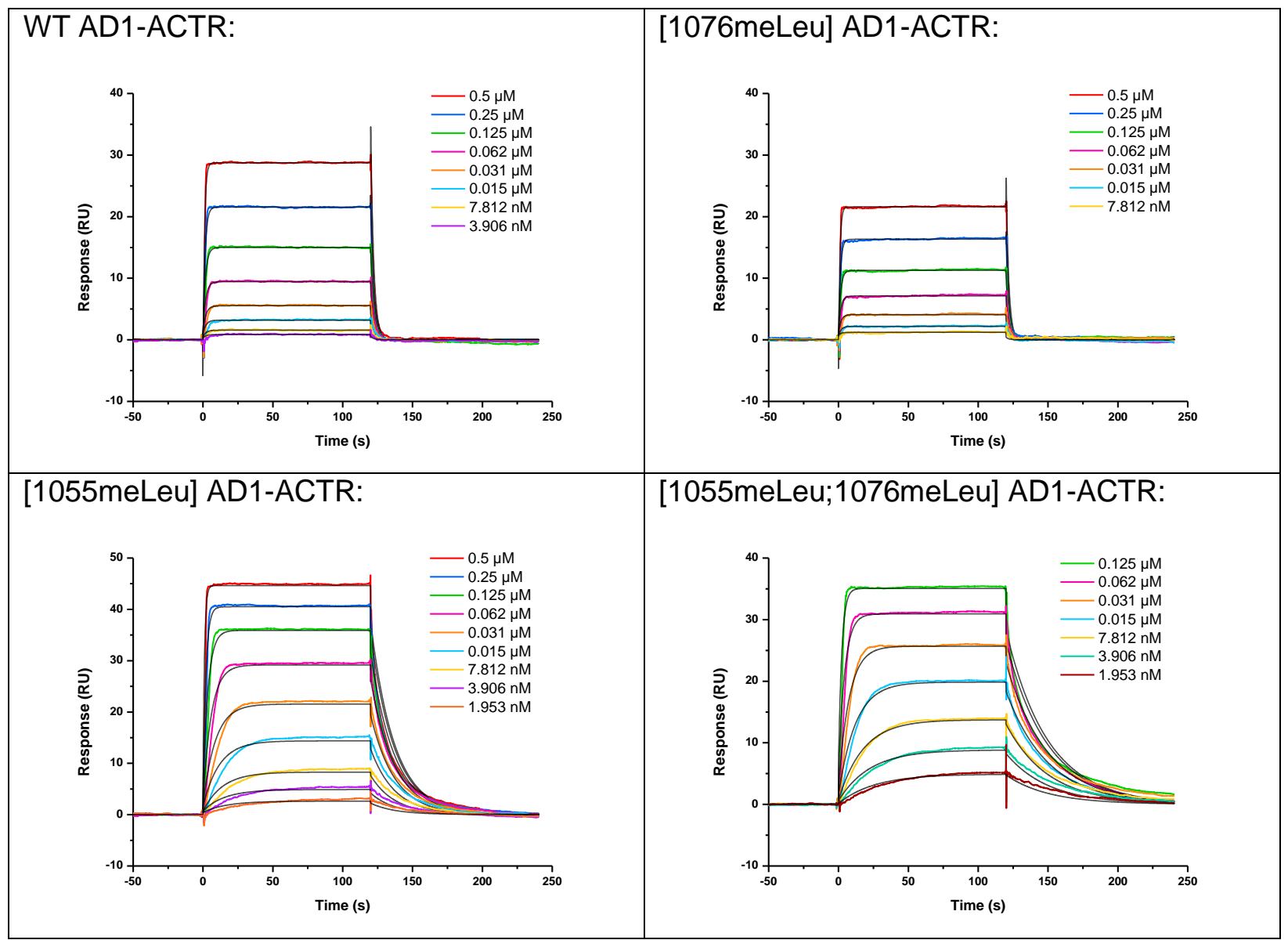


Supplementary Fig. 18: (continued from p. 37) Surface plasmon resonance curves for WT AD1-ACTR, [1055meLeu] AD1-ACTR, [1076meLeu] AD1-ACTR and [1055meLeu;1076meLeu] AD1-ACTR at $31{ }^{\circ} \mathrm{C}$ $(304 \mathrm{~K})$ (curves in black correspond to fitting to 1:1 association model).

\section{Panel 5:}

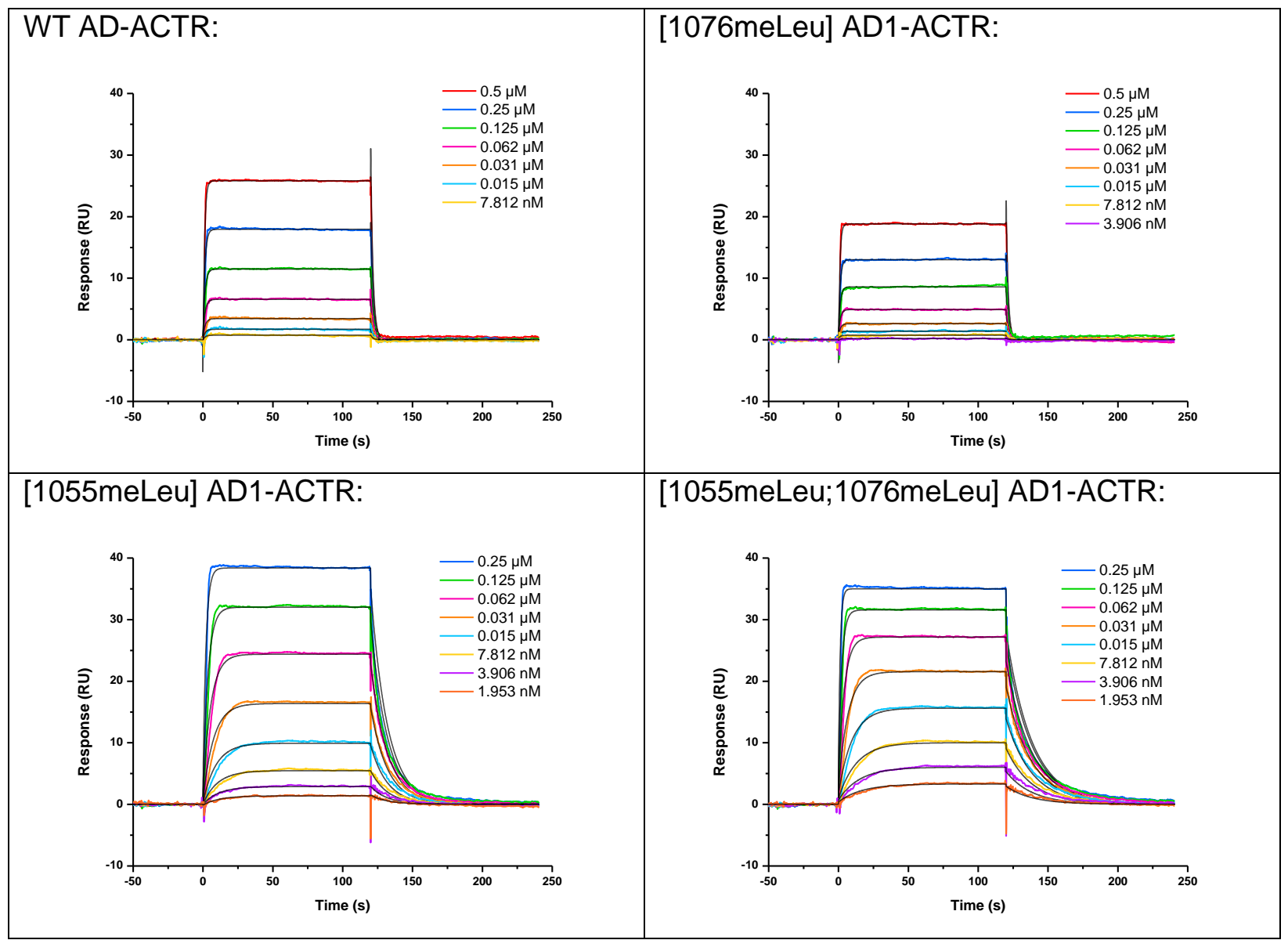


a)

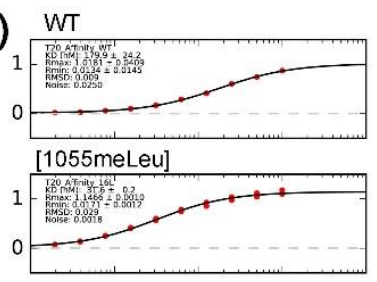

c)

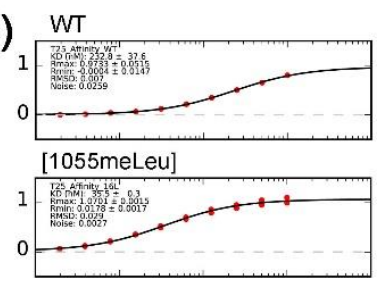

e)

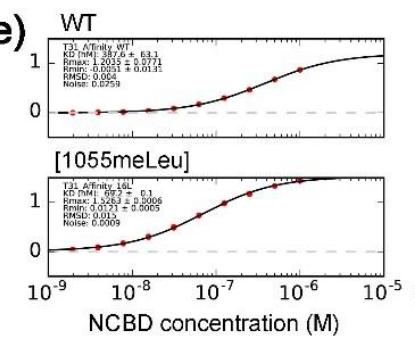

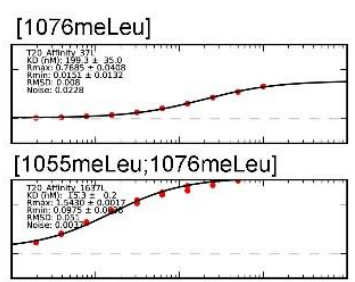

b)
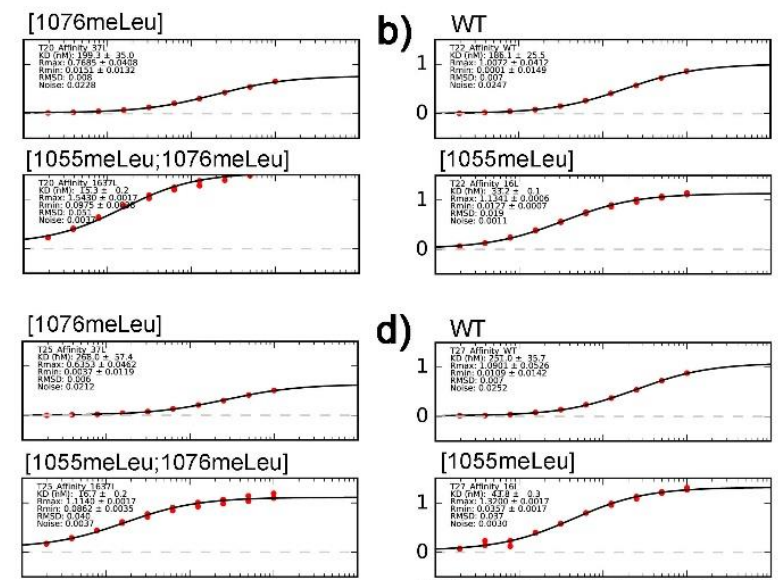

d)
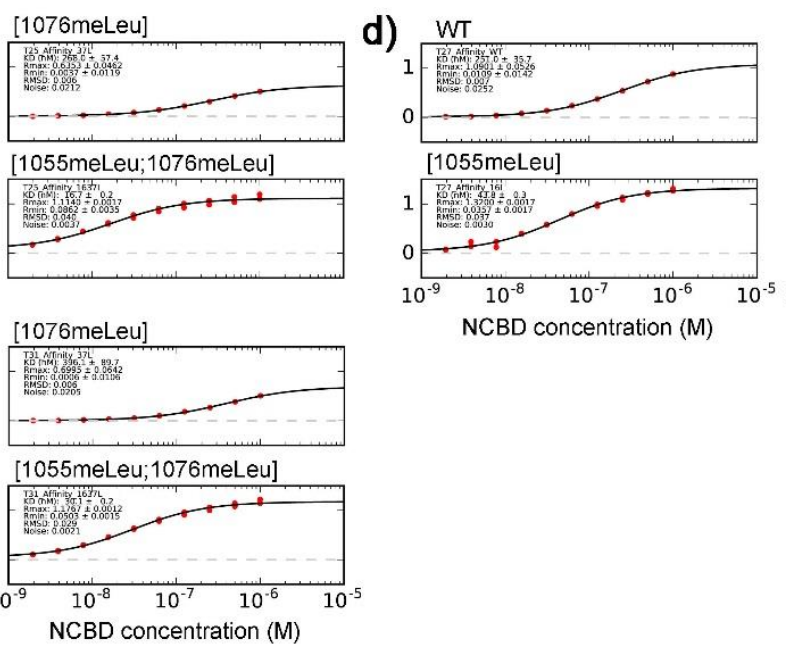
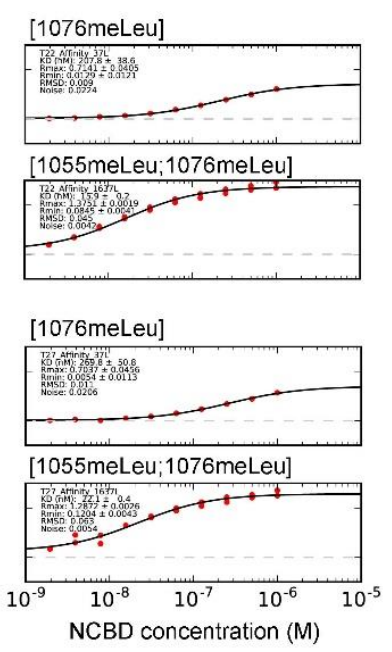

Supplementary Fig. 19: Steady-state analysis of the NCBD binding to four variants of AD1-ACTR (WT, [1076meLeu], [1055meLeu], [1055meLeu;1076meLeu]) at five different temperatures (a) $20^{\circ} \mathrm{C}$, (b) $22{ }^{\circ} \mathrm{C}$, (c) $25^{\circ} \mathrm{C}$, (d) $27{ }^{\circ} \mathrm{C}$ and (e) $31{ }^{\circ} \mathrm{C}$. Normalized equilibrium responses ( $\left.R_{\text {eq }}\right)$ plotted as a function of NCBD concentration and fitted with a 1:1 binding model (see Supplementary Table 16 for values of $\mathrm{K}_{\mathrm{D}}$ and $R_{\max }$ ). 

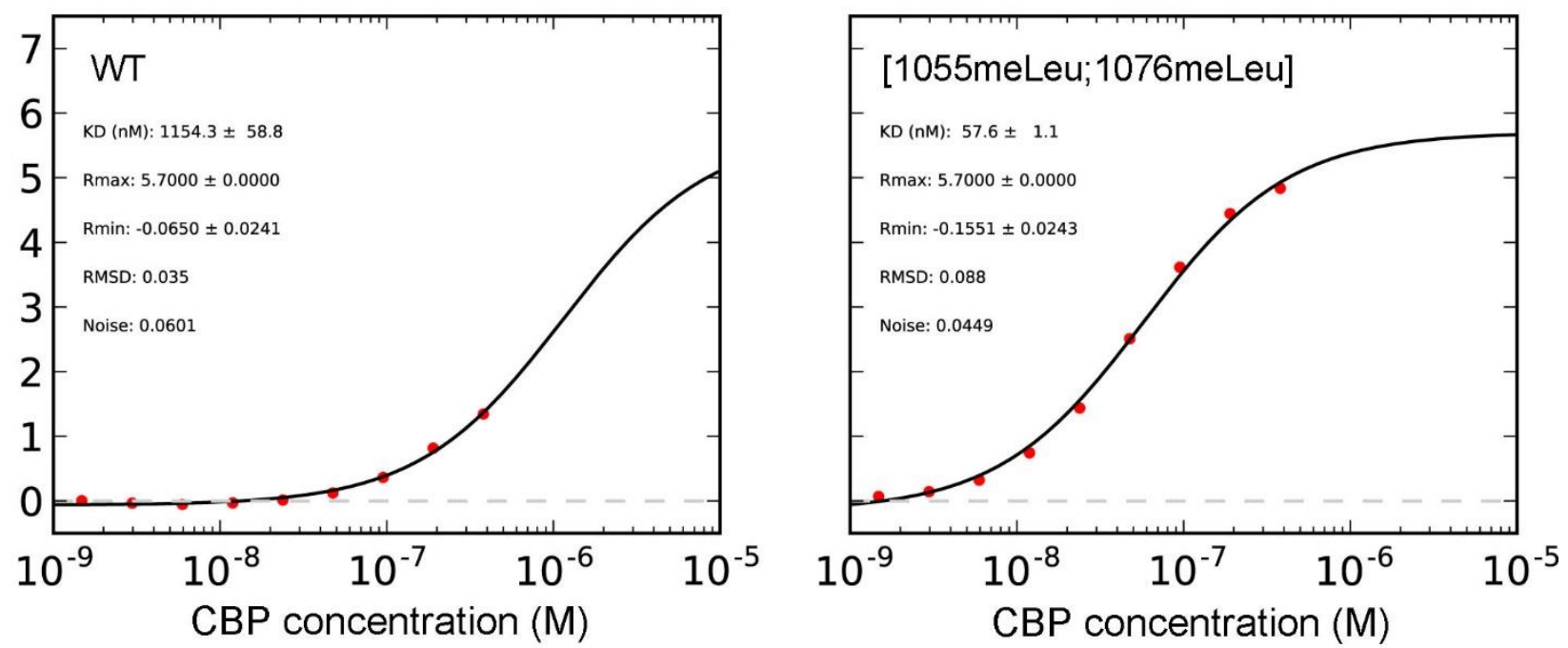

Supplementary Fig. 20: Steady-state analysis of the CBP binding to WT AD1-ACTR and [1055meLeu;1076meLeu] variant at $10{ }^{\circ} \mathrm{C}$. Equilibrium responses $\left(R_{\mathrm{eq}}\right)$ plotted as a function of CBP concentration and fitted using a 1:1 binding model (WT: $\mathrm{K}_{\mathrm{D}}=1154 \pm 59 \mathrm{nM}$; [1055meLeu;1076meLeu] AD1-ACTR: $\left.\mathrm{K}_{\mathrm{D}}=58 \pm 1 \mathrm{nM}\right)$. 


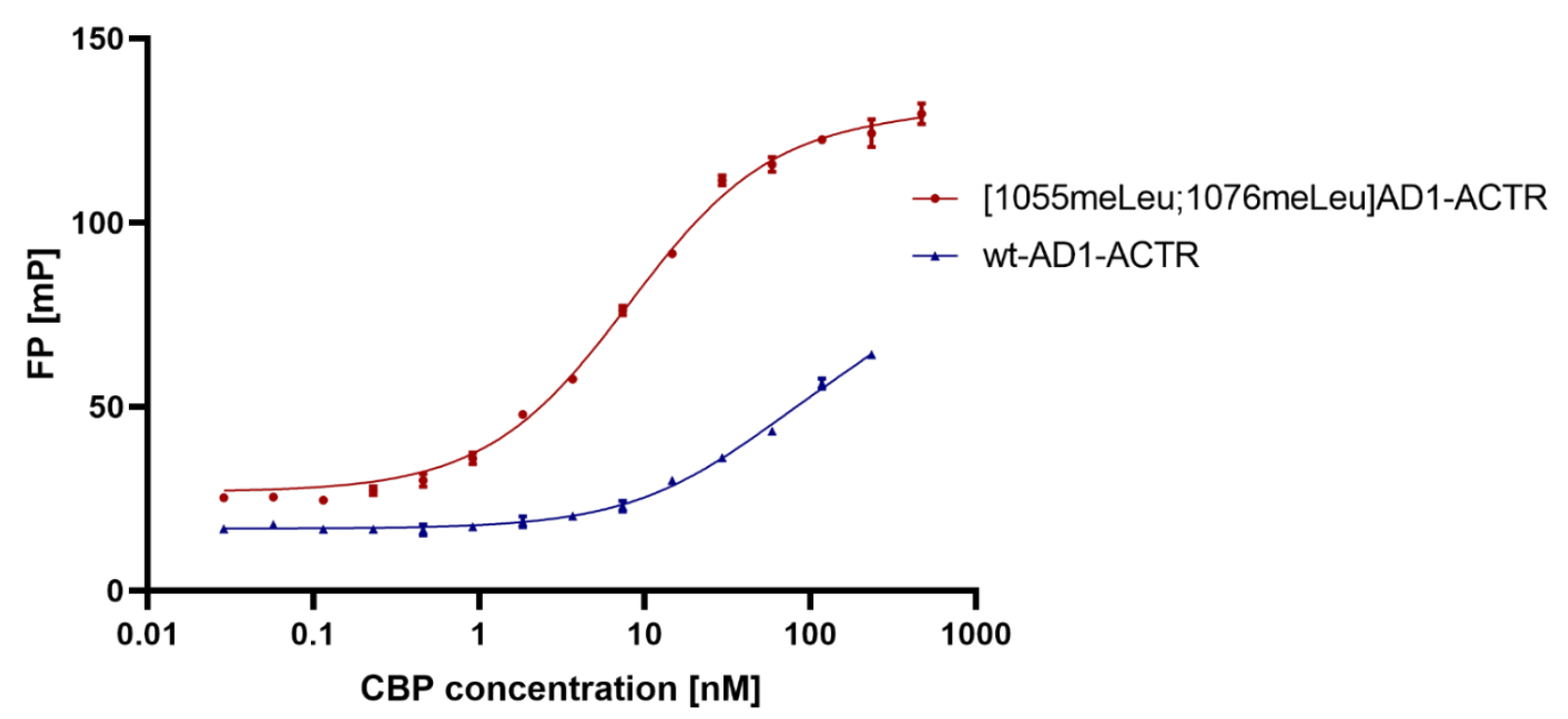

Supplementary Fig. 21: Fluorescent polarization measurements of [1055meLeu;1076meLeu]AD1-ACTR resulted in $\mathrm{K}_{\mathrm{D}}=8.1 \pm 2.5 \mathrm{nM}$, whereas for the WT AD1-ACTR $\mathrm{K}_{\mathrm{D}}$ could not be calculated accurately because of not reaching the saturation but the affinity is definitively significantly lower. The difference in $\mathrm{K}_{\mathrm{D}}$ in the fluorescence polarization and SPR measurements may be explained by differential conditions (FP: $\mathrm{T}=25^{\circ} \mathrm{C}$, buffer: $25 \mathrm{mM}$ Hepes $\mathrm{pH} 7.5,150 \mathrm{mM} \mathrm{NaCl}, 1 \mathrm{mM}$ TCEP, 0.05\% Tween-20, protease inhibitors versus SPR: $\mathrm{T}=10{ }^{\circ} \mathrm{C}$, buffer: $50 \mathrm{mM}$ Tris $\mathrm{pH}$ 7.5, $300 \mathrm{mM} \mathrm{NaCl}, 1 \mathrm{mM}$ TCEP, 0.01\% P20, protease inhibitors). In SPR experiments, higher salt concentration was used to minimize nonspecific binding to the chip surface. 


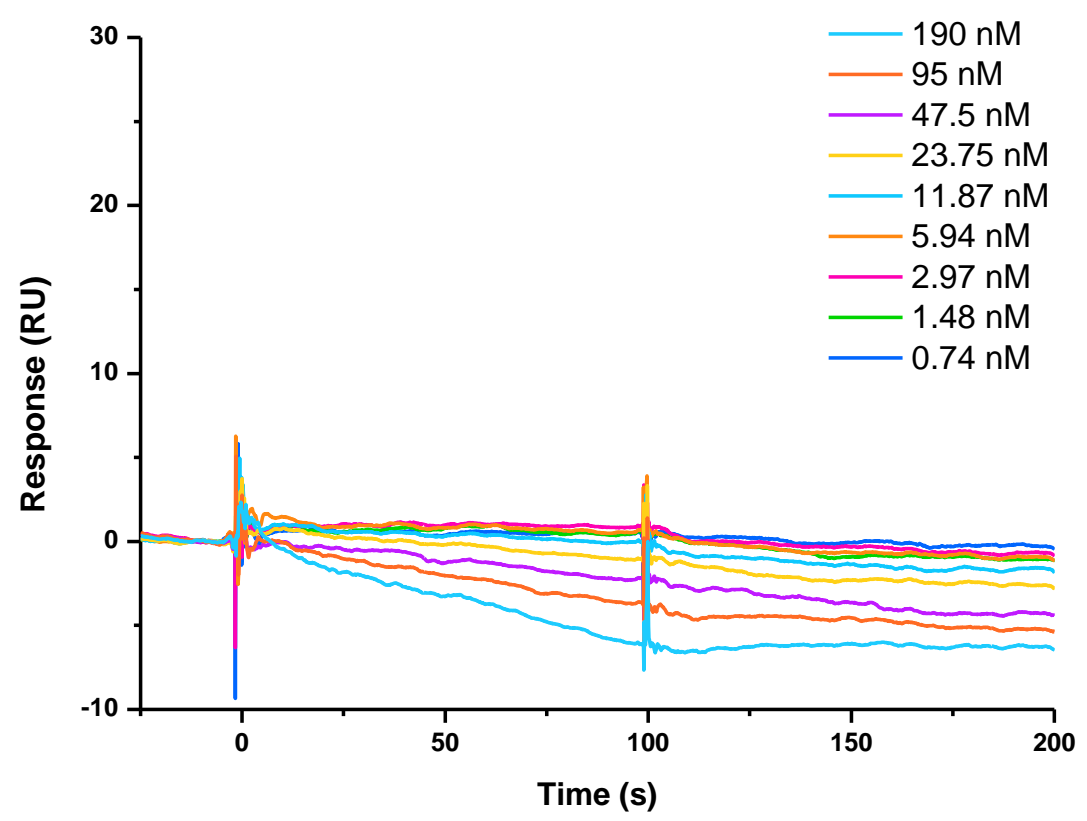

Supplementary Fig. 22: SPR binding sensogram of $270 \mathrm{kDa}$ CBP to [1064meLeu;1071meLeu]AD1ACTR indicating no appreciable binding. Negative signal after subtraction is due to non-specific binding of $\mathrm{CBP}$ at higher concentrations. 


\section{Supplementary Tables}

\section{Supplementary Table 1: Amino acid sequences of the variants of AD1-ACTR studied in this work ${ }^{\#}$}

\begin{tabular}{|c|c|c|}
\hline & Protein & Sequence \\
\hline 1 & wild type (WT) AD1-ACTR & EGQSDERALLDQLHTLLSNTDATGLEEIDRALGIPELVNQGQALEPK \\
\hline 2 & [S1043M;D1050E;T1054Q] $]^{*}$ & EGQMDERALLEQLHTLLSNTDATGLEEIDRALGIPELVNQGQALEPK \\
\hline 3 & {$[\mathrm{~A} 1047 \mathrm{G}]^{*}$} & EGQSDERGLLDQLHTLLSNTDATGLEEIDRALGIPELVNQGQALEPK \\
\hline 4 & {$[1047 \mathrm{~mA}]^{\star *}$} & EGQSDERALLDQLHTLLSNTDATGLEEIDRALGIPELVNQGQALEPK \\
\hline 5 & {$[1048 \mathrm{~mL}]$} & EGQSDERALLDQLHTLLSNTDATGLEEIDRALGIPELVNQGQALEPK \\
\hline 6 & {$[1049 \mathrm{~mL}]$} & EGQSDERALLDQLHTLLSNTDATGLEEIDRALGIPELVNQGQALEPK \\
\hline 7 & {$[1050 \mathrm{mD}]^{* *}$} & EGQSDERALLDQLHTLLSNTDATGLEEIDRALGIPELVNQGQALEPK \\
\hline 8 & {$[1052 \mathrm{~mL}]$} & EGQSDERALLDQLHTLLSNTDATGLEEIDRALGIPELVNQGQALEPK \\
\hline 9 & {$[1055 \mathrm{~mL}]$} & EGQSDERALLDQLHTLLSNTDATGLEEIDRALGIPELVNQGQALEPK \\
\hline 10 & {$[1056 \mathrm{~mL}]$} & EGQSDERALLDQLHTLLSNTDATGLEEIDRALGIPELVNQGQALEPK \\
\hline 11 & {$[1061 \mathrm{~mA}]^{\star *}$} & EGQSDERALLDQLHTLLSNTDATGLEEIDRALGIPELVNQGQALEPK \\
\hline 12 & {$[1064 \mathrm{~mL}]$} & EGQSDERALLDQLHTLLSNTDATGLEEIDRALGIPELVNQGQALEPK \\
\hline 13 & {$[1071 \mathrm{~mL}]^{\star *}$} & EGQSDERALLDQLHTLLSNTDATGLEEIDRALGIPELVNQGQALEPK \\
\hline 14 & {$[1072 \mathrm{~mA}]$} & EGQSDERALLDQLHTLLSNTDATGLEEIDRALGIPELVNQGQALEPK \\
\hline 15 & {$[1076 \mathrm{~mL}]^{\star *}$} & EGQSDERALLDQLHTLLSNTDATGLEEIDRALGIPELVNQGQALEPK \\
\hline 16 & {$[1077 \mathrm{mV}]$} & EGQSDERALLDQLHTLLSNTDATGLEEIDRALGIPELVNQGQALEPK \\
\hline 17 & {$[1080 \mathrm{~mA}]$} & EGQSDERALLDQLHTLLSNTDATGLEEIDRALGIPELVNQGQALEPK \\
\hline 18 & {$[1082 \mathrm{~mA}]$} & EGQSDERALLDQLHTLLSNTDATGLEEIDRALGIPELVNQGQALEPK \\
\hline 19 & {$[1083 \mathrm{~mL}]^{\star \star}$} & EGQSDERALLDQLHTLLSNTDATGLEEIDRALGIPELVNQGQALEPK \\
\hline 20 & {$[1085 \mathrm{mP}]^{\star *}$} & EGQSDERALLDQLHTLLSNTDATGLEEIDRALGIPELVNQGQALEPK \\
\hline 21 & {$[1047 \mathrm{~mA} ; 1071 \mathrm{~mL}]^{\star *}$} & EGQSDERALLDQLHTLLSNTDATGLEEIDRALGIPELVNQGQALEPK \\
\hline 22 & {$[1047 \mathrm{~mA} ; 1072 \mathrm{~mA}]$} & EGQSDERALLDQLHTLLSNTDATGLEEIDRALGIPELVNQGQALEPK \\
\hline 23 & {$[1047 \mathrm{~mA} ; 1076 \mathrm{~mL}]^{\star *}$} & EGQSDERALLDQLHTLLSNTDATGLEEIDRALGIPELVNQGQALEPK \\
\hline 24 & {$[1047 \mathrm{~mA} ; 1077 \mathrm{mV}]$} & EGQSDERALLDQLHTLLSNTDATGLEEIDRALGIPELVNQGQALEPK \\
\hline 25 & {$[1047 \mathrm{~mA} ; 1083 \mathrm{~mL}]^{\star *}$} & EGQSDERALLDQLHTLLSNTDATGLEEIDRALGIPELVNQGQALEPK \\
\hline 26 & {$[1048 \mathrm{~mL} ; 1076 \mathrm{~mL}]$} & EGQSDERALLDQLHTLLSNTDATGLEEIDRALGIPELVNQGQALEPK \\
\hline 27 & {$[1048 \mathrm{~mL} ; 1077 \mathrm{mV}]$} & EGQSDERALLDQLHTLLSNTDATGLEEIDRALGIPELVNQGQALEPK \\
\hline 28 & {$[1048 \mathrm{~mL} ; 1083 \mathrm{~mL}]$} & EGQSDERALLDQLHTLLSNTDATGLEEIDRALGIPELVNQGQALEPK \\
\hline 29 & {$[1050 \mathrm{mD} ; 1071 \mathrm{~mL}]$} & EGQSDERALLDQLHTLLSNTDATGLEEIDRALGIPELVNQGQALEPK \\
\hline 30 & {$[1050 \mathrm{mD} ; 1072 \mathrm{~mA}]$} & EGQSDERALLDQLHTLLSNTDATGLEEIDRALGIPELVNQGQALEPK \\
\hline 31 & {$[1050 \mathrm{mD} ; 1076 \mathrm{~mL}]$} & EGQSDERALLDQLHTLLSNTDATGLEEIDRALGIPELVNQGQALEPK \\
\hline 32 & {$[1050 \mathrm{mD} ; 1077 \mathrm{mV}]$} & EGQSDERALLDQLHTLLSNTDATGLEEIDRALGIPELVNQGQALEPK \\
\hline 33 & {$[1050 \mathrm{mD} ; 1083 \mathrm{~mL}]^{* *}$} & EGQSDERALLDQLHTLLSNTDATGLEEIDRALGIPELVNQGQALEPK \\
\hline 34 & {$[1055 \mathrm{~mL} ; 1076 \mathrm{~mL}]$} & EGQSDERALLDQLHTLLSNTDATGLEEIDRALGIPELVNQGQALEPK \\
\hline 35 & {$[1061 \mathrm{~mA} ; 1071 \mathrm{~mL}]$} & EGQSDERALLDQLHTLLSNTDATGLEEIDRALGIPELVNQGQALEPK \\
\hline 36 & {$[1061 \mathrm{~mA} ; 1076 \mathrm{~mL}]^{* *}$} & EGQSDERALLDQLHTLLSNTDATGLEEIDRALGIPELVNQGQALEPK \\
\hline 37 & {$[1061 \mathrm{~mA} ; 1077 \mathrm{mV}]$} & EGQSDERALLDQLHTLLSNTDATGLEEIDRALGIPELVNQGQALEPK \\
\hline 38 & {$[1061 \mathrm{~mA} ; 1083 \mathrm{~mL}]^{* *}$} & EGQSDERALLDQLHTLLSNTDATGLEEIDRALGIPELVNQGQALEPK \\
\hline 39 & {$[1064 \mathrm{~mL} ; 1071 \mathrm{~mL}]$} & EGQSDERALLDQLHTLLSNTDATGLEEIDRALGIPELVNQGQALEPK \\
\hline 40 & {$[1064 \mathrm{~mL} ; 1076 \mathrm{~mL}]$} & EGQSDERALLDQLHTLLSNTDATGLEEIDRALGIPELVNQGQALEPK \\
\hline 41 & {$[1064 \mathrm{~mL} ; 1077 \mathrm{mV}]$} & EGQSDERALLDQLHTLLSNTDATGLEEIDRALGIPELVNQGQALEPK \\
\hline 42 & {$[1064 \mathrm{~mL} ; 1083 \mathrm{~mL}]$} & EGQSDERALLDQLHTLLSNTDATGLEEIDRALGIPELVNQGQALEPK \\
\hline 43 & {$[1047 \mathrm{~mA} ; 1055 \mathrm{~mL} ; 1061 \mathrm{~mA}]$} & EGQSDERALLDQLHTLLSNTDATGLEEIDRALGIPELVNQGQALEPK \\
\hline 44 & {$[1055 \mathrm{~mL} ; 1076 \mathrm{~mL} ; 1083 \mathrm{~mL}]$} & EGQSDERALLDQLHTLLSNTDATGLEEIDRALGIPELVNQGQALEPK \\
\hline 45 & {$[1047 \mathrm{~mA} ; 1050 \mathrm{mD} ; 1061 \mathrm{~mA} ; 1076 \mathrm{~mL}]$} & EGQSDERALLDQLHTLLSNTDATGLEEIDRALGIPELVNQGQALEPK \\
\hline 46 & {$[1047 \mathrm{~mA} ; 1055 \mathrm{~mL} ; 1061 \mathrm{~mA} ; 1076 \mathrm{~mL}]$} & EGQSDERALLDQLHTLLSNTDATGLEEIDRALGIPELVNQGQALEPK \\
\hline 47 & {$[1047 \mathrm{~mA} ; 1055 \mathrm{~mL} ; 1076 \mathrm{~mL} ; 1083 \mathrm{~mL}]$} & EGQSDERALLDQLHTLLSNTDATGLEEIDRALGIPELVNQGQALEPK \\
\hline 48 & {$[1047 \mathrm{~mA} ; 1061 \mathrm{~mA} ; 1076 \mathrm{~mL} ; 1083 \mathrm{~mL}]$} & EGQSDERALLDQLHTLLSNTDATGLEEIDRALGIPELVNQGQALEPK \\
\hline 49 & {$[1047 \mathrm{~mA} ; 1055 \mathrm{~mL} ; 1061 \mathrm{~mA} ; 1076 \mathrm{~mL} ; 1083 \mathrm{~mL}]$} & EGQSDERALLDQLHTLLSNTDATGLEEIDRALGIPELVNQGQALEPK \\
\hline 50 & {$[1047 \mathrm{~mA} ; 1055 \mathrm{~mL} ; 1061 \mathrm{~mA} ; 1076 \mathrm{~mL} ; 1083 \mathrm{~mL} ; 1085 \mathrm{mP}]$} & EGQSDERALLDQLHTLLSNTDATGLEEIDRALGIPELVNQGQALEPK \\
\hline 51 & NCBD & SALQDLLRTLKSPSSPQQQQQVLNILKSNPQLNIeAAFIKQRTAKYVAN*** \\
\hline
\end{tabular}

\# Residues in red are a-methylated;

* These sequences correspond to protein variants with canonical amino acids incorporated to modify the helix propensity: lešmantavičius et al. Angew. Chem. Int. Ed. 2014, 53, 1548-1551. We synthesized these protein variants and included them in our study to compare their properties with a-methylated analogues;

** These variants were reported in our previous communication: Schmidtgall et al. Chem. Commun. 2017, 53, 7369-7372;

${ }^{* * *} \mathrm{Nle}=$ norleucine in the sequence replaces Met being nearly isosteric to the native residue and resistant to oxidation. 
Supplementary Table 2: Characterization of synthesized proteins by mass-spectrometry**

\begin{tabular}{|c|c|c|}
\hline Protein & Measured mass [Da] & Calculated mass [Da] \\
\hline [S1043M;D1050E;T1054Q] & 5184.9 & 5184.8 \\
\hline [A1047G] & 5085.1 & 5085.6 \\
\hline$[1048 \mathrm{~mL}]$ & 5113.7 & 5113.6 \\
\hline [1049mL] & 5113.6 & 5113.6 \\
\hline$[1052 \mathrm{~mL}]$ & 5113.6 & 5113.6 \\
\hline$[1055 \mathrm{~mL}]$ & 5113.6 & 5113.6 \\
\hline$[1056 \mathrm{~mL}]$ & 5113.6 & 5113.6 \\
\hline$[1064 \mathrm{~mL}]$ & 5112.6 & 5113.6 \\
\hline$[1072 \mathrm{~mA}]$ & 5128.3 & 5127.6 \\
\hline [1077mV] & 5114.6 & 5113.6 \\
\hline$[1080 \mathrm{~mA}]$ & 5127.9 & 5127.6 \\
\hline$[1082 \mathrm{~mA}]$ & 5113.8 & 5113.6 \\
\hline [1047mA;1072mA] & 5142.2 & 5141.6 \\
\hline [1047mA;1077mV] & 5128.0 & 5127.6 \\
\hline$[1048 \mathrm{~mL} ; 1076 \mathrm{~mL}]$ & 5127.6 & 5127.6 \\
\hline$[1048 \mathrm{~mL} ; 1077 \mathrm{mV}]$ & 5127.6 & 5127.6 \\
\hline$[1048 \mathrm{~mL} ; 1083 \mathrm{~mL}]$ & 5127.6 & 5127.6 \\
\hline$[1050 \mathrm{mD} ; 1071 \mathrm{~mL}]$ & 5127.5 & 5127.6 \\
\hline$[1050 \mathrm{mD} ; 1072 \mathrm{~mA}]$ & 5141.4 & 5141.6 \\
\hline$[1050 \mathrm{mD} ; 1076 \mathrm{~mL}]$ & 5127.5 & 5127.6 \\
\hline$[1050 \mathrm{mD} ; 1077 \mathrm{mV}]$ & 5126.6 & 5127.6 \\
\hline$[1055 \mathrm{~mL} ; 1076 \mathrm{~mL}]$ & 5127.6 & 5127.6 \\
\hline$[1061 \mathrm{~mA} ; 1071 \mathrm{~mL}]$ & 5128.8 & 5127.6 \\
\hline$[1061 \mathrm{~mA} ; 1077 \mathrm{mV}]$ & 5127.9 & 5127.6 \\
\hline$[1064 \mathrm{~mL} ; 1071 \mathrm{~mL}]$ & 5127.6 & 5127.6 \\
\hline$[1064 \mathrm{~mL} ; 1076 \mathrm{~mL}]$ & 5127.1 & 5127.6 \\
\hline$[1064 \mathrm{~mL} ; 1077 \mathrm{mV}]$ & 5127.9 & 5127.6 \\
\hline$[1064 \mathrm{~mL} ; 1083 \mathrm{~mL}]$ & 5128.3 & 5127.6 \\
\hline$[1047 \mathrm{~mA} ; 1055 \mathrm{~mL} ; 1061 \mathrm{~mA}]$ & 5141.6 & 5141.6 \\
\hline$[1055 \mathrm{~mL} ; 1076 \mathrm{~mL} ; 1083 \mathrm{~mL}]$ & 5141.0 & 5141.6 \\
\hline$[1047 \mathrm{~mA} ; 1050 \mathrm{mD} ; 1061 \mathrm{~mA} ; 1076 \mathrm{~mL}]$ & 5155.7 & 5155.7 \\
\hline [1047mA;1055mL;1061mA;1076mL] & 5155.0 & 5155.7 \\
\hline$[1047 \mathrm{~mA} ; 1055 \mathrm{~mL} ; 1076 \mathrm{~mL} ; 1083 \mathrm{~mL}]$ & 5155.7 & 5155.7 \\
\hline$[1047 \mathrm{~mA} ; 1061 \mathrm{~mA} ; 1076 \mathrm{~mL} ; 1083 \mathrm{~mL}]$ & 5155.5 & 5155.7 \\
\hline$[1047 \mathrm{~mA} ; 1055 \mathrm{~mL} ; 1061 \mathrm{~mA} ; 1076 \mathrm{~mL} ; 1083 \mathrm{~mL}]$ & 5169.7 & 5169.7 \\
\hline [1047mA;1055mL;1061mA;1076mL;1083mL;1085mP] & 5183.7 & 5183.7 \\
\hline WT-AD1-ACTR-GGG-(PEG) ${ }_{3}-\mathrm{K}($ Biotin)-amide* & 5826.5 & 5827.5 \\
\hline [1055mL]AD1-ACTR-GGG-(PEG) ${ }_{3}-\mathrm{K}($ Biotin)-amide* & 5841.3 & 5841.5 \\
\hline [1076mL]AD1-ACTR-GGG-(PEG) ${ }_{3}-\mathrm{K}$ (Biotin)-amide* & 5841.7 & 5841.5 \\
\hline [1055mL;1076mL]AD1-ACTR-GGG-(PEG) ${ }_{3}-K($ Biotin)-amide* & 5854.9 & 5855.5 \\
\hline [1064mL;1071mL]AD1-ACTR-GGG-(PEG) ${ }_{3}-\mathrm{K}$ (Biotin)-amide* & 5854.2 & 5855.5 \\
\hline Fluo-(PEG) ${ }_{5}-$ WT-AD1-ACTR ${ }^{*}$ & 5879.3 & 5880.5 \\
\hline Fluo-(PEG)5-[1055meLeu;1076meLeu]-AD1-ACTR* ${ }^{*}$ & 5907.3 & 5908.5 \\
\hline
\end{tabular}

* The exact chemical structures for '(PEG) ${ }_{3}$ ' and 'Fluo-(PEG) $)_{5}$ ' are provided on p.3 of Supplementary Materials and Methods;

${ }^{* *}$ Analytical characterization of the variants marked with two asterisks $\left({ }^{* *}\right)$ in Table 1 is not listed here and reported in our previous communication: Schmidtgall et al. Chem. Commun. 2017, 53, 7369-7372. 
Supplementary Table 3: Thermodynamic parameters of binding of AD1-ACTR variants to NCBD obtained by isothermal titration calorimetry (ITC)*

\begin{tabular}{|c|c|c|c|c|c|}
\hline & Protein & $\begin{array}{c}\mathrm{K}_{\mathrm{d}} \\
{[\mu \mathrm{M}]}\end{array}$ & $\begin{array}{c}\Delta \mathrm{G} \\
{\left[\mathrm{kcal} \mathrm{mol}{ }^{-1}\right]}\end{array}$ & $\begin{array}{c}\Delta \mathrm{H} \\
{\left[\mathrm{kcal} \mathrm{mol}^{-1}\right]}\end{array}$ & $\begin{array}{c}-\mathrm{T} \Delta \mathrm{S} \\
{\left[\mathrm{kcal} \mathrm{mol}{ }^{-1}\right]}\end{array}$ \\
\hline 1 & wild type (WT) AD1-ACTR ${ }^{* \star}$ & 0.206 & -9.30 & -12.7 & 3.40 \\
\hline 2 & [S1043M;D1050E;T1054Q] & 0.188 & -9.36 & -13.7 & 4.29 \\
\hline 3 & [A1047G] & 0.844 & -8.45 & -13.8 & 5.33 \\
\hline 4 & {$[1047 \mathrm{~mA}]^{\star \star}$} & 0.145 & -9.51 & -11.8 & 2.29 \\
\hline 5 & {$[1048 \mathrm{~mL}]$} & 0.281 & -9.12 & -12.2 & 3.04 \\
\hline 6 & {$[1049 \mathrm{~mL}]$} & 0.806 & -8.48 & -14.8 & 6.32 \\
\hline 7 & {$[1050 \mathrm{mD}]^{\star *}$} & 0.800 & -8.48 & -11.7 & 3.22 \\
\hline 8 & {$[1052 \mathrm{~mL}]$} & 0.634 & -8.63 & -12.1 & 3.52 \\
\hline 9 & {$[1055 \mathrm{~mL}]$} & 0.075 & -9.91 & -18.7 & 8.78 \\
\hline 10 & {$[1056 \mathrm{~mL}]$} & 2.60 & -7.77 & -9.07 & 1.30 \\
\hline 11 & {$[1061 \mathrm{~mA}]^{* *}$} & 0.327 & -9.02 & -13.6 & 4.58 \\
\hline 12 & {$[1064 \mathrm{~mL}]$} & 1.34 & -8.17 & -12.6 & 4.43 \\
\hline 13 & {$[1071 \mathrm{~mL}]^{\star *}$} & 7.11 & -7.16 & -5.58 & -1.58 \\
\hline 14 & {$[1072 \mathrm{~mA}]$} & 0.144 & -9.52 & -11.8 & 2.30 \\
\hline 15 & {$[1076 \mathrm{~mL}]^{* *}$} & 0.206 & -9.30 & -15.0 & 5.70 \\
\hline 16 & {$[1077 \mathrm{mV}]$} & 0.347 & -8.99 & -20.5 & 11.5 \\
\hline 17 & {$[1080 \mathrm{~mA}]$} & 0.496 & -8.77 & -19.4 & 10.7 \\
\hline 18 & {$[1082 \mathrm{~mA}]$} & 0.518 & -8.75 & -18.3 & 9.58 \\
\hline 19 & {$[1083 \mathrm{~mL}]^{\star *}$} & 0.520 & -8.74 & -13.1 & 4.36 \\
\hline 20 & {$[1085 \mathrm{mP}]^{* *}$} & 0.487 & -8.78 & -14.8 & 6.02 \\
\hline 21 & {$[1047 \mathrm{~mA} ; 1071 \mathrm{~mL}]^{* *}$} & 5.11 & -7.36 & -5.18 & -2.18 \\
\hline 22 & {$[1047 \mathrm{~mA} ; 1072 \mathrm{~mA}]$} & 0.569 & -8.69 & -15.2 & 6.51 \\
\hline 23 & {$[1047 \mathrm{~mA} ; 1076 \mathrm{~mL}]^{* *}$} & 0.055 & -10.1 & -13.2 & 3.10 \\
\hline 24 & {$[1047 \mathrm{~mA} ; 1077 \mathrm{mV}]$} & 0.311 & -9.06 & -18.9 & 9.88 \\
\hline 25 & {$[1047 \mathrm{~mA} ; 1083 \mathrm{~mL}]^{* *}$} & 0.166 & -9.43 & -11.5 & 2.07 \\
\hline 26 & {$[1048 \mathrm{~mL} ; 1076 \mathrm{~mL}]$} & 0.301 & -9.08 & -15.9 & 6.79 \\
\hline 27 & {$[1048 \mathrm{~mL} ; 1077 \mathrm{mV}]$} & 0.483 & -8.79 & -14.4 & 5.59 \\
\hline 28 & {$[1048 \mathrm{~mL} ; 1083 \mathrm{~mL}]$} & 0.788 & -8.49 & -13.4 & 4.97 \\
\hline 29 & {$[1050 \mathrm{mD} ; 1071 \mathrm{~mL}]$} & 4.99 & -7.37 & -4.20 & -3.18 \\
\hline 30 & {$[1050 \mathrm{mD} ; 1072 \mathrm{~mA}]$} & 0.798 & -8.49 & -14.3 & 5.86 \\
\hline 31 & {$[1050 \mathrm{mD} ; 1076 \mathrm{~mL}]$} & 0.659 & -8.60 & -17.1 & 8.46 \\
\hline 32 & {$[1050 \mathrm{mD} ; 1077 \mathrm{mV}]$} & 0.595 & -8.66 & -16.5 & 7.81 \\
\hline 33 & {$[1050 \mathrm{mD} ; 1083 \mathrm{~mL}]^{\star *}$} & 0.614 & -8.64 & -11.7 & 3.06 \\
\hline 34 & {$[1055 \mathrm{~mL} ; 1076 \mathrm{~mL}]$} & 0.042 & -10.3 & -20.4 & 10.1 \\
\hline 35 & [1061mA;1071mL] & 3.37 & -7.62 & -6.50 & -1.12 \\
\hline 36 & {$[1061 \mathrm{~mA} ; 1076 \mathrm{~mL}]^{\star *}$} & 0.180 & -9.38 & -16.3 & 6.92 \\
\hline 37 & {$[1061 \mathrm{~mA} ; 1077 \mathrm{mV}]$} & 0.236 & -9.22 & -19.2 & 9.96 \\
\hline 38 & {$[1061 \mathrm{~mA} ; 1083 \mathrm{~mL}]^{\star *}$} & 0.277 & -9.12 & -15.3 & 6.18 \\
\hline 39 & {$[1064 \mathrm{~mL} ; 1071 \mathrm{~mL}]$} & 6.05 & -7.26 & -2.20 & -5.06 \\
\hline 40 & {$[1064 \mathrm{~mL} ; 1076 \mathrm{~mL}]$} & 0.796 & -8.49 & -15.4 & 6.94 \\
\hline 41 & {$[1064 \mathrm{~mL} ; 1077 \mathrm{mV}]$} & 0.829 & -8.46 & -15.2 & 6.69 \\
\hline 42 & {$[1064 \mathrm{~mL} ; 1083 \mathrm{~mL}]$} & 1.60 & -8.07 & -13.3 & 5.20 \\
\hline 43 & {$[1047 \mathrm{~mA} ; 1055 \mathrm{~mL} ; 1061 \mathrm{~mA}]$} & 0.177 & -9.40 & -20.2 & 10.8 \\
\hline 44 & {$[1055 \mathrm{~mL} ; 1076 \mathrm{~mL} ; 1083 \mathrm{~mL}]$} & 0.042 & -10.3 & -20.3 & 10.0 \\
\hline 45 & {$[1047 \mathrm{~mA} ; 1050 \mathrm{mD} ; 1061 \mathrm{~mA} ; 1076 \mathrm{~mL}]$} & 0.221 & -9.20 & -18.1 & 8.91 \\
\hline 46 & {$[1047 \mathrm{~mA} ; 1055 \mathrm{~mL} ; 1061 \mathrm{~mA} ; 1076 \mathrm{~mL}]$} & 0.136 & -9.56 & -21.6 & 12.0 \\
\hline 47 & {$[1047 \mathrm{~mA} ; 1055 \mathrm{~mL} ; 1076 \mathrm{~mL} ; 1083 \mathrm{~mL}]$} & 0.298 & -9.07 & -16.8 & 7.71 \\
\hline 48 & {$[1047 \mathrm{~mA} ; 1061 \mathrm{~mA} ; 1076 \mathrm{~mL} ; 1083 \mathrm{~mL}]$} & 0.155 & -9.48 & -18.6 & 9.16 \\
\hline 49 & {$[1047 \mathrm{~mA} ; 1055 \mathrm{~mL} ; 1061 \mathrm{~mA} ; 1076 \mathrm{~mL} ; 1083 \mathrm{~mL}]$} & 0.090 & -9.80 & -21.8 & 12.0 \\
\hline 50 & {$[1047 \mathrm{~mA} ; 1055 \mathrm{~mL} ; 1061 \mathrm{~mA} ; 1076 \mathrm{~mL} ; 1083 \mathrm{~mL} ; 1085 \mathrm{mP}]$} & 0.108 & -9.70 & -20.5 & 10.8 \\
\hline
\end{tabular}

* The ITC data for 13 analogues marked with two asterisks $\left(^{* *}\right)$ was published in our previous communication: Schmidtgall et al. Chem. Commun. 2017, 53, 7369-7372. 
Supplementary Table 4: Apparent melting points of AD1-ACTR/NCBD complexes (CD-monitored)

\begin{tabular}{lc}
\hline AD1-ACTR variant complexed with NCBD & $T_{\mathrm{m}}\left[{ }^{\circ} \mathrm{C}\right]$ \\
\hline WT & 69 \\
{$[1071 \mathrm{~mL}]$} & 50 \\
{$[1047 \mathrm{~mA} ; 1071 \mathrm{~mL}]$} & 50 \\
{$[$ A1047G] } & 67 \\
{$[1050 \mathrm{mD}]$} & 67 \\
{$[1056 \mathrm{~mL}]$} & 66 \\
{$[1047 \mathrm{~mA} ; 1076 \mathrm{~mL}]$} & 73 \\
{$[$ S1043M;D1050E;T1054Q] } & 74 \\
{$[1055 \mathrm{~mL}]$} & $>85$ \\
{$[1055 \mathrm{~mL} ; 1076 \mathrm{~mL}]$} & $>85$ \\
{$[1047 \mathrm{~mA} ; 1061 \mathrm{~mA} ; 1076 \mathrm{~mL} ; 1083 \mathrm{~mL}]$} & $>85$ \\
{$[1047 \mathrm{~mA} ; 1055 \mathrm{~mL} ; 1061 \mathrm{~mA} ; 1076 \mathrm{~mL} ; 1083 \mathrm{~mL}]$} & $>85$ \\
{$[1047 \mathrm{~mA} ; 1055 \mathrm{~mL} ; 1061 \mathrm{~mA} ; 1076 \mathrm{~mL} ; 1083 \mathrm{~mL} ; 1086 \mathrm{mP}]$} & $>85$ \\
\hline
\end{tabular}


Supplementary Table 5: Ratios of ellipticities in CD spectra of AD1-ACTR variants

\begin{tabular}{|c|c|c|}
\hline & Protein & $\theta_{222} / \theta_{199}$ \\
\hline$\overline{1}$ & WT AD1-ACTR & 0.23 \\
\hline 2 & [S1043M;D1050E;T1054Q] & 0.33 \\
\hline 3 & [A1047G] & 0.20 \\
\hline 4 & {$[1047 \mathrm{~mA}]^{\star *}$} & 0.23 \\
\hline 5 & {$[1048 \mathrm{~mL}]$} & 0.30 \\
\hline 6 & {$[1049 \mathrm{~mL}]$} & 0.28 \\
\hline 7 & {$[1050 \mathrm{mD}]^{\star *}$} & 0.26 \\
\hline 8 & {$[1052 \mathrm{~mL}]$} & 0.31 \\
\hline 9 & {$[1055 \mathrm{~mL}]$} & 0.44 \\
\hline 10 & {$[1056 \mathrm{~mL}]$} & 0.26 \\
\hline 11 & {$[1061 \mathrm{~mA}]^{\star *}$} & 0.24 \\
\hline 12 & {$[1064 \mathrm{~mL}]$} & 0.25 \\
\hline 13 & {$[1071 \mathrm{~mL}]^{* *}$} & 0.24 \\
\hline 14 & {$[1072 \mathrm{~mA}]$} & 0.26 \\
\hline 15 & {$[1076 \mathrm{~mL}]^{\star *}$} & 0.27 \\
\hline 16 & {$[1077 \mathrm{mV}]$} & 0.29 \\
\hline 17 & {$[1080 \mathrm{~mA}]$} & 0.24 \\
\hline 18 & {$[1082 \mathrm{~mA}]$} & 0.25 \\
\hline 19 & {$[1083 \mathrm{~mL}]^{\star \star}$} & 0.26 \\
\hline 20 & {$[1085 \mathrm{mP}]^{* *}$} & 0.25 \\
\hline 21 & {$[1047 \mathrm{~mA} ; 1071 \mathrm{~mL}]^{\star \star}$} & 0.26 \\
\hline 22 & {$[1047 \mathrm{~mA} ; 1072 \mathrm{~mA}]$} & 0.24 \\
\hline 23 & {$[1047 \mathrm{~mA} ; 1076 \mathrm{~mL}]^{\star *}$} & 0.28 \\
\hline 24 & {$[1047 \mathrm{~mA} ; 1077 \mathrm{mV}]$} & 0.29 \\
\hline 25 & {$[1047 \mathrm{~mA} ; 1083 \mathrm{~mL}]^{* *}$} & 0.25 \\
\hline 26 & {$[1048 \mathrm{~mL} ; 1076 \mathrm{~mL}]$} & 0.34 \\
\hline 27 & {$[1048 \mathrm{~mL} ; 1077 \mathrm{mV}]$} & 0.37 \\
\hline 28 & [1048mL;1083mL] & 0.28 \\
\hline 29 & {$[1050 \mathrm{mD} ; 1071 \mathrm{~mL}]$} & 0.21 \\
\hline 30 & {$[1050 \mathrm{mD} ; 1072 \mathrm{~mA}]$} & 0.23 \\
\hline 31 & {$[1050 \mathrm{mD} ; 1076 \mathrm{~mL}]$} & 0.23 \\
\hline 32 & {$[1050 \mathrm{mD} ; 1077 \mathrm{mV}]$} & 0.24 \\
\hline 33 & {$[1050 \mathrm{mD} ; 1083 \mathrm{~mL}]^{\star *}$} & 0.27 \\
\hline 34 & {$[1055 \mathrm{~mL} ; 1076 \mathrm{~mL}]$} & 0.40 \\
\hline 35 & {$[1061 \mathrm{~mA} ; 1071 \mathrm{~mL}]$} & 0.25 \\
\hline 36 & {$[1061 \mathrm{~mA} ; 1076 \mathrm{~mL}]^{* *}$} & 0.31 \\
\hline 37 & {$[1061 \mathrm{~mA} ; 1077 \mathrm{mV}]$} & 0.30 \\
\hline 38 & {$[1061 \mathrm{~mA} ; 1083 \mathrm{~mL}]^{\star \star}$} & 0.25 \\
\hline 39 & {$[1064 \mathrm{~mL} ; 1071 \mathrm{~mL}]$} & 0.26 \\
\hline 40 & {$[1064 \mathrm{~mL} ; 1076 \mathrm{~mL}]$} & 0.28 \\
\hline 41 & [1064mL;1077mV] & 0.33 \\
\hline 42 & {$[1064 \mathrm{~mL} ; 1083 \mathrm{~mL}]$} & 0.23 \\
\hline 43 & {$[1047 \mathrm{~mA} ; 1055 \mathrm{~mL} ; 1061 \mathrm{~mA}]$} & 0.48 \\
\hline 44 & {$[1055 \mathrm{~mL} ; 1076 \mathrm{~mL} ; 1083 \mathrm{~mL}]$} & 0.50 \\
\hline 45 & {$[1047 \mathrm{~mA} ; 1050 \mathrm{mD} ; 1061 \mathrm{~mA} ; 1076 \mathrm{~mL}]$} & 0.29 \\
\hline 46 & {$[1047 \mathrm{~mA} ; 1055 \mathrm{~mL} ; 1061 \mathrm{~mA} ; 1076 \mathrm{~mL}]$} & 0.57 \\
\hline 47 & {$[1047 \mathrm{~mA} ; 1055 \mathrm{~mL} ; 1076 \mathrm{~mL} ; 1083 \mathrm{~mL}]$} & 0.63 \\
\hline 48 & {$[1047 \mathrm{~mA} ; 1061 \mathrm{~mA} ; 1076 \mathrm{~mL} ; 1083 \mathrm{~mL}]$} & 0.29 \\
\hline 49 & {$[1047 \mathrm{~mA} ; 1055 \mathrm{~mL} ; 1061 \mathrm{~mA} ; 1076 \mathrm{~mL} ; 1083 \mathrm{~mL}]$} & 0.61 \\
\hline 50 & {$[1047 \mathrm{~mA} ; 1055 \mathrm{~mL} ; 1061 \mathrm{~mA} ; 1076 \mathrm{~mL} ; 1083 \mathrm{~mL} ; 1085 \mathrm{mP}]$} & 0.75 \\
\hline
\end{tabular}

** The CD spectra for these analogues were previously published in our preceding communication: Schmidtgall et al. Chem. Commun. 2017, 53, 7369-7372. 


\section{Supplementary Table 6: Ratios of ellipticities in CD spectra of AD1-ACTR variants complexes with NCBD}

\begin{tabular}{|c|c|c|}
\hline & Protein complex & $\theta_{222} / \theta_{208}$ \\
\hline 1 & WT AD1-ACTR / NCBD & 0.949 \\
\hline 2 & [S1043M;D1050E;T1054Q] / NCBD & 0.948 \\
\hline 3 & [A1047G] / NCBD & 0.924 \\
\hline 4 & {$[1047 \mathrm{~mA}] / \mathrm{NCBD}^{* *}$} & 0.964 \\
\hline 5 & {$[1048 \mathrm{~mL}] /$ NCBD } & 0.953 \\
\hline 6 & [1049mL] / NCBD & 0.944 \\
\hline 7 & {$[1050 \mathrm{mD}] / \mathrm{NCBD}^{\star *}$} & 0.934 \\
\hline 8 & [1052mL] / NCBD & 0.941 \\
\hline 9 & {$[1055 \mathrm{~mL}] /$ NCBD } & 0.960 \\
\hline 10 & {$[1056 \mathrm{~mL}] /$ NCBD } & 0.922 \\
\hline 11 & {$[1061 \mathrm{~mA}] / \mathrm{NCBD}^{* *}$} & 0.949 \\
\hline 12 & {$[1064 \mathrm{~mL}] /$ NCBD } & 0.935 \\
\hline 13 & {$[1071 \mathrm{~mL}] / \mathrm{NCBD}^{* *}$} & 0.889 \\
\hline 14 & {$[1072 \mathrm{~mA}] /$ NCBD } & 0.939 \\
\hline 15 & {$[1076 \mathrm{~mL}] / / \mathrm{NCBD}{ }^{* *}$} & 1.00 \\
\hline 16 & {$[1077 \mathrm{mV}] /$ NCBD } & 0.932 \\
\hline 17 & {$[1080 \mathrm{~mA}] / \mathrm{NCBD}$} & 0.968 \\
\hline 18 & {$[1082 \mathrm{~mA}] /$ NCBD } & 0.963 \\
\hline 19 & {$[1083 \mathrm{~mL}] / / \mathrm{NCBD}{ }^{* *}$} & 0.968 \\
\hline 20 & {$[1085 \mathrm{mP}] / \mathrm{NCBD}^{* *}$} & 0.975 \\
\hline 21 & {$[1047 \mathrm{~mA} ; 1071 \mathrm{~mL}] / \mathrm{NCBD}^{* *}$} & 0.893 \\
\hline 22 & {$[1047 \mathrm{~mA} ; 1072 \mathrm{~mA}] /$ NCBD } & 0.959 \\
\hline 23 & {$[1047 \mathrm{~mA} ; 1076 \mathrm{~mL}] / \mathrm{NCBD}^{* *}$} & 1.02 \\
\hline 24 & [1047mA;1077mV] / NCBD & 0.987 \\
\hline 25 & {$[1047 \mathrm{~mA} ; 1083 \mathrm{~mL}] / \mathrm{NCBD}^{* *}$} & 0.924 \\
\hline 26 & {$[1048 \mathrm{~mL} ; 1076 \mathrm{~mL}] /$ NCBD } & 0.974 \\
\hline 27 & {$[1048 \mathrm{~mL} ; 1077 \mathrm{mV}] /$ NCBD } & 0.977 \\
\hline 28 & {$[1048 \mathrm{~mL} ; 1083 \mathrm{~mL}] /$ NCBD } & 0.943 \\
\hline 29 & {$[1050 \mathrm{mD} ; 1071 \mathrm{~mL}] /$ NCBD } & 0.944 \\
\hline 30 & {$[1050 \mathrm{mD} ; 1072 \mathrm{~mA}] /$ NCBD } & 0.943 \\
\hline 31 & {$[1050 \mathrm{mD} ; 1076 \mathrm{~mL}] /$ NCBD } & 0.979 \\
\hline 32 & {$[1050 \mathrm{mD} ; 1077 \mathrm{mV}] /$ NCBD } & 0.981 \\
\hline 33 & {$[1050 \mathrm{mD} ; 1083 \mathrm{~mL}] / \mathrm{NCBD}^{\star *}$} & 0.980 \\
\hline 34 & {$[1055 \mathrm{~mL} ; 1076 \mathrm{~mL}] /$ NCBD } & 0.949 \\
\hline 35 & {$[1061 \mathrm{~mA} ; 1071 \mathrm{~mL}] /$ NCBD } & 0.900 \\
\hline 36 & {$[1061 \mathrm{~mA} ; 1076 \mathrm{~mL}] / \mathrm{NCBD}^{* *}$} & 0.989 \\
\hline 37 & [1061mA;1077mV] / NCBD & 0.993 \\
\hline 38 & {$[1061 \mathrm{~mA} ; 1083 \mathrm{~mL}] / \mathrm{NCBD}^{* *}$} & 0.981 \\
\hline 39 & {$[1064 \mathrm{~mL} ; 1071 \mathrm{~mL}] /$ NCBD } & 0.882 \\
\hline 40 & {$[1064 \mathrm{~mL} ; 1076 \mathrm{~mL}] /$ NCBD } & 0.973 \\
\hline 41 & {$[1064 \mathrm{~mL} ; 1077 \mathrm{mV}] /$ NCBD } & 0.953 \\
\hline 42 & {$[1064 \mathrm{~mL} ; 1083 \mathrm{~mL}] /$ NCBD } & 0.938 \\
\hline 43 & {$[1047 \mathrm{~mA} ; 1055 \mathrm{~mL} ; 1061 \mathrm{~mA}] /$ NCBD } & 0.973 \\
\hline 44 & {$[1055 \mathrm{~mL} ; 1076 \mathrm{~mL} ; 1083 \mathrm{~mL}] /$ NCBD } & 1.02 \\
\hline 45 & {$[1047 \mathrm{~mA} ; 1050 \mathrm{mD} ; 1061 \mathrm{~mA} ; 1076 \mathrm{~mL}] /$ NCBD } & 1.01 \\
\hline 46 & {$[1047 \mathrm{~mA} ; 1055 \mathrm{~mL} ; 1061 \mathrm{~mA} ; 1076 \mathrm{~mL}] /$ NCBD } & 0.996 \\
\hline 47 & {$[1047 \mathrm{~mA} ; 1055 \mathrm{~mL} ; 1076 \mathrm{~mL} ; 1083 \mathrm{~mL}] / \mathrm{NCBD}$} & 0.965 \\
\hline 48 & {$[1047 \mathrm{~mA} ; 1061 \mathrm{~mA} ; 1076 \mathrm{~mL} ; 1083 \mathrm{~mL}] /$ NCBD } & 0.986 \\
\hline 49 & {$[1047 \mathrm{~mA} ; 1055 \mathrm{~mL} ; 1061 \mathrm{~mA} ; 1076 \mathrm{~mL} ; 1083 \mathrm{~mL}] /$ NCBD } & 0.990 \\
\hline 50 & {$[1047 \mathrm{~mA} ; 1055 \mathrm{~mL} ; 1061 \mathrm{~mA} ; 1076 \mathrm{~mL} ; 1083 \mathrm{~mL} ; 1085 \mathrm{mP}] /$ NCBD } & 0.994 \\
\hline
\end{tabular}

** The CD spectra for these analogues were previously published in our preceding communication: Schmidtgall et al. Chem. Commun. 2017, 53, 7369-7372. 
Supplementary Table 7: Chemical shifts (ppm) for wild type [1040-1086]-fragment of AD1-ACTR measured on a $700 \mathrm{MHz}$ spectrometer used to calculate secondary chemical shifts

\begin{tabular}{|c|c|c|c|c|}
\hline Residue number & Residue type & $\mathrm{Ha}$ & $\mathrm{Ca}$ & $C \beta$ \\
\hline 1040 & $E$ & not determined & not determined & \begin{tabular}{|l|} 
not determined \\
\end{tabular} \\
\hline 1041 & $G$ & 4.008 & 45.136 & not present \\
\hline 1042 & $Q$ & 4.415 & 55.818 & 29.566 \\
\hline 1043 & $\mathrm{~S}$ & 4.441 & 58.257 & 63.699 \\
\hline 1044 & $\mathrm{D}$ & 4.611 & 54.425 & 41.175 \\
\hline 1045 & $E$ & 4.188 & 57.569 & 29.878 \\
\hline 1046 & $R$ & 4.205 & 56.889 & 30.325 \\
\hline 1047 & $A$ & 4.249 & 53.193 & 18.778 \\
\hline 1048 & $\mathrm{~L}$ & 4.262 & 55.807 & not assigned \\
\hline 1049 & $\mathrm{~L}$ & 4.230 & 56.089 & not assigned \\
\hline 1050 & $\mathrm{D}$ & 4.537 & 55.082 & 40.978 \\
\hline 1051 & $Q$ & 4.275 & 56.359 & 29.160 \\
\hline 1052 & $\mathrm{~L}$ & 4.251 & 55.927 & not assigned \\
\hline 1053 & $\mathrm{H}$ & 4.573 & 57.182 & 30.926 \\
\hline 1054 & $\mathrm{~T}$ & 4.227 & 62.600 & 69.496 \\
\hline 1055 & $\mathrm{~L}$ & 4.363 & 55.206 & not assigned \\
\hline 1056 & $\mathrm{~L}$ & 4.363 & 55.240 & not assigned \\
\hline 1057 & $S$ & 4.447 & 58.437 & 63.746 \\
\hline 1058 & $\mathrm{~N}$ & 4.803 & 53.316 & 38.898 \\
\hline 1059 & $\mathrm{~T}$ & 4.341 & 61.985 & 69.592 \\
\hline 1060 & $\mathrm{D}$ & 4.615 & 54.391 & 41.134 \\
\hline 1061 & $\mathrm{~A}$ & 4.381 & 52.635 & 19.113 \\
\hline 1062 & $\mathrm{~T}$ & 4.295 & 62.508 & 69.849 \\
\hline 1063 & $G$ & 3.980 & 45.452 & not present \\
\hline 1064 & $\mathrm{~L}$ & 4.340 & 54.830 & not assigned \\
\hline 1065 & $E$ & 4.244 & 57.036 & 30.158 \\
\hline 1066 & $E$ & 4.264 & 56.773 & 30.150 \\
\hline 1067 & I & 4.100 & 61.515 & 38.933 \\
\hline 1068 & $D$ & 4.563 & 54.650 & 41.001 \\
\hline 1069 & $R$ & 4.233 & 56.581 & 30.527 \\
\hline 1070 & $A$ & 4.274 & 52.797 & 18.824 \\
\hline 1071 & $\mathrm{~L}$ & 4.300 & 55.270 & not assigned \\
\hline 1072 & $G$ & 3.880 & 45.108 & not present \\
\hline 1073 & I & 4.443 & 58.970 & 38.389 \\
\hline 1074 & $P$ & 4.374 & 63.692 & 32.081 \\
\hline 1075 & $E$ & 4.211 & 56.942 & 30.196 \\
\hline 1076 & $\mathrm{~L}$ & 4.344 & 55.247 & not assigned \\
\hline 1077 & $\mathrm{~V}$ & 4.077 & 62.512 & 32.748 \\
\hline 1078 & $\mathrm{~N}$ & 4.692 & 53.267 & 38.769 \\
\hline 1079 & $Q$ & 4.305 & 56.228 & 29.229 \\
\hline 1080 & $G$ & 3.944 & 45.391 & not present \\
\hline 1081 & $Q$ & 4.324 & 55.657 & 29.646 \\
\hline 1082 & $A$ & 4.313 & 52.366 & 19.063 \\
\hline 1083 & $\mathrm{~L}$ & 4.336 & 55.593 & not assigned \\
\hline 1084 & $E$ & 4.580 & 54.229 & 29.933 \\
\hline 1085 & $\mathrm{P}$ & 4.413 & 63.335 & 31.919 \\
\hline 1086 & $\mathrm{~K}$ & 4.169 & 57.434 & \begin{tabular}{|l|}
33.957 \\
\end{tabular} \\
\hline
\end{tabular}


Supplementary Table 8: Chemical shifts (ppm) for [1055meLeu] variant of [1040-1086]-fragment of AD1ACTR measured on a $700 \mathrm{MHz}$ spectrometer used to calculate secondary chemical shifts

\begin{tabular}{|c|c|c|c|c|}
\hline Residue number & Residue type & $\mathrm{Ha}$ & $\mathrm{Ca}$ & $C \beta$ \\
\hline 1040 & $\mathrm{E}$ & not determined & not determined & not determined \\
\hline 1041 & G & 4.042 & 45.134 & not present \\
\hline 1042 & Q & 4.408 & 55.897 & 29.548 \\
\hline 1043 & $\mathrm{~S}$ & 4.442 & 58.500 & 63.6830 \\
\hline 1044 & $\mathrm{D}$ & 4.609 & 54.442 & 41.172 \\
\hline 1045 & $\mathrm{E}$ & 4.165 & 57.827 & 29.870 \\
\hline 1046 & $\mathrm{R}$ & 4.181 & 57.143 & 30.2490 \\
\hline 1047 & A & 4.245 & 53.484 & 18.660 \\
\hline 1048 & $\mathrm{~L}$ & 4.225 & 56.209 & not assigned \\
\hline 1049 & $\mathrm{~L}$ & 4.195 & 56.332 & not assigned \\
\hline 1050 & $\mathrm{D}$ & 4.524 & 55.631 & 40.899 \\
\hline 1051 & Q & 4.181 & 56.383 & 28.904 \\
\hline 1052 & $\mathrm{~L}$ & 4.186 & 56.372 & not assigned \\
\hline 1053 & $\mathrm{H}$ & 4.483 & 58.010 & 30.642 \\
\hline 1054 & $\mathrm{~T}$ & 4.062 & 64.236 & 69.290 \\
\hline 1055 & $\mathrm{~mL}$ (meLeu) & $\mathrm{n} / \mathrm{a}$ & $\mathrm{n} / \mathrm{a}$ & $\begin{array}{l}\alpha-\mathrm{CH}_{3}(\mathrm{C}: 23.79 \mathrm{ppm} ; \\
\mathrm{H} 1.501 \mathrm{ppm}), \text { Leu } \\
\text { side chain not as- } \\
\text { signed }\end{array}$ \\
\hline 1056 & $\mathrm{~L}$ & 4.195 & 56.391 & not assigned \\
\hline 1057 & $\mathrm{~s}$ & 4.381 & 59.288 & 63.586 \\
\hline 1058 & $\mathrm{~N}$ & 4.834 & 53.341 & 39.066 \\
\hline 1059 & $\mathrm{~T}$ & 4.359 & 62.149 & 69.749 \\
\hline 1060 & D & 4.617 & 54.388 & 41.116 \\
\hline 1061 & A & 4.368 & 52.709 & 19.131 \\
\hline 1062 & $\mathrm{~T}$ & 4.283 & 62.625 & 69.805 \\
\hline 1063 & G & 3.979 & 45.498 & not present \\
\hline 1064 & $\mathrm{~L}$ & 4.400 & 54.823 & not assigned \\
\hline 1065 & $\mathrm{E}$ & 4.229 & 57.167 & 30.144 \\
\hline 1066 & $\mathrm{E}$ & 4.257 & 56.834 & 30.096 \\
\hline 1067 & 1 & 4.085 & 61.599 & 38.890 \\
\hline 1068 & D & 4.552 & 54.748 & 41.000 \\
\hline 1069 & $\mathrm{R}$ & 4.224 & 56.624 & 30.508 \\
\hline 1070 & A & 4.269 & 52.845 & 18.843 \\
\hline 1071 & $\mathrm{~L}$ & 4.296 & 55.278 & not assigned \\
\hline 1072 & $\mathrm{G}$ & 3.868 & 45.112 & not present \\
\hline 1073 & 1 & 4.432 & 59.036 & 38.355 \\
\hline 1074 & $\mathrm{P}$ & 4.369 & 63.746 & 32.068 \\
\hline 1075 & $\mathrm{E}$ & 4.205 & 57.003 & 30.185 \\
\hline 1076 & $\mathrm{~L}$ & 4.355 & 55.258 & not assigned \\
\hline 1077 & $\mathrm{~V}$ & 4.072 & 62.530 & 32.741 \\
\hline 1078 & $\mathrm{~N}$ & 4.690 & 53.280 & 38.716 \\
\hline 1079 & Q & 4.302 & 56.257 & 29.222 \\
\hline 1080 & G & 3.943 & 45.396 & not present \\
\hline 1081 & Q & 4.322 & 55.679 & 29.633 \\
\hline 1082 & $\mathrm{~A}$ & 4.311 & 52.376 & 19.078 \\
\hline 1083 & $\mathrm{~L}$ & 4.333 & 55.298 & not assigned \\
\hline 1084 & $\mathrm{E}$ & 4.578 & 54.238 & 29.933 \\
\hline 1085 & $\mathrm{P}$ & 4.412 & 63.325 & 31.925 \\
\hline 1086 & $\mathrm{~K}$ & 4.167 & 57.419 & 33.957 \\
\hline
\end{tabular}


Supplementary Table 9: Chemical shifts (ppm) for [1055meLeu;1076meLeu] variant of [1040-1086]-fragment of AD1-ACTR measured on a $700 \mathrm{MHz}$ spectrometer used to calculate secondary chemical shifts

\begin{tabular}{|c|c|c|c|c|}
\hline Residue number & Residue type & $\mathrm{Ha}$ & $\mathrm{Ca}$ & $C \beta$ \\
\hline 1040 & $E$ & not determined & not determined & not determined \\
\hline 1041 & $G$ & 4.029 & 45.138 & not present \\
\hline 1042 & $Q$ & 4.414 & 55.848 & 29.561 \\
\hline 1043 & $\mathrm{~S}$ & 4.445 & 58.469 & 63.703 \\
\hline 1044 & D & 4.612 & 54.437 & 41.158 \\
\hline 1045 & $E$ & 4.164 & 57.857 & 29.856 \\
\hline 1046 & $\mathrm{R}$ & 4.178 & 57.160 & 30.239 \\
\hline 1047 & A & 4.244 & 53.514 & 18.641 \\
\hline 1048 & $\mathrm{~L}$ & 4.223 & 56.303 & not assigned \\
\hline 1049 & $\mathrm{~L}$ & 4.184 & 56.433 & not assigned \\
\hline 1050 & $\mathrm{D}$ & 4.522 & 55.732 & 40.867 \\
\hline 1051 & $Q$ & 4.173 & 56.432 & 28.905 \\
\hline 1052 & $\mathrm{~L}$ & 4.181 & 56.434 & not assigned \\
\hline 1053 & $\mathrm{H}$ & 4.466 & 58.159 & 30.675 \\
\hline 1054 & $T$ & 4.045 & 64.419 & 69.241 \\
\hline 1055 & $\mathrm{~mL}$ (meLeu) & $\mathrm{n} / \mathrm{a}$ & $\mathrm{n} / \mathrm{a}$ & $\begin{array}{l}\alpha-\mathrm{CH}_{3}(\mathrm{C}: 23.68 \mathrm{ppm} ; \mathrm{H}: \\
1.500 \mathrm{pm}), \text { Leu side chain } \\
\text { not assigned }\end{array}$ \\
\hline 1056 & $\mathrm{~L}$ & 4.177 & 56.436 & not assigned \\
\hline 1057 & $S$ & 4.380 & 59.356 & 63.580 \\
\hline 1058 & $\mathrm{~N}$ & 4.838 & 53.321 & 39.102 \\
\hline 1059 & $T$ & 4.361 & 62.150 & 69.740 \\
\hline 1060 & $\mathrm{D}$ & 4.619 & 54.381 & 41.114 \\
\hline 1061 & A & 4.362 & 52.768 & 19.112 \\
\hline 1062 & $\mathrm{~T}$ & 4.280 & 62.671 & 69.787 \\
\hline 1063 & $G$ & 3.978 & 45.503 & not present \\
\hline 1064 & $\mathrm{~L}$ & 4.334 & 54.843 & not assigned \\
\hline 1065 & $E$ & 4.224 & 57.241 & 30.110 \\
\hline 1066 & $E$ & 4.253 & 56.884 & 30.111 \\
\hline 1067 & $\mathrm{I}$ & 4.077 & 61.677 & 38.868 \\
\hline 1068 & $\mathrm{D}$ & 4.548 & 54.802 & 41.018 \\
\hline 1069 & $\mathrm{R}$ & 4.217 & 56.689 & 30.498 \\
\hline 1070 & A & 4.269 & 52.905 & 18.831 \\
\hline 1071 & $\mathrm{~L}$ & 4.300 & 55.302 & not assigned \\
\hline 1072 & $\mathrm{G}$ & 3.880 & 45.149 & not present \\
\hline 1073 & $\mathrm{I}$ & 4.408 & 59.205 & 38.289 \\
\hline 1074 & $\mathrm{P}$ & 4.397 & 63.589 & 32.083 \\
\hline 1075 & $E$ & 4.133 & 57.820 & 29.891 \\
\hline 1076 & $\mathrm{~mL}$ (meLeu) & $\mathrm{n} / \mathrm{a}$ & $\mathrm{n} / \mathrm{a}$ & $\begin{array}{l}\alpha-\mathrm{CH}_{3}(\mathrm{C}: 24.54 \mathrm{ppm} ; \mathrm{H}: \\
1.444 \mathrm{ppm}), \text { Leu side chain } \\
\text { not assigned }\end{array}$ \\
\hline 1077 & $\mathrm{~V}$ & 3.928 & 63.806 & 32.180 \\
\hline 1078 & $\mathrm{~N}$ & 4.704 & 53.641 & 38.847 \\
\hline 1079 & $\mathrm{Q}$ & 4.307 & 56.411 & 29.133 \\
\hline 1080 & $G$ & 3.956 & 45.506 & not present \\
\hline 1081 & $Q$ & 4.327 & 55.685 & 29.600 \\
\hline 1082 & A & 4.315 & 52.357 & 19.093 \\
\hline 1083 & $\mathrm{~L}$ & 4.329 & 55.363 & not assigned \\
\hline 1084 & $\mathrm{E}$ & 4.578 & 54.226 & 29.935 \\
\hline 1085 & $P$ & 4.411 & 63.330 & 31.929 \\
\hline 1086 & $\mathrm{~K}$ & 4.169 & 57.430 & 33.962 \\
\hline
\end{tabular}


Supplementary Table 10: The ${ }^{13} \mathrm{C} \alpha$ spin-lattice $\mathrm{R}_{1}$ relaxation rates $\left(\mathrm{s}^{-1}\right)$ for wild type AD1-ACTR, [1055meLeu] and [1055meLeu;1076meLeu] variants

\begin{tabular}{|c|c|c|c|c|c|c|}
\hline & \multicolumn{2}{|c|}{ WT AD1-ACTR } & \multicolumn{2}{|c|}{ [1055meLeu] } & \multicolumn{2}{|c|}{ [1055meLeu;1076meLeu] } \\
\hline Residue & $\mathrm{R}_{1}$ & uncertainty & $\mathrm{R}_{1}$ & uncertainty & $\mathrm{R}_{1}$ & uncertainty \\
\hline 1040 & $\mathrm{~N} / \mathrm{A}$ & $\mathrm{N} / \mathrm{A}$ & $\mathrm{N} / \mathrm{A}$ & $\mathrm{N} / \mathrm{A}$ & $\mathrm{N} / \mathrm{A}$ & $\mathrm{N} / \mathrm{A}$ \\
\hline 1041 & $\mathrm{~N} / \mathrm{A}$ & $\mathrm{N} / \mathrm{A}$ & $\mathrm{N} / \mathrm{A}$ & $\mathrm{N} / \mathrm{A}$ & $\mathrm{N} / \mathrm{A}$ & $\mathrm{N} / \mathrm{A}$ \\
\hline 1042 & 2.29 & 1.15 & 2.40 & 1.56 & 2.53 & 1.15 \\
\hline 1043 & 2.22 & 0.832 & 2.23 & 0.647 & 2.44 & 1.44 \\
\hline 1044 & 2.38 & 0.882 & 2.30 & 0.836 & 2.49 & 1.80 \\
\hline 1045 & 2.50 & 1.41 & 2.11 & 0.864 & 1.96 & 1.02 \\
\hline 1046 & 2.49 & 1.76 & 2.56 & 1.36 & 2.17 & 1.01 \\
\hline 1047 & 2.35 & 0.772 & 2.27 & 0.579 & 2.42 & 1.27 \\
\hline 1048 & 2.55 & 0.870 & 1.65 & 0.405 & 1.90 & 0.80 \\
\hline 1049 & 2.47 & 1.04 & 2.40 & 0.953 & 2.17 & 1.29 \\
\hline 1050 & 2.25 & 0.839 & 2.45 & 1.43 & 2.44 & 1.45 \\
\hline 1051 & 2.48 & 0.887 & 1.94 & 1.21 & 2.37 & 1.49 \\
\hline 1052 & 2.26 & 1.13 & 2.37 & 0.507 & 2.00 & 1.17 \\
\hline 1053 & 2.31 & 0.579 & 2.22 & 1.15 & 2.71 & 0.853 \\
\hline 1054 & 2.36 & 0.777 & 2.41 & 1.05 & 2.50 & 1.47 \\
\hline 1055 & 2.26 & 1.61 & $\mathrm{~N} / \mathrm{A}$ & $\mathrm{N} / \mathrm{A}$ & $\mathrm{N} / \mathrm{A}$ & $\mathrm{N} / \mathrm{A}$ \\
\hline 1056 & 2.40 & 1.59 & 2.40 & 0.953 & 2.10 & 1.04 \\
\hline 1057 & 2.32 & 1.16 & 2.21 & 1.06 & 2.18 & 1.23 \\
\hline 1058 & 2.33 & 0.871 & 2.18 & 1.06 & 2.28 & 1.60 \\
\hline 1059 & 2.41 & 1.12 & 2.12 & 1.46 & 2.53 & 1.40 \\
\hline 1060 & 2.46 & 0.842 & 2.32 & 1.04 & 2.30 & 1.21 \\
\hline 1061 & 2.14 & 1.01 & 2.29 & 0.894 & 2.18 & 1.14 \\
\hline 1062 & 2.25 & 1.04 & 2.08 & 0.875 & 2.14 & 1.57 \\
\hline 1063 & $\mathrm{~N} / \mathrm{A}$ & $\mathrm{N} / \mathrm{A}$ & $\mathrm{N} / \mathrm{A}$ & $\mathrm{N} / \mathrm{A}$ & $\mathrm{N} / \mathrm{A}$ & $\mathrm{N} / \mathrm{A}$ \\
\hline 1064 & 2.51 & 1.08 & 2.38 & 0.880 & 2.71 & 1.13 \\
\hline 1065 & 2.46 & 0.762 & 2.25 & 0.488 & 2.24 & 1.13 \\
\hline 1066 & 2.37 & 1.51 & 2.43 & 0.624 & 2.42 & 1.03 \\
\hline 1067 & 2.40 & 1.48 & 2.11 & 0.787 & 2.24 & 0.947 \\
\hline 1068 & 2.36 & 1.45 & 2.31 & 1.09 & 2.64 & 0.569 \\
\hline 1069 & 2.31 & 0.881 & 2.22 & 0.743 & 2.54 & 0.995 \\
\hline 1070 & 2.35 & 0.893 & 2.00 & 1.19 & 2.02 & 1.14 \\
\hline 1071 & 2.41 & 0.628 & 2.26 & 0.894 & 1.89 & 0.713 \\
\hline 1072 & $\mathrm{~N} / \mathrm{A}$ & $\mathrm{N} / \mathrm{A}$ & $\mathrm{N} / \mathrm{A}$ & $\mathrm{N} / \mathrm{A}$ & $\mathrm{N} / \mathrm{A}$ & $\mathrm{N} / \mathrm{A}$ \\
\hline 1073 & 2.61 & 0.858 & 2.45 & 1.28 & 2.36 & 1.21 \\
\hline 1074 & 2.45 & 0.703 & 2.37 & 0.683 & 2.30 & 1.01 \\
\hline 1075 & 2.37 & 1.37 & 2.00 & 0.837 & 2.54 & 0.988 \\
\hline 1076 & 2.39 & 1.02 & 2.20 & 0.789 & $\mathrm{~N} / \mathrm{A}$ & $\mathrm{N} / \mathrm{A}$ \\
\hline 1077 & 2.50 & 1.05 & 2.50 & 1.11 & 2.36 & 1.05 \\
\hline 1078 & 2.67 & 1.10 & 2.51 & 0.875 & 2.25 & 2.22 \\
\hline 1079 & 2.23 & 1.15 & 2.15 & 0.842 & 2.37 & 0.789 \\
\hline 1080 & $\mathrm{~N} / \mathrm{A}$ & $\mathrm{N} / \mathrm{A}$ & $\mathrm{N} / \mathrm{A}$ & $\mathrm{N} / \mathrm{A}$ & $\mathrm{N} / \mathrm{A}$ & $\mathrm{N} / \mathrm{A}$ \\
\hline 1081 & 2.45 & 1.16 & 2.45 & 0.768 & 2.55 & 0.615 \\
\hline 1082 & 2.33 & 1.10 & 2.50 & 1.17 & 2.07 & 1.10 \\
\hline 1083 & 2.54 & 1.02 & 2.44 & 0.887 & 2.10 & 0.832 \\
\hline 1084 & 2.58 & 0.988 & 2.63 & 0.973 & 2.61 & 0.784 \\
\hline 1085 & 2.37 & 1.63 & 2.38 & 0.476 & 2.25 & 0.704 \\
\hline 1086 & 1.97 & 0.971 & 1.96 & 1.02 & 1.86 & 1.28 \\
\hline
\end{tabular}


Supplementary Table 11: The ${ }^{13} \mathrm{C} \alpha$ spin-spin $\mathrm{R}_{2}$ relaxation rates $\left(\mathrm{s}^{-1}\right)$ for wild type AD1-ACTR, [1055meLeu] and [1055meLeu;1076meLeu] variants

\begin{tabular}{|c|c|c|c|c|c|c|}
\hline & \multicolumn{2}{|c|}{ WT AD1-ACTR } & \multicolumn{2}{|c|}{ [1055meLeu] } & \multicolumn{2}{|c|}{ [1055meLeu;1076meLeu] } \\
\hline Residue & $\mathrm{R}_{2}$ & uncertainty & $\mathrm{R}_{2}$ & uncertainty & $\mathrm{R}_{2}$ & uncertainty \\
\hline 1040 & $\mathrm{~N} / \mathrm{A}$ & $\mathrm{N} / \mathrm{A}$ & N/A & $\mathrm{N} / \mathrm{A}$ & $N / A$ & $\mathrm{~N} / \mathrm{A}$ \\
\hline 1041 & $\mathrm{~N} / \mathrm{A}$ & $\mathrm{N} / \mathrm{A}$ & N/A & $\mathrm{N} / \mathrm{A}$ & $N / A$ & $N / A$ \\
\hline 1042 & 3.25 & 1.04 & \begin{tabular}{|l|}
3.92 \\
\end{tabular} & 0.937 & 4.09 & 0.708 \\
\hline 1043 & 4.33 & 0.694 & \begin{tabular}{|l|}
4.43 \\
\end{tabular} & 1.29 & 5.48 & 1.11 \\
\hline 1044 & 5.28 & 1.10 & 5.56 & 1.27 & 5.98 & 1.31 \\
\hline 1045 & 5.76 & 0.864 & \begin{tabular}{|l|}
6.67 \\
\end{tabular} & 1.10 & 8.66 & 0.923 \\
\hline 1046 & 5.66 & 0.772 & \begin{tabular}{|l|}
8.78 \\
\end{tabular} & 1.18 & 6.48 & 0.451 \\
\hline 1047 & 5.49 & 1.39 & \begin{tabular}{|l|}
8.21 \\
\end{tabular} & 0.871 & 8.61 & 0.701 \\
\hline 1048 & 5.23 & 0.805 & \begin{tabular}{|l|}
7.31 \\
\end{tabular} & 0.932 & 11.0 & 0.984 \\
\hline 1049 & 6.24 & 1.16 & \begin{tabular}{|l|}
8.66 \\
\end{tabular} & 0.668 & 10.5 & 0.515 \\
\hline 1050 & 6.00 & 0.405 & \begin{tabular}{|l|l|}
13.2 \\
\end{tabular} & 1.36 & 16.0 & 0.853 \\
\hline 1051 & 6.87 & 0.970 & \begin{tabular}{|l|}
9.44 \\
\end{tabular} & 1.17 & 9.45 & 1.27 \\
\hline 1052 & 6.58 & 1.45 & \begin{tabular}{|l|}
11.0 \\
\end{tabular} & 0.958 & 10.2 & 1.01 \\
\hline 1053 & 6.85 & 0.744 & 10.6 & 0.967 & 14.3 & 0.801 \\
\hline 1054 & 6.14 & 0.834 & \begin{tabular}{|l|}
14.0 \\
\end{tabular} & 0.831 & 24.9 & 0.689 \\
\hline 1055 & 5.17 & 0.615 & N/A & N/A & $\mathrm{N} / \mathrm{A}$ & N/A \\
\hline 1056 & 6.31 & 0.917 & 8.66 & 0.668 & 9.73 & 1.17 \\
\hline 1057 & 4.37 & 1.12 & \begin{tabular}{|l|}
9.41 \\
\end{tabular} & 0.507 & 9.83 & 1.26 \\
\hline 1058 & 5.10 & 0.745 & \begin{tabular}{|l|}
6.70 \\
\end{tabular} & 0.671 & 7.23 & 0.748 \\
\hline 1059 & 5.39 & 0.990 & 5.99 & 1.20 & 7.45 & 1.05 \\
\hline 1060 & 4.87 & 0.598 & \begin{tabular}{|l|}
5.48 \\
\end{tabular} & 0.922 & 5.62 & 1.35 \\
\hline 1061 & 4.75 & 0.696 & 4.50 & 1.20 & 6.55 & 1.16 \\
\hline 1062 & 4.70 & 0.844 & 5.59 & 1.30 & 6.89 & 1.01 \\
\hline 1063 & $\mathrm{~N} / \mathrm{A}$ & $\mathrm{N} / \mathrm{A}$ & $\mathrm{N} / \mathrm{A}$ & $\mathrm{N} / \mathrm{A}$ & $\mathrm{N} / \mathrm{A}$ & $\mathrm{N} / \mathrm{A}$ \\
\hline 1064 & 4.18 & 0.900 & 4.10 & 1.07 & 4.45 & 0.672 \\
\hline 1065 & 6.20 & 1.01 & \begin{tabular}{|l|}
9.62 \\
\end{tabular} & 1.02 & 10.5 & 0.976 \\
\hline 1066 & 7.51 & 1.25 & $\begin{array}{ll}7.02 \\
\end{array}$ & 1.15 & 8.00 & 0.974 \\
\hline 1067 & 6.59 & 0.843 & 6.92 & 0.380 & 9.04 & 0.999 \\
\hline 1068 & 6.28 & 1.46 & 7.90 & 0.520 & 8.18 & 0.926 \\
\hline 1069 & 5.58 & 0.920 & \begin{tabular}{|l|}
8.06 \\
\end{tabular} & 1.43 & 8.71 & 0.649 \\
\hline 1070 & 5.21 & 0.710 & 7.00 & 1.22 & 6.70 & 0.791 \\
\hline 1071 & 5.37 & 0.968 & 5.51 & 1.52 & 5.46 & 0.880 \\
\hline 1072 & $\mathrm{~N} / \mathrm{A}$ & $\mathrm{N} / \mathrm{A}$ & $\mathrm{N} / \mathrm{A}$ & $\mathrm{N} / \mathrm{A}$ & $\mathrm{N} / \mathrm{A}$ & $\mathrm{N} / \mathrm{A}$ \\
\hline 1073 & 8.42 & 0.860 & \begin{tabular}{|l|l|}
7.77 \\
\end{tabular} & 0.999 & 13.0 & 0.524 \\
\hline 1074 & 5.64 & 0.396 & 6.73 & 1.05 & 8.32 & 0.842 \\
\hline 1075 & 6.98 & 0.868 & \begin{tabular}{|l|l|}
6.58 \\
\end{tabular} & 1.05 & \begin{tabular}{|l|l|}
8.06 \\
\end{tabular} & 0.549 \\
\hline 1076 & 6.01 & 0.802 & 6.15 & 1.57 & $\mathrm{~N} / \mathrm{A}$ & $\mathrm{N} / \mathrm{A}$ \\
\hline 1077 & 4.54 & 0.439 & \begin{tabular}{|l|l|}
4.74 \\
\end{tabular} & 0.835 & \begin{tabular}{|l|l|}
7.28 \\
\end{tabular} & 1.08 \\
\hline 1078 & 4.67 & 1.22 & 5.26 & 0.795 & 6.50 & 0.965 \\
\hline 1079 & 4.87 & 0.716 & \begin{tabular}{|l|l}
5.48 \\
\end{tabular} & 0.918 & \begin{tabular}{|l|l|}
6.02 \\
\end{tabular} & 1.12 \\
\hline 1080 & $\mathrm{~N} / \mathrm{A}$ & $\mathrm{N} / \mathrm{A}$ & $\mathrm{N} / \mathrm{A}$ & $\mathrm{N} / \mathrm{A}$ & $\mathrm{N} / \mathrm{A}$ & $\mathrm{N} / \mathrm{A}$ \\
\hline 1081 & 4.59 & 0.900 & \begin{tabular}{|l|l|}
4.18 \\
\end{tabular} & 0.888 & \begin{tabular}{|l|l|}
4.90 \\
\end{tabular} & 1.43 \\
\hline 1082 & 3.50 & 1.14 & 3.26 & 0.775 & \begin{tabular}{|l|l|}
4.24 \\
\end{tabular} & 0.729 \\
\hline 1083 & 5.32 & 0.637 & 5.51 & 1.016 & \begin{tabular}{|l|l|}
7.31 \\
\end{tabular} & 1.11 \\
\hline 1084 & 3.91 & 0.687 & 4.05 & 0.828 & \begin{tabular}{|l|l|} 
\\
\end{tabular} & 0.579 \\
\hline 1085 & 2.83 & 1.08 & 3.12 & 1.01 & \begin{tabular}{|l|l|}
3.10 \\
\end{tabular} & 0.574 \\
\hline 1086 & 2.55 & 0.853 & 2.73 & 0.557 & 2.76 & 1.069 \\
\hline
\end{tabular}


Supplementary Table 12: Crystallographic data collection and refinement statistics for the complex of NCBD with [1055meLeu;1076meLeu]AD1-ACTR variant (values in parentheses are for the highest resolution shell)

\begin{tabular}{|c|c|}
\hline \multicolumn{2}{|l|}{ Data collection } \\
\hline X-ray source & Swiss Light Source (PXIII beamline) \\
\hline Wavelength & $1.00003 \AA$ \\
\hline Resolution range & $41.72-2.28 \AA(2.362-2.28 \AA)$ \\
\hline Space group & $C 2$ \\
\hline Unit cell & $\begin{array}{l}a=103.18 \AA, b=42.46 \AA, c=113.79 \AA \\
\alpha=\gamma=90^{\circ}, \beta=101.125^{\circ}\end{array}$ \\
\hline Total reflections & $73662(7372)$ \\
\hline Unique reflections & $21924(2175)$ \\
\hline Multiplicity & $3.4(3.4)$ \\
\hline Completeness & $97.23 \%(96.97 \%)$ \\
\hline Mean I/sigma(I) & $9.58(1.94)$ \\
\hline Wilson B-factor & $33.76 \AA^{2}$ \\
\hline R-merge & $0.09578(0.6837)$ \\
\hline $\mathrm{CC} 1 / 2$ & $0.995(0.745)$ \\
\hline \multicolumn{2}{|l|}{ Refinement } \\
\hline Reflections used in refinement & $21873(2173)$ \\
\hline Reflections used for R-free & $1100(107)$ \\
\hline R-work & $0.2264(0.2965)$ \\
\hline R-free & $0.2712(0.3260)$ \\
\hline Number of non-hydrogen atoms & 3765 \\
\hline macromolecules & 3578 \\
\hline ligands & 29 \\
\hline solvent & 158 \\
\hline Protein residues & 466 \\
\hline RMS(bonds) & 0.006 \\
\hline RMS(angles) & 1.13 \\
\hline Ramachandran favored & $97.36 \%$ \\
\hline Ramachandran allowed & $2.64 \%$ \\
\hline Ramachandran outliers & $0 \%$ \\
\hline Rotamer outliers & $2.72 \%$ \\
\hline Clash score & 7.93 \\
\hline Average B-factor & $50.92 \AA^{2}$ \\
\hline macromolecules & $51.33 \AA^{2}$ \\
\hline ligands & $36.86 \AA^{2}$ \\
\hline solvent & $44.35 \AA^{2}$ \\
\hline Number of TLS groups & 8 \\
\hline
\end{tabular}


Supplementary Table 13: Hydrogen bond analysis. The increase in occurrences of intermolecular hydrogen bonds between AD1-ACTR and NCBD for the [1055meLeu]AD1-ACTR and [1055meLeu;1076meLeu]AD1-ACTR analogues indicates the increase in stabilizing interactions between the two proteins and agrees with enhanced binding affinities observed for NCBD binding. The differences in the hydrogen bonding patterns between activation domain of ACTR and NCBD for different complexes indicate structural differences between the three complexes. Listed are hydrogen bonds that occur for at least $20 \%$ of the time in at least one of the three complexes. Shaded in gray are hydrogen bonds that occur in at least two complexes (10 out of 40). First $50 \mathrm{~ns}$ were excluded from the analysis.

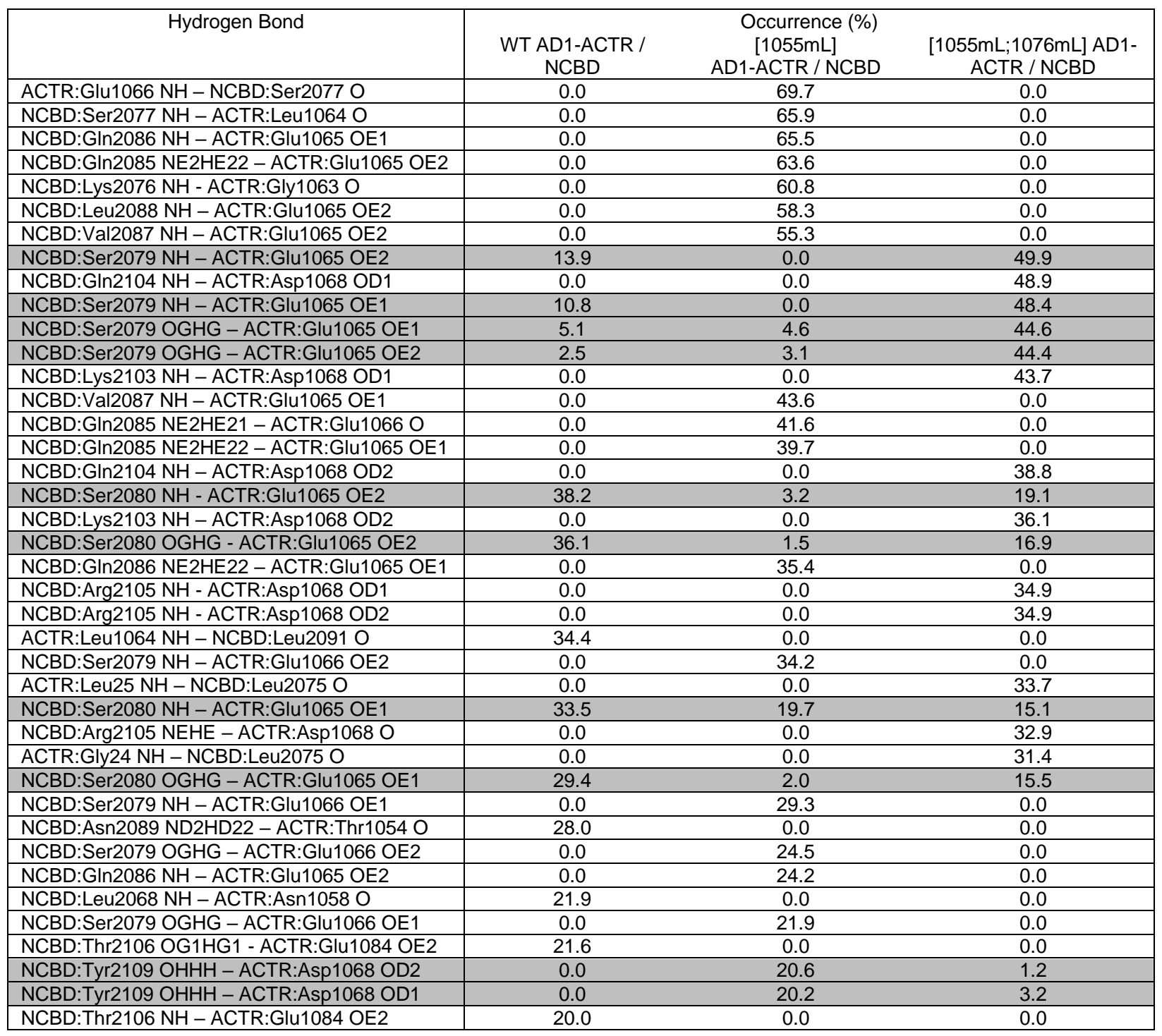


Supplementary Table 14: Salt-bridge analysis. The differences in occurrences of intermolecular and intramolecular salt bridges between AD1-ACTR and NCBD for the three complexes agree with the results of the hydrogen bond analysis and indicate structural differences at the ACTR/NCBD interface of the complexes. First 50 ns are excluded from the analysis.

Intermolecular salt bridges:

\begin{tabular}{|c|c|c|c|}
\hline Salt Bridge & WT AD1-ACTR / NCBD & $\begin{array}{c}\text { Occurrence (\%) } \\
\text { [1055mL] AD1-ACTR } \\
\text { / NCBD }\end{array}$ & $\begin{array}{c}\text { [1055mL;1076mL] AD1- } \\
\text { ACTR / NCBD }\end{array}$ \\
\hline ACTR:Glu1045 OE1 - NCBD:Arg2073 NH2 & 30.9 & 7.2 & 0.2 \\
\hline ACTR:Glu1045 OE2 - NCBD:Arg2073 NH2 & 30.6 & 7.5 & 0.2 \\
\hline ACTR:Asp1060 OD2 - NCBD:Lys2092 NZ & 24.3 & 0.0 & 0.0 \\
\hline ACTR:Glu1045 OE1 - NCBD:Arg2073 NH1 & 23.1 & 3.8 & 0.2 \\
\hline ACTR:Asp1060 OD1 - NCBD:Lys2092 NZ & 23.1 & 0.0 & 0.0 \\
\hline ACTR:Glu1045 OE2 - NCBD:Arg2073 NH1 & 22.0 & 3.9 & 0.2 \\
\hline ACTR:Glu1066 OE1 - NCBD:Lys2076 NZ & 13.7 & 8.9 & 0.0 \\
\hline ACTR:Glu1066 OE2 - NCBD:Lys2076 NZ & 12.5 & 8.8 & 0.0 \\
\hline ACTR:Glu1084 OE1 - NCBD:Lys2108 NZ & 10.7 & 0.0 & 0.0 \\
\hline ACTR:Asp1060 OD1 - NCBD:Arg2105 NH2 & 0.0 & 29.5 & 0.0 \\
\hline ACTR:Asp1060 OD2 - NCBD:Arg2105 NH2 & 0.0 & 29.2 & 0.0 \\
\hline ACTR:Asp1060 OD1 - NCBD:Arg2105 NH1 & 0.0 & 12.5 & 0.0 \\
\hline ACTR:Asp1060 OD2 - NCBD:Arg2105 NH1 & 0.0 & 13.0 & 0.0 \\
\hline ACTR:Asp1068 OD1 - NCBD:Arg2105 NH2 & 1.6 & 27.3 & 14.5 \\
\hline ACTR:Asp1068 OD2 - NCBD:Arg2105 NH2 & 1.8 & 26.9 & 15.5 \\
\hline ACTR:Asp1068 OD1 - NCBD:Arg2105 NH1 & 1.3 & 21.5 & 12.8 \\
\hline ACTR:Asp1068 OD2 - NCBD:Arg2105 NH1 & 1.3 & 20.7 & 12.8 \\
\hline ACTR:Asp1060 OD1 - NCBD:Lys2076 NZ & 0.0 & 1.5 & 29.9 \\
\hline ACTR:Asp1060 OD2 - NCBD:Lys2076 NZ & 0.0 & 1.3 & 29.5 \\
\hline ACTR:Glu1075 OE2 - NCBD:Lys2092 NZ & 0.0 & 1.8 & 23.1 \\
\hline ACTR:Glu1075 OE1 - NCBD:Lys2092 NZ & 0.0 & 1.6 & 21.7 \\
\hline ACTR:Glu1066 OE1 - NCBD:Lys2103 NZ & 6.2 & 0.0 & 12.3 \\
\hline ACTR:Glu1066 OE2 - NCBD:Lys2103 NZ & 6.7 & 0.0 & 11.9 \\
\hline
\end{tabular}

\section{Intramolecular salt bridges:}

\begin{tabular}{|c|c|c|c|}
\hline Salt Bridge & WT AD1-ACTR / NCBD & $\begin{array}{c}\text { Occurrence (\%) } \\
\text { [1055mL] AD1-ACTR } \\
\text { / NCBD }\end{array}$ & $\begin{array}{c}{[1055 \mathrm{~mL} ; 1076 \mathrm{~mL}] \mathrm{AD} 1-} \\
\text { ACTR / NCBD }\end{array}$ \\
\hline ASP1050 OD2 - HIS1053 NE2 & 19.4 & 27.3 & 3.0 \\
\hline ASP1050 OD1 - HIS1053 NE2 & 18.7 & 29.7 & 3.0 \\
\hline Glu1084 OE2 - LYS1086 NZ & 16.7 & 28.3 & 19.8 \\
\hline Glu1084 OE1 - LYS1086 NZ & 15.6 & 18.0 & 19.8 \\
\hline ASP1060 OD2 - LYS1086 NZ & 12.1 & 0.3 & 0.0 \\
\hline ASP1060 OD1 - LYS1086 NZ & 11.8 & 0.5 & 0.0 \\
\hline GLU1066 OE1 - ARG1069 NH2 & 10.1 & 18.6 & 33.3 \\
\hline GLU1066 OE2 - ARG1069 NH2 & 9.6 & 17.5 & 34.2 \\
\hline GLU1066 OE1 - ARG1069 NH1 & 9.0 & 22.1 & 37.3 \\
\hline GLU1066 OE2 - ARG1069 NH1 & 8.6 & 21.5 & 37.9 \\
\hline GLU1040 OE1 - ARG1046 NH1 & 0.0 & 19.1 & 3.6 \\
\hline GLU1040 OE2 - ARG1046 NH1 & 0.0 & 18.0 & 3.5 \\
\hline GLU1040 OE2 - ARG1046 NH2 & 0.0 & 17.6 & 3.7 \\
\hline ASP1068 OD2 - ARG1069 NH2 & 0.1 & 12.7 & 1.6 \\
\hline ASP1068 OD1 - ARG1069 NH2 & 0.1 & 12.6 & 3.0 \\
\hline ASP1068 OD2 - ARG1069 NH1 & 0.2 & 10.2 & 0.8 \\
\hline ASP1068 OD1 - ARG1069 NH1 & 0.1 & 10.0 & 2.0 \\
\hline GLU1045 OE1 - ARG1046 NH2 & 3.7 & 5.7 & 15.1 \\
\hline GLU1045 OE2 - ARG1046 NH2 & 4.2 & 5.1 & 14.6 \\
\hline GLU1045 OE1 - ARG1046 NH1 & 2.3 & 3.6 & 12.6 \\
\hline GLU1045 OE2 - ARG1046 NH1 & 2.6 & 3.0 & 11.9 \\
\hline
\end{tabular}


Supplementary Table 15: Binding parameters obtained upon fitting the SPR binding of AD1-ACTR variants to NCBD using a 1:1 association model with BiaEvaluation 3.2 software.

\begin{tabular}{|c|c|c|c|c|c|}
\hline $\begin{array}{l}\text { Temper- } \\
\text { ature }\end{array}$ & AD1-ACTR variant & $k_{\text {on }}\left(M^{-1} \cdot s^{-1}\right)$ & $k_{\text {off }}\left(\mathrm{s}^{-1}\right)$ & $\begin{array}{c}\mathrm{K}_{\mathrm{D}} \text { (nM, from } \\
\text { kinetics) }\end{array}$ & $\begin{array}{c}\text { Chi }^{2} \text { from } \\
\text { kinetics }\left(\mathrm{RU}^{2}\right)\end{array}$ \\
\hline \multirow{4}{*}{$\begin{array}{c}20^{\circ} \mathrm{C} \\
(293 \mathrm{~K})\end{array}$} & WT & $1.20 \times 10^{6}$ & 0.286 & 238 & 0.25 \\
\hline & {$[1076 \mathrm{~mL}]$} & $1.28 \times 10^{6}$ & 0.339 & 264 & 0.17 \\
\hline & {$[1055 \mathrm{~mL}]$} & $1.46 \times 10^{6}$ & 0.031 & 21.6 & 1.0 \\
\hline & [1055mL;1076mL] & $2.71 \times 10^{6}$ & 0.021 & 7.57 & 1.1 \\
\hline \multirow{4}{*}{$\begin{array}{c}22^{\circ} \mathrm{C} \\
(295 \mathrm{~K})\end{array}$} & WT & $1.21 \times 10^{6}$ & 0.356 & 295 & 0.20 \\
\hline & {$[1076 \mathrm{~mL}]$} & $1.35 \times 10^{6}$ & 0.410 & 304 & 0.14 \\
\hline & {$[1055 \mathrm{~mL}]$} & $1.54 \times 10^{6}$ & 0.036 & 23.4 & 0.88 \\
\hline & [1055mL;1076mL] & $2.97 \times 10^{6}$ & 0.024 & 8.06 & 0.96 \\
\hline \multirow{4}{*}{$\begin{array}{c}25^{\circ} \mathrm{C} \\
(298 \mathrm{~K})\end{array}$} & WT & $1.09 \times 10^{6}$ & 0.406 & 374 & 0.17 \\
\hline & {$[1076 \mathrm{~mL}]$} & $1.07 \times 10^{6}$ & 0.521 & 489 & 0.07 \\
\hline & {$[1055 \mathrm{~mL}]$} & $1.85 \times 10^{6}$ & 0.049 & 26.3 & 1.2 \\
\hline & [1055mL;1076mL] & $3.77 \times 10^{6}$ & 0.030 & 7.84 & 0.69 \\
\hline \multirow{4}{*}{$\begin{array}{c}27^{\circ} \mathrm{C} \\
(300 \mathrm{~K})\end{array}$} & WT & $1.02 \times 10^{6}$ & 0.454 & 448 & 0.19 \\
\hline & [1076mL] & $1.07 \times 10^{6}$ & 0.526 & 493 & 0.15 \\
\hline & {$[1055 \mathrm{~mL}]$} & $1.78 \times 10^{6}$ & 0.059 & 33.3 & 1.2 \\
\hline & [1055mL;1076mL] & $3.20 \times 10^{6}$ & 0.034 & 10.6 & 0.76 \\
\hline \multirow{4}{*}{$\begin{array}{c}31^{\circ} \mathrm{C} \\
(304 \mathrm{~K})\end{array}$} & WT & $7.14 \times 10^{5}$ & 0.602 & 843 & 0.15 \\
\hline & {$[1076 \mathrm{~mL}]$} & $7.72 \times 10^{5}$ & 0.696 & 902 & 0.10 \\
\hline & [1055mL] & $1.57 \times 10^{6}$ & 0.084 & 53.3 & 0.53 \\
\hline & [1055mL;1076mL] & $3.03 \times 10^{6}$ & 0.055 & 18.1 & 0.60 \\
\hline
\end{tabular}


Supplementary Table 16: Steady-state analysis of SPR data with a 1:1 binding isotherm model.

\begin{tabular}{|c|c|c|c|}
\hline Temperature & AD1-ACTR variant & $\begin{array}{c}\mathrm{K}_{\mathrm{D}} \\
\text { (nM } \pm \text { uncertainty) }\end{array}$ & $\begin{array}{c}R_{\max } \\
(R U \pm \text { uncertainty) }\end{array}$ \\
\hline \multirow{4}{*}{$\begin{array}{c}20^{\circ} \mathrm{C} \\
(293 \mathrm{~K})\end{array}$} & WT & $180 \pm 24$ & $1.018 \pm 0.041$ \\
\hline & [1076meLeu] & $199 \pm 35$ & $0.768 \pm 0.041$ \\
\hline & [1055meLeu] & $31.6 \pm 0.2$ & $1.147 \pm 0.001$ \\
\hline & [1055meLeu;1076meLeu] & $15.3 \pm 0.2$ & $1.543 \pm 0.002$ \\
\hline \multirow{4}{*}{$\begin{array}{l}22^{\circ} \mathrm{C} \\
(295 \mathrm{~K})\end{array}$} & WT & $186 \pm 25$ & $1.007 \pm 0.041$ \\
\hline & [1076meLeu] & $208 \pm 39$ & $0.714 \pm 0.041$ \\
\hline & [1055meLeu] & $33.2 \pm 0.1$ & $1.134 \pm 0.001$ \\
\hline & [1055meLeu;1076meLeu] & $15.9 \pm 0.2$ & $1.375 \pm 0.002$ \\
\hline \multirow{4}{*}{$\begin{array}{l}25^{\circ} \mathrm{C} \\
(298 \mathrm{~K})\end{array}$} & WT & $233 \pm 38$ & $0.973 \pm 0.051$ \\
\hline & [1076meLeu] & $268 \pm 57$ & $0.635 \pm 0.046$ \\
\hline & [1055meLeu] & $35.5 \pm 0.3$ & $1.070 \pm 0.002$ \\
\hline & [1055meLeu;1076meLeu] & $16.7 \pm 0.2$ & $1.114 \pm 0.002$ \\
\hline \multirow{4}{*}{$\begin{array}{l}27^{\circ} \mathrm{C} \\
(300 \mathrm{~K})\end{array}$} & WT & $251 \pm 36$ & $1.090 \pm 0.053$ \\
\hline & [1076meLeu] & $270 \pm 51$ & $0.704 \pm 0.046$ \\
\hline & [1055meLeu] & $43.8 \pm 0.3$ & $1.320 \pm 0.002$ \\
\hline & [1055meLeu;1076meLeu] & $22.1 \pm 0.4$ & $1.287 \pm 0.003$ \\
\hline \multirow{4}{*}{$\begin{array}{c}31^{\circ} \mathrm{C} \\
(304 \mathrm{~K})\end{array}$} & WT & $388 \pm 63$ & $1.203 \pm 0.077$ \\
\hline & [1076meLeu] & $396 \pm 90$ & $0.700 \pm 0.064$ \\
\hline & [1055meLeu] & $69.2 \pm 0.1$ & $1.526 \pm 0.001$ \\
\hline & [1055meLeu;1076meLeu] & $30.2 \pm 0.2$ & $1.177 \pm 0.001$ \\
\hline
\end{tabular}




\section{Supplementary References}

1. Schmidtgall, B., Chaloin, O., Bauer, V., Sumyk, M., Birck, C., Torbeev, V. Dissecting mechanism of coupled folding and binding of an intrinsically disordered protein by chemical synthesis of conformationally constrained analogues. Chem. Commun. 53, 7369-7372 (2017).

2. Stavropoulos, G., Gatos, D., Magafa, V., Barlos, K. Preparation of polymer-bound trityl-hydrazines and their application in the solid phase synthesis of partially protected peptide hydrazides. Lett. Pept. Sci. 2, 315-318 (1995).

3. Zheng, J.-S., Tang, S., Guo, Y., Chang, H. N., Liu, L. Synthesis of cyclic peptides and cyclic proteins via ligation of peptide hydrazides. ChemBioChem 13, 542-546 (2012).

4. Fang, G.-M., Wang, J. X., Liu, L. Convergent chemical synthesis of proteins by ligation of peptide hydrazides, Angew. Chem. Int. Ed. 51, 10347-10350 (2012).

5. Bekesi, A., Abdellaoui, S., Holroyd, N., Van Delm, W., Pardon, E., Pauwels, J., Gevaert, K., Steyaer, J., Derveaux, S., Borysik, A., Tompa, P. Challenges in the structural-functional characterization of multidomain, partially disordered proteins CBP and p300: preparing native proteins and developing nanobody tools. Methods Enzymol. 611, 607-675 (2018).

6. Keller, S., Vargas, C., Zhao, H., Piszczek, G., Brautigam, C. A., Schuck, P. High-precision isothermal titration calorimetry with automated peak-shape analysis. Anal. Chem. 84, 5066-5073 (2012).

7. Scheuermann, T. H., Brautigam, C. A. High-precision, automated integration of multiple isothermal titration calorimetric thermograms: New features of NITPIC. Methods 76, 87-98 (2015).

8. Brautigam C. A., Zhao, H., Vargas, C., Keller, S., Schuck, P. Integration and global analysis of isothermal titration calorimetry data for studying macromolecular interactions, Nat. Protocols 11, 882894 (2016).

9. Iešmantavičius, V., Dogan, J., Jemth, P., Teilum, K., Kjaergaard, M. Helical propensity in an intrinsically disordered protein accelerates ligand binding. Angew. Chem. Int. Ed. 53, 1548-1551 (2014).

10. Kwok, S. C., Hodges, R. S. Stabilizing and destabilizing clusters in the hydrophobic core of long twostranded alpha-helical coiled-coils. J. Biol. Chem. 279, 21576-21588 (2004).

11. Wishart, D. S., Bigam, C. G., Yao, J., Abildgaard, F., Dyson, H. J., Oldfield, E., Markley, J. L., Sykes, B. D. ${ }^{1} \mathrm{H},{ }^{13} \mathrm{C}$ and ${ }^{15} \mathrm{~N}$ chemical shift referencing in biomolecular NMR. J. Biomol. NMR 6, 135-140 (1995).

12. Kay, L. E., Torchia, D. A., Bax, A. Backbone dynamics of proteins as studied by N-15 inverse detected heteronuclear NMR-spectroscopy - application to staphylococcal nuclease. Biochemistry 28, 89728979 (1989).

13. Vranken, W. F., Boucher, W., Stevens, T. J., Fogh, R. H., Pajon, A., Llinas, M., Ulrich, E. L., Markley, J. L., Ionides, J., Laue, E. D. The CCPN Data Model for NMR Spectroscopy: Development of a Software Pipeline. Proteins 59, 687-696 (2005).

14. Nielsen, J. T., Mulder, F. A. A. POTENCI: prediction of temperature, neighbor and pH-corrected chemical shifts for intrinsically disordered proteins. J. Biomol. NMR 70, 141-165 (2018).

15. Kabsch, W. XDS. Acta Crystallogr. D (Biol. Crystallogr.) 66, 125-132 (2010).

16. Jin, T., Chuenchor, W., Jiang, J., Cheng, J., Li, Y., Fang, K., Huang, M., Smith, P., Xiao T. S. Design of an expression system to enhance MBP-mediated crystallization. Sci. Rep. 7, 40991 (2017). 
17. McCoy, A. J., Grosse-Kunstleve, R. W., Adams, P. D., Winn, M. D., Storoni, L. C., Read, R. J. Phaser crystallographic software. J. Appl. Crystallogr. 40, 658-674 (2007).

18. Adams, P. D. et al. PHENIX: a comprehensive Python-based system for macromolecular structure solution. Acta Crystallogr. D (Biol. Crystallogr.) 66, 213-221 (2010).

19. Moriarty, N. W., Grosse-Kunstleve, R. W., Adams, P. D. electronic Ligand Builder and Optimization Workbench (eLBOW): a tool for ligand coordinate and restraint generation. Acta Crystallogr. D (Biol. Crystallogr.) 65, 1074-1080 (2009).

20. Painter, J., Merritt, E. A. Optimal description of a protein structure in terms of multiple groups undergoing TLS motion. Acta Crystallogr. D (Biol. Crystallogr.) 62, 439-450 (2006).

21. Schmid, N., Christ, C. D., Christen, M., Eichenberger, A. P., van Gunsteren, W. F. Architecture, implementation and parallelisation of the GROMOS software for biomolecular simulation. Comput. Phys. Commun. 183, 890-903 (2012).

22. www.gromos.net (accessed July 20, 2019).

23. Poger, D., van Gunsteren, W. F., Mark, A. E. A new force field for simulating phosphatidylcholine bilayers. J. Comput. Chem. 31, 1117-1125 (2010).

24. Schmid, N., Eichenberger, A. P., Choutko, A., Riniker, S., Winger, M., Mark, A. E., van Gunsteren, W. F. Definition and testing of the GROMOS force-field versions 54A7 and 54B7. Eur. Biophys. J. 40, 843-856 (2011).

25. Berendsen, H. J. C., Postma, J. P. M., van Gunsteren, W. F., Hermans, J. Interaction models for water in relation to protein hydration. In Intermolecular Forces; Pullman, B., Ed.; Reidel: Dordrecht, The Netherlands, 1981; pp 331-342.

26. Berendsen, H. J. C., Postma, J. P. M., van Gunsteren, W. F., DiNola, A., Haak, J. R. Molecular dynamics with coupling to an external bath. J. Chem. Phys. 81, 3684-3690 (1984).

27. Ryckaert, J. P., Ciccotti, G., Berendsen, H. J. C. Numerical integration of the cartesian equations of motion of a system with constraints: molecular dynamics of n-alkanes. J. Comput. Phys. 23, 327-341 (1977).

28. Tironi, I. G., Sperb, R., Smith, P. E., van Gunsteren, W. F. A generalized reaction field method for molecular dynamics simulations. J. Chem. Phys. 102, 5451-5459 (1995).

29. Glättli, A., Daura, X., van Gunsteren, W. F. Derivation of an improved simple point charge model for liquid water: SPC/A and SPC/L. J. Chem. Phys. 116, 9811-9828 (2002).

30. Eichenberger, A. P., Allison, J. R., Dolenc, J., Geerke, D. P., Horta, B. A. C., Meier, K., Oostenbrink, C., Schmid, N., Steiner, D., Wang, D. Q., van Gunsteren, W. F. GROMOS++ software for the analysis of biomolecular simulation trajectories. J. Chem. Theory Comput. 7, 3379-3390 (2011).

31. Daura, X., van Gunsteren, W. F., Mark, A. E. Folding-unfolding thermodynamics of a $\beta$-heptapeptide from equilibrium simulations. Proteins 34, 269-280 (1999).

32. Fournane, S., Charbonnier, S., Chapelle, A., Kieffer B., Orfanoudakis, G., Travé, G., Masson, M., Nominé, Y. Surface plasmon resonance analysis of the binding of high-risk mucosal HPV E6 oncoproteins to the PDZ1 domain of the tight junction protein MAGI-1. J. Mol. Recognit. 24, 511 (2010). 